\title{
Facilitators and Barriers to
}

\section{Pharmacists' Patient Communication:}

The Pharmacist Profession, the Regulatory Framework, and the Pharmacy Undergraduate Education

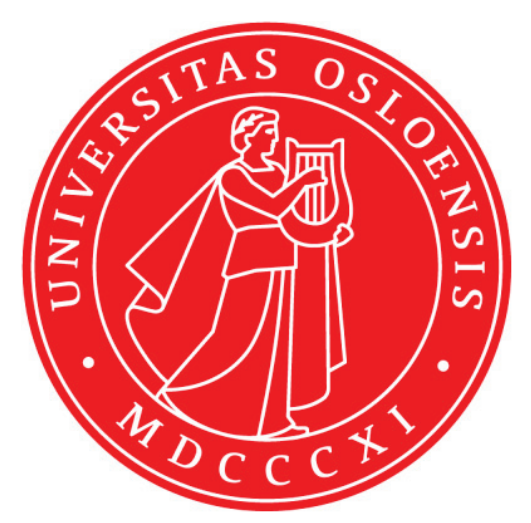

\section{KARIN SVENSBERG}

PharmacoEpidemiology and Drug Safety Research Group, Department of Pharmacy, School of Pharmacy, Faculty of Mathematics and Natural Sciences, University of Oslo, Norway

Oslo 2017

Submitted for the Degree of Philosophiae Doctor (PhD) 
(C) Karin Svensberg, 2017

Series of dissertations submitted to the

Faculty of Mathematics and Natural Sciences, University of Oslo No. 1879

ISSN 1501-7710

All rights reserved. No part of this publication may be reproduced or transmitted, in any form or by any means, without permission.

Photo back cover: Camilla Sophie Storvollen

Cover: Hanne Baadsgaard Utigard.

Print production: Reprosentralen, University of Oslo. 
To Roberth and Theodor for communicating the lessons of love. 



\section{List of Papers}

This thesis is based on the following papers:

- $\quad$ Svensberg K, Sporrong SK, Håkonsen H, Toverud EL. 'Because of the circumstances, we cannot develop our role': Norwegian community pharmacists' perceived responsibility in role development. The International Journal of Pharmacy Practice. 2014;23(4):256-65, reprinted with permission from Wiley.

- $\quad$ Svensberg K, Sporrong SK, Björnsdóttir I. A review of countries' pharmacist-patient communication legal requirements on prescription medications and alignment with practice: Comparison of Nordic countries. Research in Social \& Administrative Pharmacy. 2015;11(6):784-802, reprinted with permission from Elsevier.

- Svensberg K, Björnsdóttir I, Wallman A, Sporrong SK. Strategies for Enhancing Communication Skills Training: Lessons from 11 Nordic Pharmacy Schools. The American Journal of Pharmaceutical Education (Accepted for publication), reprinted with permission from the American Journal of Pharmaceutical Education.

- $\quad$ Svensberg K, Sporrong SK, Lupattelli A, Olsson E, Wallman A, Björnsdóttir I. Nordic Pharmacy Students' Opinions of their Patient Communication Skills Training. The American Journal of Pharmaceutical Education (Accepted for publication), reprinted with permission from the American Journal of Pharmaceutical Education.

- $\quad$ Svensberg K, Brandlistuen RE, Björnsdóttir I, Sporrong SK. Factors Associated with Pharmacy Students' Attitudes towards Learning Communication Skills - a Study among Nordic Pharmacy Students. Research in Social \& Administrative Pharmacy (in press, online first 28 March 2017: DOI: 10.1016/j.sapharm.2017.03.055), reprinted with permission from Elsevier. 



\section{Pre-understanding}

The inseparability of researcher and self.

Nancy Drew

Dear reader,

Taking on a $\mathrm{PhD}$ journey has really been a great decision. I have so much enjoyed every moment, getting the opportunity to be absorbed in a topic which I am passionate about and learning the handcraft of science. In addition, I found out how differently you can look upon science/knowledge and its performance, depending on your background and traditions. My background is from pharmacy training with strong roots in natural science. I had a 'technical' mentality of what constitutes knowledge, and I believed that knowledge was objective and collected by instruments in a controlled reality, aiming at casual explanation of a phenomenon. ${ }^{1}$ From there, social science in the context of social pharmacy was introduced to me. In social science I have learned that knowledge can be viewed as being 'qualitative,' i.e., a collection of social knowledge by talking to people, aiming at understanding a phenomenon in depth. ${ }^{1}$

I am Swedish, with a Master of Pharmacy degree from Uppsala University, Sweden. Since the age of 14, I have worked in community and hospital pharmacies, serving in various positions as a technician and pharmacist both in Sweden and Norway.

In this thesis, I have studied my own profession. I can identify myself with the participating pharmacists, students and educators. I have been socialized into this environment and have a clear personal opinion about the role of communication, pharmacists and community pharmacies in the society. I believe pharmacists can and should contribute more in improving appropriate use of medicines. I think good communication is a key factor to improve a patient's adherence and appropriate medicine use. This is an important standpoint since it impacts on how I look at the role of the community pharmacists in pharmacies today and in the future.

As a pharmacist and nurse's assistant, I have experience of communicating with patients. I understand what a difference good communication can make to patients, for example, by detecting medicine-related problems. As a patient, I have personally experienced the impact on my own health from different health-care professional communication styles-or insufficient 
communication. I have also heard the perceptions among the public that pharmacists are 'only' dispensing medicines and are no different from a random store. As a pharmacy student, I received little formalized education in communication with patients, reflections about pharmacists as health-care professionals, and the philosophy around patient care. The ambition of the thesis is to understand the pharmacists' communication role from various perspectives and contribute to implications for improving practice.

Karin Svensberg Oslo May 2, 2017 


\section{Abstract}

Worldwide, the role of the community pharmacist is changing from distribution of medicines towards being a patient-centered profession and putting the patient and not the medicine in the center. Ideally, pharmacists use their specialized health and pharmacotherapeutic knowledge along with communication skills. This professional development involves a complex interplay between community pharmacists, the regulatory framework, and the pharmacy undergraduate education among others.

The overall aim of this thesis was to explore, in the Nordic setting, how community pharmacists, the regulatory framework, and the pharmacy undergraduate education have responded to the shift in focus towards the increased communicative role of the pharmacists. The specific aims of this thesis were 1) to explore Norwegian community pharmacists' motivation and perceived responsibility regarding role development and involvement in patient-centered care; 2) to describe society's expectations of community pharmacist-patient communication around medications as expressed by the states in the Nordic legislation, economic incentives, and authority control; 3) to map communication skills building in pharmacy curricula in order to find ways to potentially improve the training by $3 a$ ) exploring current practice and $3 \mathrm{~b}$ ) course leaders' opinions regarding teaching of patient communication skills in Nordic pharmacy schools; 4) to describe Nordic pharmacy students' opinions of their patient communication skills training, and the association between course leaders' reports of patient communication skills training qualities and the students' perceptions of their training. Secondary was to determine what factors influence these associations; and 5) to explore Nordic pharmacy students' attitudes to communication skills learning, as well as the associations with various student characteristics.

In order to explore the study aims, focus groups and a document review were utilized to address Aims 1 and 2. For Aims 3-5, two questionnaire studies were undertaken.

Paper I showed a gap between the pharmacists day-to-day work as 'distributors' and their ideal tasks of patient care in the pharmacy. The pharmacists discussed, e.g., the patients, doctors, pharmacy chains, or time constraints as reasons for not claiming a more active role in patient's medicine use and their role development. Paper II identified a general, but not very detailed, 
legislation on communication on prescription medicines during dispensing. Communication on medicines was not directly supported with economic incentives or effective control thereof. In Paper III it was shown that the pharmacy practical experience is the main period for patient communication skills training, and the training is often placed late in the education. During the five years of education, the teacher-led training varied from 6 to 92 hours, and few schools used experiential training methods. Most course leaders identified a need for larger focus on communication skills training. Paper IV showed that students with more experiential training methods and $>20$ hours of training were significantly more likely to report having received sufficient training (adjusted OR:4.20; 95\% CI:2.03 to 8.69, p<0.001), and that the pharmacy school had contributed to their skills (adjusted OR:3.65; 95\% CI:1.89 to 7.04, p<0.001) compared to students without such training. Paper V showed that Nordic pharmacy students in general had moderately positive attitudes towards learning communication skills and that such attitudes were associated with female gender (adjusted $\beta: 0.42 ; 95 \%$ CI:0.20 to $0.63, p<0.001$ ), newer types of pharmacy education (adjusted $\beta: 0.81 ; 95 \% \mathrm{CI}: 0.63$ to $0.98, \mathrm{p}<0.001$ ), students who thought their skills needed improvement (adjusted $\beta: 0.50 ; 95 \%$ CI:0.30 to $0.71, p<0.001$ ), and students who thought their communication skills were a result of their personality (adjusted $\beta:-0.24 ; 95 \% \mathrm{CI}$ :0.44 to $-0.04, p=0.017)$.

The findings from this thesis imply that the pharmacists have positive beliefs towards the increased communicative role, the legislations are not hindering the role, but they are not supporting it either. Nordic pharmacy schools could have strengthened the role more. An overall conclusion is that the three factors need improvements and alignment if pharmacists' communicative role is going to reach full potential in practice. 


\section{Contents}

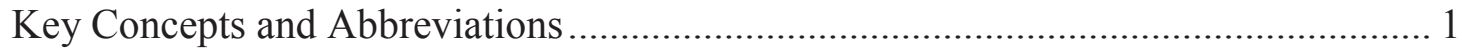

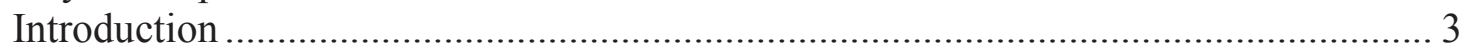

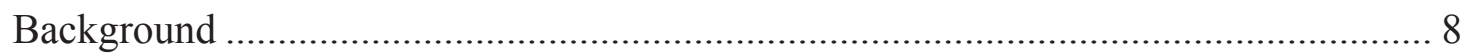

The Communicative Role of Community Pharmacists …...................................... 8

The communication process: an overview ..................................................... 10

Terms, definitions, and concepts used for describing communication in

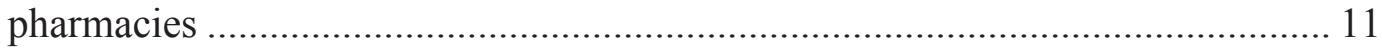

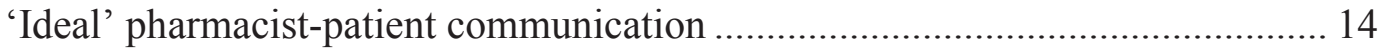

Essential communication skills for pharmacists …........................................... 15

Impact of the Communicative Role on Patient Outcomes ...................................... 17

Medicine use-related problems, adherence, reassurance, and patient

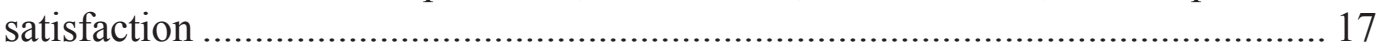

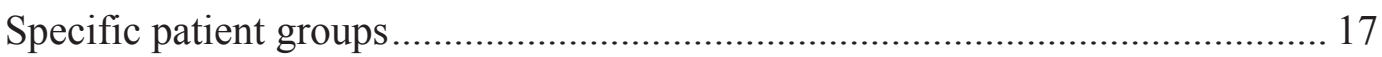

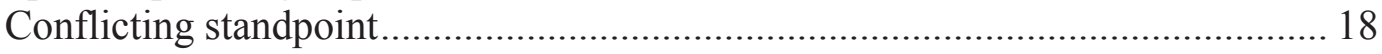

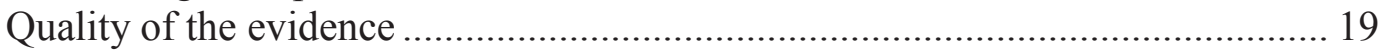

The Communicative Role in Practice: Extent, Content, and Process of

Pharmacist-Patient Communication .................................................................. 20

Extent of communication and professional pharmacy services in pharmacies.... 20

Content of pharmacist-patient communication activities ................................... 20

Transmission of content (process skills) ........................................................... 21

Communication studies from the Nordic countries ............................................ 22

Factors Affecting Pharmacist-Patient Communication in Pharmacies..................... 24

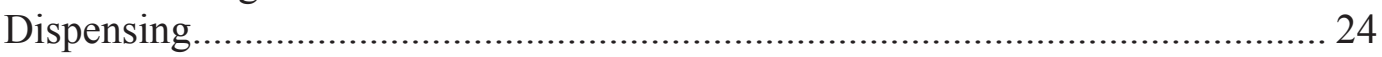

Professional pharmacy services .................................................................. 24

Community Pharmacists' Beliefs towards their Communicative Role ................ 30

Society's Expectations of a Profession as Stated in the Regulatory

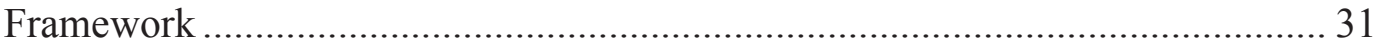

Pharmacy Undergraduate Education of Future Communicators ........................ 32

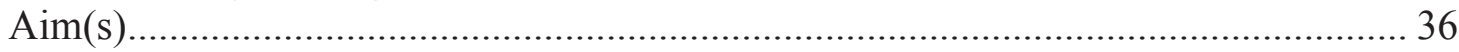

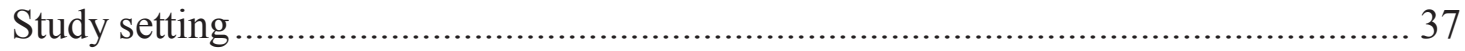

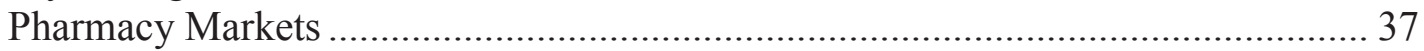

The Pharmacy Undergraduate Education ............................................................. 38

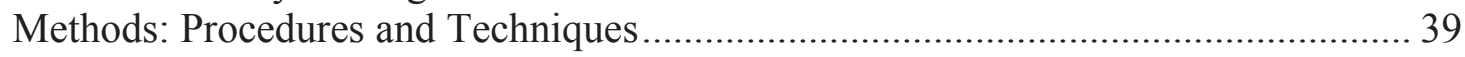

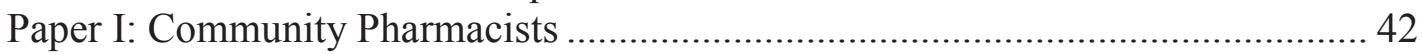

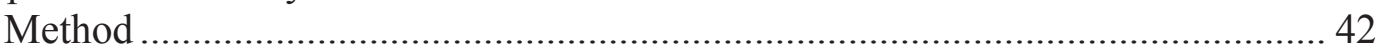

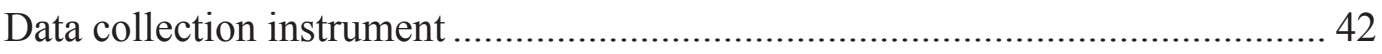

Study population, sample selection and requirement ...................................... 42

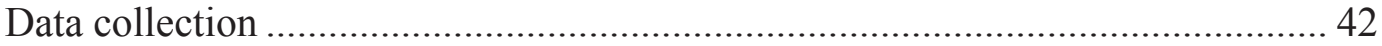

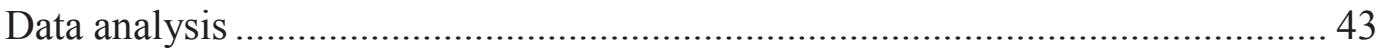

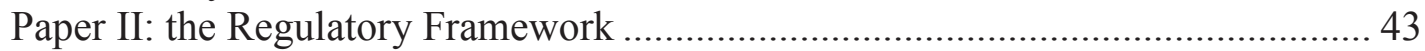

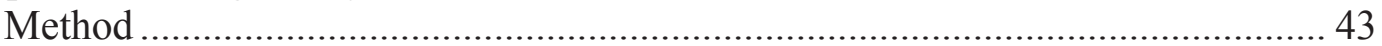

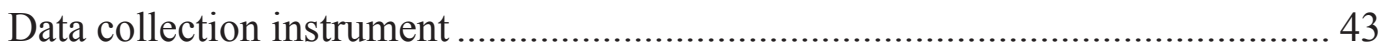

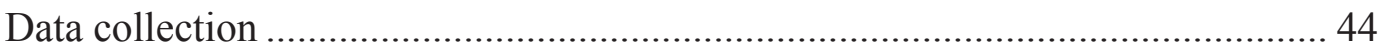

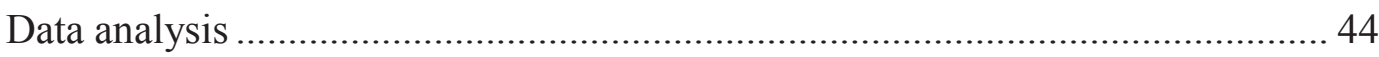


Paper III: Patient Communication Education: Educators ...................................... 44

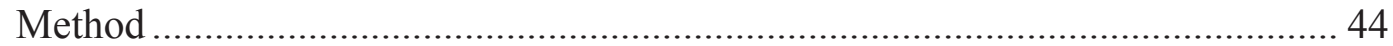

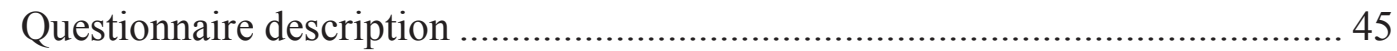

Study population, sample selection and requirement ...................................... 45

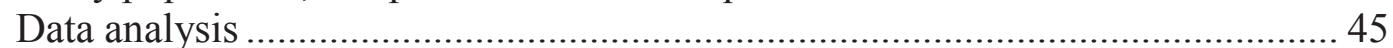

Papers IV and V: Students' Opinions of their Communication Training and

Attitudes towards Learning Communication Skills.................................................... 46

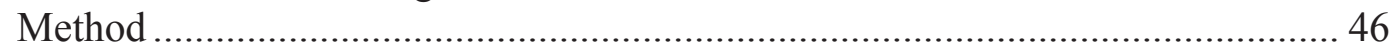

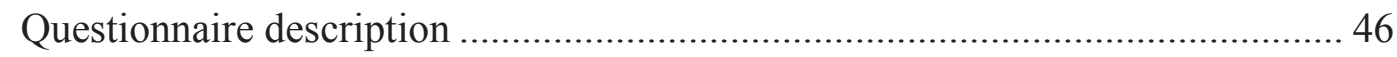

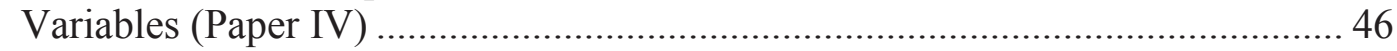

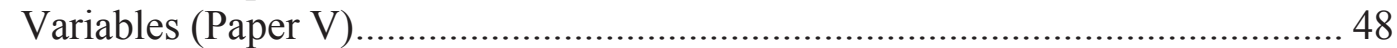

Study population, sample selection, requirement and data collection ................. 48

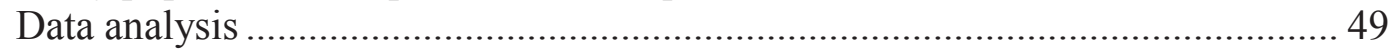

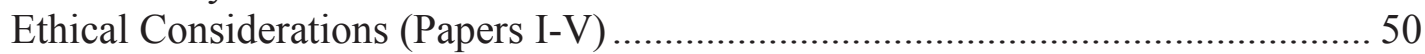

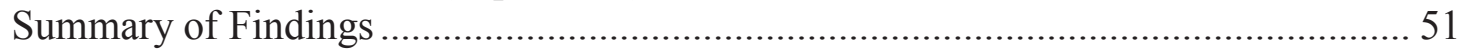

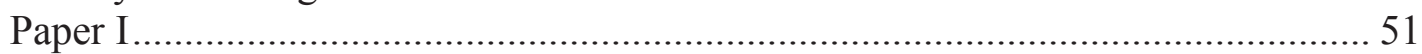

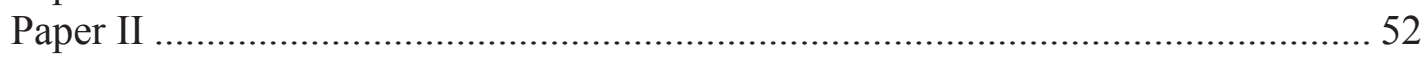

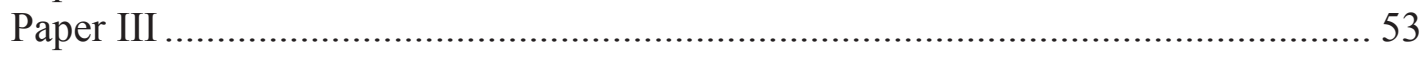

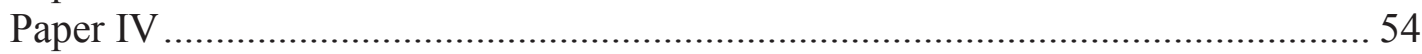

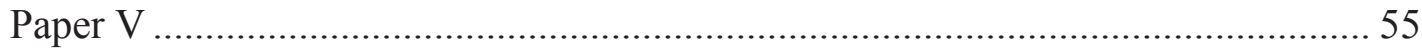

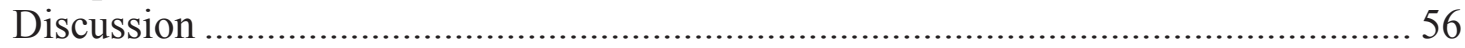

Discussion of Main Findings of Individual Papers .............................................. 56

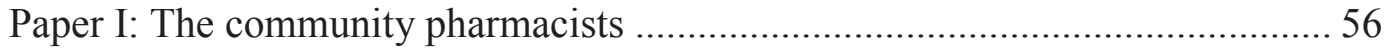

Paper II: The regulatory framework …............................................................. 57

Papers III-V: Pharmacy undergraduate education ............................................ 58

The Professional Expectation Gap of Pharmacists' Communicative Role

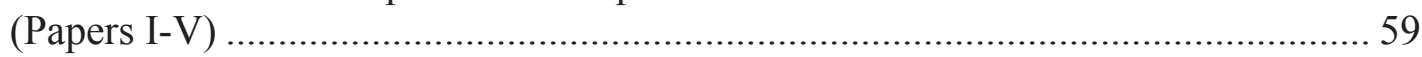

Understanding the expectation gap: theories of a profession ............................. 60

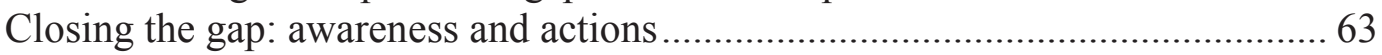

Aligning forces: the pharmacist, policies and the education ............................. 66

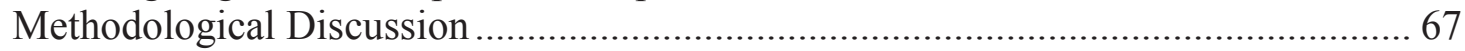

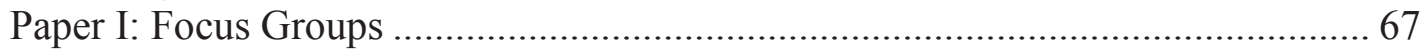

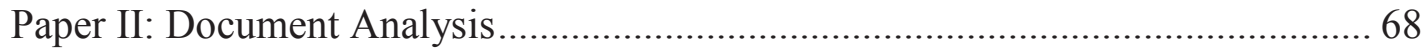

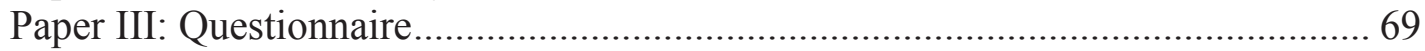

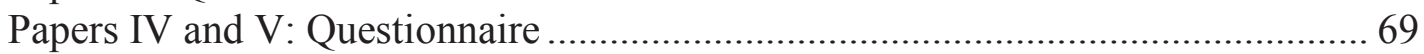

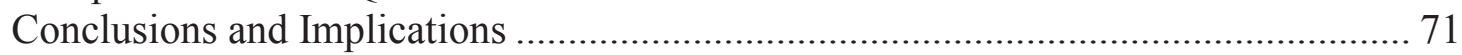

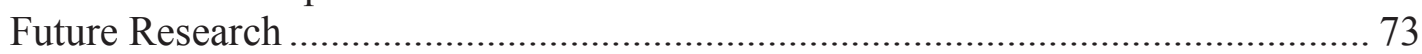

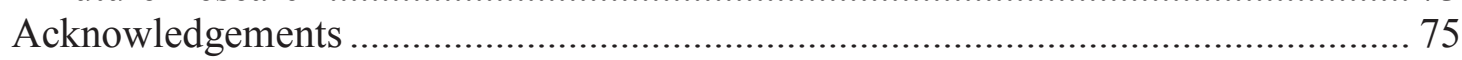

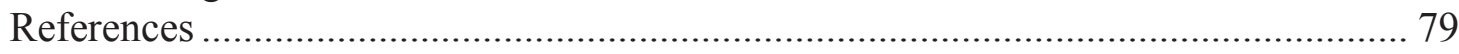

Papers I-V

Appendices 


\section{Key Concepts and Abbreviations}

Dispensing

Legemiddelsamtal (LMS)

Patient-centered care

Pharmacists

Pharmaceutical care
In this thesis, dispensing is seen as the process where a patient is handed over a prescription drug by a pharmacist. This process can comprise just the delivery or include application of the pharmacist's specialized health knowledge in optimization of the process of care, with the aim of improving health outcomes.

A Norwegian version of the English/Welsh Medicines Use Reviews. ${ }^{2}$

'Care that meets and responds to patient's wants, needs, and preferences and where patients are autonomous and able to decide for themselves. 3

In this thesis both the five-year and the three-year university or university college education are defined as 'pharmacists,' if not made explicit.

'A practice in which the practitioner takes responsibility for a patient's drug-related needs, and is held accountable for this commitment. (/.../) Responsible drug therapy is provided for the purpose of achieving positive patient outcomes. ${ }^{4}$ 
Professional pharmacy services (PPS)

The communicative role
'An action or set of actions undertaken in or organized by a pharmacy, delivered by a pharmacist or other health practitioner, who applies his/her specialized health knowledge personally or via an intermediary, with a patient/client, population or other health professional, to optimize the process of care, with the aim to improve health outcomes and the value of healthcare. ${ }^{5}$ In this thesis, PPS by pharmacists is the focus.

In this thesis, the pharmacist as a communicator combines his/her specialized health knowledge and communication skills in optimizing the process of care, with the aim to improve health outcomes during dispensing or in PPS. 


\section{Introduction}

I think that (new services) promotes confidence in the pharmacist, or yes in us as pharmacy employees, because I think we can show there, like, some of the knowledge we have. A Norwegian pharmacist (quote from a focus group study) ${ }^{6}$

Every day, community pharmacists interact with patients: dispensing prescriptions, suggesting over-the counter (OTC) medicines or other self-care treatments, and discussing medicine use in extended professional pharmacy services, such as Medicines Use Reviews. Globally, the role of the pharmacist is evolving from mainly supplying medicines towards being a patient-centered profession, putting the patient and not the medicine in focus. This professional development involves an interchange between practice, the regulatory framework, and the pharmacy undergraduate education. ${ }^{7}$ They all have to respond to the shift in focus towards more counseling in pharmacies. Each factor can be the driving force and evolve at different times, but the gap between them must not be too big, as it can lead to frustration among students or practitioners. $^{7}$

Medicines are important in prevention and treatment of diseases and symptoms. In 2011, about $70 \%$ of all Norwegians collected a prescription medicine from a pharmacy. ${ }^{8}$ In addition, there is use of OTC medicines, herbs, and vitamins, and medical use in hospitals or nursing homes. In the population above 65 years, $57 \%$ used more than five different medicines in $2011 .^{8}$

Medicines have great advantages, but do not come without challenges. Medication errors defined as 'a failure in the treatment process that leads to, or has the potential to lead to, harm to the patient' ${ }^{9}$ is expensive and causes unnecessary suffering among patients. ${ }^{10}$ In the Norwegian context about $5-10 \%$ of all hospitalizations at medical wards are due to inappropriate use of medicines, and the annual cost for the Norwegian society is estimated to be more than 5 billion Norwegian Krone. ${ }^{10}$ Research has shown that around $50 \%$ of patients do not take their medicines as intended by the prescriber $^{11}$ or are using inappropriate medicines. For example, between $30-80 \%$, varying between countries and patient groups, are prescribed unsafe 
and/or ineffective medicines. ${ }^{4,12}$ A study reported that around $55 \%$ of patients received medicines without a known indication, ${ }^{13}$ questioning the necessity of that medicine.

As seen above, the patients' use of medicines needs to be optimized to minimize society's costs and improve the patient's quality of life. Patients deserve to use safe, appropriate, and effective medicines. ${ }^{4}$ They have concerns such as worries about sideeffects and drug interactions, as well as questions and needs around medicine use. ${ }^{14}$ Patients want information about medicines. In studies, $73-91 \%$ of patients report being interested in medical information from the community pharmacists, ${ }^{15,16}$ who are recognized as easily accessible health-care professionals. Pharmacists have a solid knowledge of chemistry, pharmaceuticals, pharmacology, and pharmacotherapy among others. They could help in solving the above problems.

The ideal philosophy of care in pharmacies can be based on pharmaceutical care, which is defined as 'a practice in which the pharmacist takes responsibility for a patient's drug-related needs, and is held accountable for this commitment., ${ }^{4}$ In addition, good professional communication skills are a core necessity for pharmacists to improve and evolve patient care in pharmacies. ${ }^{17}$ Ideally, pharmacists apply their specialized health and pharmacotherapeutic knowledge when communicating with patients and thereby identifying and decreasing problems in connection with medicine use. Pharmacists improve patients' health, for example, by preventing inappropriate medicine use by identifying unsafe medicines and addressing side-effects. The pharmacists can increase adherence by negotiating goals of a patient's therapy and ways to how the patient can achieve them. Further, pharmacists can educate and inform the patients about medicines' use.

However, community pharmacists fall short at times regarding communication. ${ }^{18}$ Both the content of the encounter and how it is preformed (communication skills) need improvements. ${ }^{19,20}$ Further, the provision of pharmaceutical care, during dispensing and in professional services in community pharmacies, is moderate; ${ }^{4,21}$ most time is still devoted to technical dispensing activities. ${ }^{22}$

Pharmacists' communicative patient-care activities during dispensing or in extended services do not happen in isolation; rather, several internal and external factors affect its outcome, such as pharmacist-, patient-, environmental- as well administrative factors. ${ }^{17}$ This thesis focuses on the following three: the community 
pharmacists, the regulatory framework, and the pharmacy undergraduate education in the Nordic countries:

Community pharmacists, in collaboration with the patient and other health-care professionals, are central in the success of improving patients' health outcomes. Here good professional communication skills and attitudes towards responsibility of care are important in building patient relationships. The transfer from the traditional dispenser to a health-care provider communicative role happens to be more prevalent in the United States, Canada, the United Kingdom and Australia than in the Nordic countries. ${ }^{23}$ Understanding professional attitudes, belifes and perceptions towards such a shift are important in comprehending pharmacists' willingness to engage in developing current practice by having more professional pharmacy services and in introducing patient-centered care, since it is the pharmacists who are making the transfer.

The regulatory framework (legislation, economic incentives, and authority control) sets the foundation for what is expected from the society as regards the pharmacist's communicative and patient-care role in community pharmacies. ${ }^{24-26}$ Professions have a contract with the society; of which one part is expressed in the regulatory framework. ${ }^{27}$ This contract is one of the causes for being called a profession. Therefore, it has a great impact on pharmacists' scope of practice. ${ }^{24-26}$ An analysis of the regulatory framework can serve as a platform to discuss how practice, professional vision, and society's expectations are aligning in order to understand the communicative role.

The pharmacy undergraduate education plays an essential role in equipping pharmacists with good professional communication skills and socializing them into practicing patient care. Both the World Health Organization (WHO) and International Pharmaceutical Federation (FIP) state that the education should prepare the pharmacist for his/her future professional life as a 'counselor. ${ }^{28,29}$ It has been claimed that the education often falls short in keeping up with the evolving role of the pharmacists, especially the pharmacists' role in patient care. ${ }^{30}$ Worldwide, the pharmacy programs have had a strong focus on natural science, e.g., chemistry, biology, and physics. ${ }^{31,32}$ As a consequence many pharmacists have not had any formal communication skills training, but they want it and see it as highly relevant for their role. ${ }^{32}$ More knowledge is also needed on pharmacy students' overall views, experiences, and attitudes 
regarding the patient communication skills training they received during their whole undergraduate pharmacy program. It is of great importance to increase pharmacy educators' understanding on how differences between students' perceptions and the outcome of the teaching may to some extent be linked to variations in programs. This could potentially help teachers in finding new ways to improve and refine communication skills training in pharmacy schools.

The overall aim of this thesis is to explore, in the Nordic setting, how community pharmacists, the regulatory framework, and the pharmacy undergraduate education have responded to the shift in focus towards the increased communicative role of the pharmacists. In Figure 1 the relationship between the three factors and the communication process is illustrated. This thesis is concerned with the communicative role of the pharmacists around medicines during the traditional dispensing and also in professional pharmacy services. ${ }^{5}$ Hopefully, this thesis can have an influence on the on-going development and debate of communication and patient care by pharmacists in the Nordic countries aiming at improving the use of medicines in society. 
Figure 1. Community pharmacists, the regulatory framework, and pharmacy undergraduate education's relationship with the communication process.

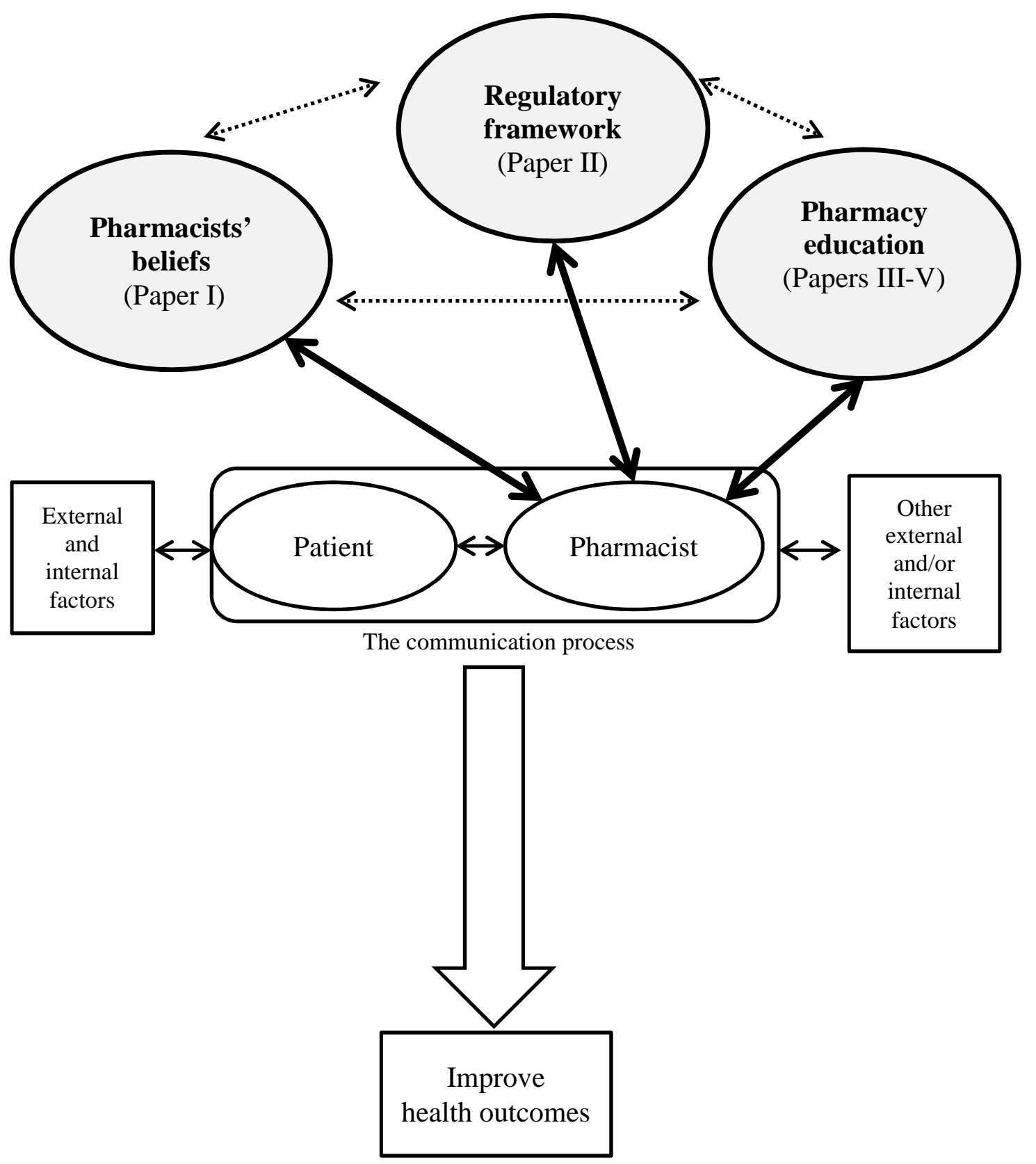




\section{Background}

Care means communication. Quality care means quality communication. Robert J. Cipolle et al..

\section{The Communicative Role of Community Pharmacists}

In the following, an overview is given of the professional role, the communication process, terms and definitions of communication, the roles which impact on patient outcomes, current communication practices and barriers and facilitators towards communication in pharmacies.

Pharmacists can be seen as members of a profession. A profession can be defined as:

'an occupation whose core element is work based upon the mastery of a complex body of knowledge and skills. It is a vocation in which knowledge of some department of science or learning or the practice of an art founded upon it is used in the service of others. Its members are governed by codes of ethics and profess a commitment to competence, integrity and morality, altruism, and the promotion of the public good within their domain. These commitments form the basis of a social contract between a profession and society, which in return grants the profession a monopoly over the use of its knowledge base, the right to considerable autonomy in practice and the privilege of self-regulation. Professions and their members are accountable to those served and to society. ${ }^{33}$

Pharmacists take on many roles and work in several settings: among others in hospital and community pharmacies, at universities, in the pharmaceutical industry, and in public administration. In all those different areas, the pharmacists are working in accordance with the FIP's Codes of Ethics (2014): ${ }^{34}$ 'given the responsibility, within the overall health system, to help people to maintain good health, to avoid ill health and, where medication is appropriate, to promote the responsible use of medicines. They assist patients, their care-givers, and those to whom they provide professional services to gain maximum therapeutic benefit from their medicines. ${ }^{34}$ According to 'the seven star pharmacist' as identified by the WHO's working group, the role includes being a care-giver, decision-maker, communicator, leader, manager, 
life-long-learner, and teacher. ${ }^{28}$ The importance of being a communicator is addressed also by the FIP. ${ }^{29}$

The traditional task of the community pharmacist was to prepare, preserve, compound, and dispense medicines. The first three were many years ago taken over by the pharmaceutical industry. The dispensing task still remains in pharmacies, often coupled with counseling around medicines. Maybe due to its traditional tasks, pharmacies have been criticized for being a commercial arena selling products, rather than a place where customers receive health- and patient-care. ${ }^{30}$ As a way to find new tasks, adapting to the loss of the manufacturing 'monopoly,' decreasing financing from dispensing, but also to getting more involved in patient care, pharmacists in several countries use their health knowledge and communicative role in 'nontraditional' activities. Those activities often have roots in the pharmaceutical care philosophy. The activities go under different labels, e.g., extended/enhanced/cognitive professional services or professional pharmacy services (see Moulin et al. for an overview of definitions ${ }^{5}$ ). Examples of services are Medication Reviews, Medicines Use Reviews, New Medicines Services, or health promotion activities such as smoking cessation, vaccination and measuring blood pressure and cholesterol. ${ }^{23,35}$ Some countries have a legislation which enables independent changes of drug dosage or therapeutic switches or prescribing. ${ }^{23,35}$ In these activities, pharmacists can evaluate the therapy more in-depth and promote medication adherence or give guidance on a more healthy lifestyle compared to the traditional dispensing encounter, as often more time, structure, and another reimbursement method can be available.

This movement of pharmacists and community pharmacies is addressed, advocated, and driven by organizations worldwide such as trade unions, professional pharmacists associations and trade organization for pharmacies, and academics in many countries, including the Nordic countries. They support and have partly described the shift, including a focus on responsibilities for a patient's medicine use and needs such as safe, appropriate, rational and effective use of medicines, and implementation of 'new' service models in their policy documents. ${ }^{23,24,29,36-41}$ The communicator's role of the pharmacist is one part of the caring professional role. It's embedded in the communication process, which will be further explained in the next section. 


\section{The communication process: an overview}

The verb communicate originates from the Latin word Communicare, which means 'to share.' One definition of communication is 'the exchange or transmission of ideas, attitudes, or beliefs between individuals or groups. ${ }^{42}$ Interpersonal health communication can be defined as how communication 'shapes people's health and medical encounters, and how, in turn, people's health and medical encounters shape communication and relationship dynamics. ${ }^{43}$ Interpersonal health communication deals with imbalanced and complex power positions between the patient and the provider, is concerned with 'life-and-death,' and can be about very sensitive topics. ${ }^{44}$ Previously this relationship, especially the doctor-patient, was authoritarian and biomedical; nowadays it is more individualized and focused on the patient. ${ }^{44}$ Interpersonal communication is a complex and social process. ${ }^{45}$

Various medical and psycho-social theories and models have tried to explain how the communication and indirectly the patient are viewed. Beginning with the biomedical model 'doctor knows best,' which has been abandoned to include more biopsychosocial perspectives, e.g., the Balint Theory, the Transactional Analysis Model, the Health Belief Model, and the Anthropological Model. ${ }^{46,47}$ In a review of interpersonal communication theories for the health-care context, the authors categorized these into three groups: individual-centered theories, interaction-centered theories, and relationship-centered theories, which imply different levels of the communication process. ${ }^{48}$

The first model to describe the communication process was probably the linear oneway transmission model by Shanon and Weaver (1949), with a sender passing over a message to a recipient. ${ }^{49}$ This model was further developed to the classic transaction two-way model: message transfer in both directions. ${ }^{50}$ The transaction model requires a sender, a message, a recipient, mutual feedback, and an idea of a 'feedforward,' i.e., a communication action impact on the next action and so on.$^{50}$ Another model was developed to include communication as a 'function of attributes,' e.g., needs, beliefs, and values of the people communicating. ${ }^{50}$ Thereafter, it was claimed that communication is a 'multidimensional process' with relationship and content components, and the communication occurs in a complex environment with social, cultural, legal, and physical values impacting it. ${ }^{50}$ In 2005, Feldman-Stewart et al. proposed a framework for provider-patient communication which builds on the above 
models. In addition, the model includes a focus on individuals' goals when communicating and discussing what attributes are important for how communication proceeds; see Figure 2. ${ }^{50}$

Figure 2. A model of the communication process between a patient and a provider. ${ }^{50}$

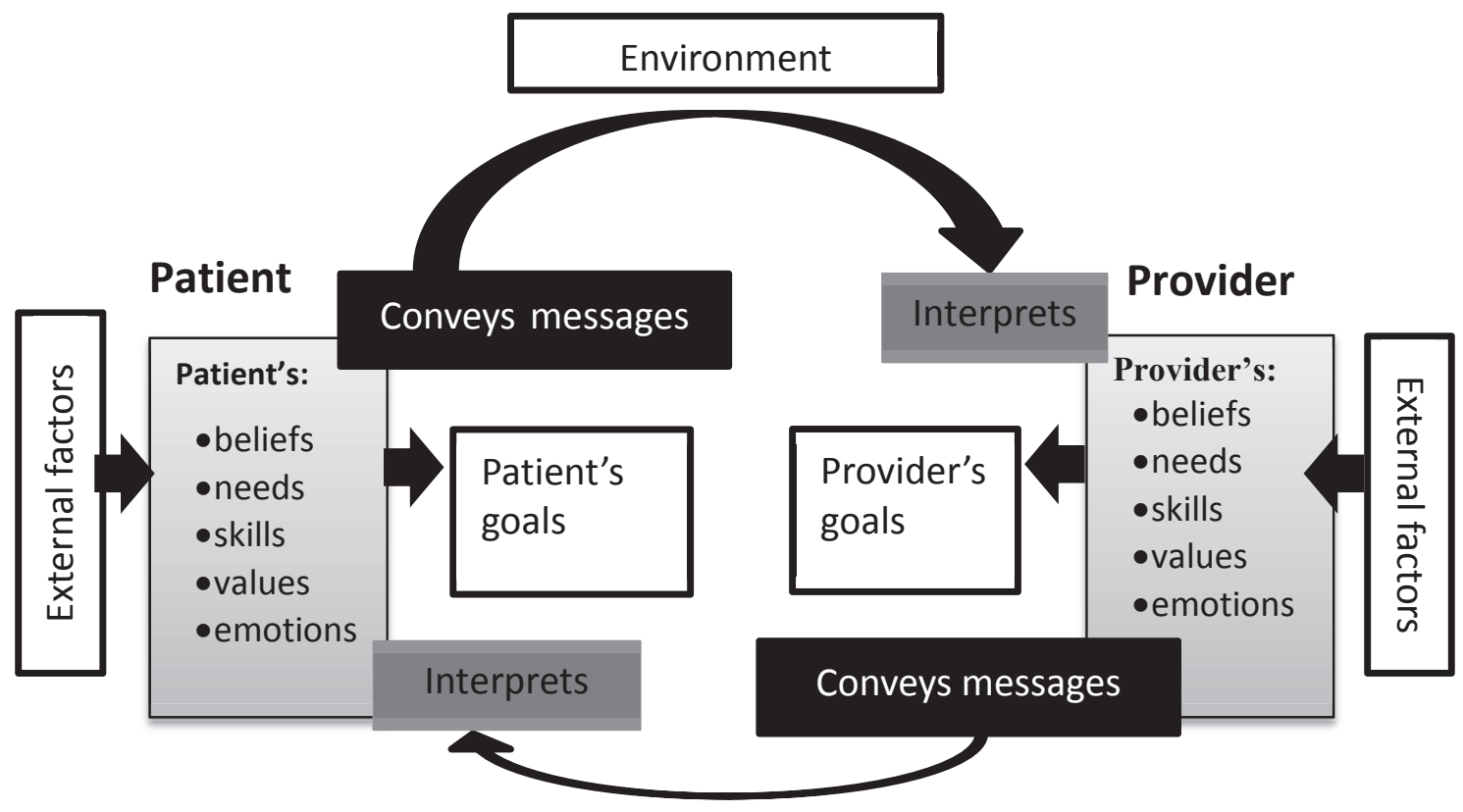

Exactly how provider-patient communication impacts secondary and hard endpoints is not fully understood. Street et al. proposed a model for how physicianpatient communication influences patient health outcomes. ${ }^{51}$ It often happens by more indirect means. For example, proximal outcomes of an interaction, such as increased trust or patient understanding, affect intermediate outcomes like adherence. Those can then impact harder health outcomes such as survival and disease cure. ${ }^{51}$

Terms, definitions, and concepts used for describing communication in pharmacies

There is no published consensus on terms or definitions used to describe communication between pharmacists and patients among researchers or professionals in the field. ${ }^{52-56}$ Rather, several terms have been used to describe the encounter between pharmacists and patients, sometimes without defining communication. ${ }^{54,57}$ Professional guidelines, white papers, individual communication studies, or books on communication for pharmacists provide terms and definitions of communication. 
Table 1 provides some examples of terminology and definitions used in a community pharmacy (for more examples, see Shah et al. 2006 ${ }^{54}$ ). Several researchers' focus on the process of the communication and others in their definitions instead stressed the outcome or the content of communication. On the other hand, communication in the pharmacy setting is often simply defined as providing information. ${ }^{54}$ A review of 39 studies found that researchers mainly used the term counseling ( $\mathrm{n}=28,72 \%)$, some used communication, education or consultation $(n=11,28 \%)$ to describe the pharmacist-patient communication. ${ }^{54}$ The members of FIP's Pharmacy Information Section argue that the terms pharmacist-patient communication, medication counseling, patient education/counseling, advice-giving as used in the pharmacy literature can be used interchangeably, and that differences rather come from linguistic differences between countries. ${ }^{55}$ Conversely, according to other researchers, there are nuance differences between the terms of informing, counseling, educating, and advicegiving. Those terms can be argued to be communication strategies, rather than terms for the communication process. ${ }^{54,58,59}$ See Box 1 for an overview of suggested differences of those terms.

Box 1. Terms for describing a provider-patient encounter.

Advice (advice-giving): recommendations offered with regard to prudent action, more judgmental than informational. ${ }^{a}$ Advice can be personal and specific ${ }^{59}$ and is often interpreted as binding for the receiver. ${ }^{60}$

Consultation: a meeting with an expert, such as a medical doctor, in order to seek advice. $^{\mathrm{b}}$

Consult: seek information or advice from (someone), especially an expert or professional. Have discussions with (someone), typically before undertaking a course of action. ${ }^{\mathrm{c}}$

Counseling: give professional help and advice to (someone) to resolve personal or psychological problems. ${ }^{\mathrm{d}}$

Educate: give (someone) training in or information on a particular subject. ${ }^{\mathrm{e}}$

Guidance: advice or information aimed at resolving a problem or difficulty, especially as given by someone in authority. ${ }^{f}$ The one being guided is in focus and should be the one finding the answers; it is not the 'coach' who gives the answers. ${ }^{60}$

Information: facts provided about something or someone. ${ }^{\mathrm{g}}$ Information is often nonspecific and non-personalized talk. ${ }^{59}$

Inform: give (someone) facts or information. ${ }^{\mathrm{h}}$

Instruct: tell or order someone to do something. ${ }^{\text {i }}$

https://en.oxforddictionaries.com/definition/ ${ }^{a}$ advice; ${ }^{b}$ consultation; ${ }^{c}$ consult; ${ }^{d}$ counseling; ${ }^{\mathrm{e}}$ educate; ${ }^{\mathrm{f}}$ guidance; ${ }^{\mathrm{g}}$ information; ${ }^{\mathrm{h}}$ inform; ${ }^{\mathrm{i}}$ instruct. 


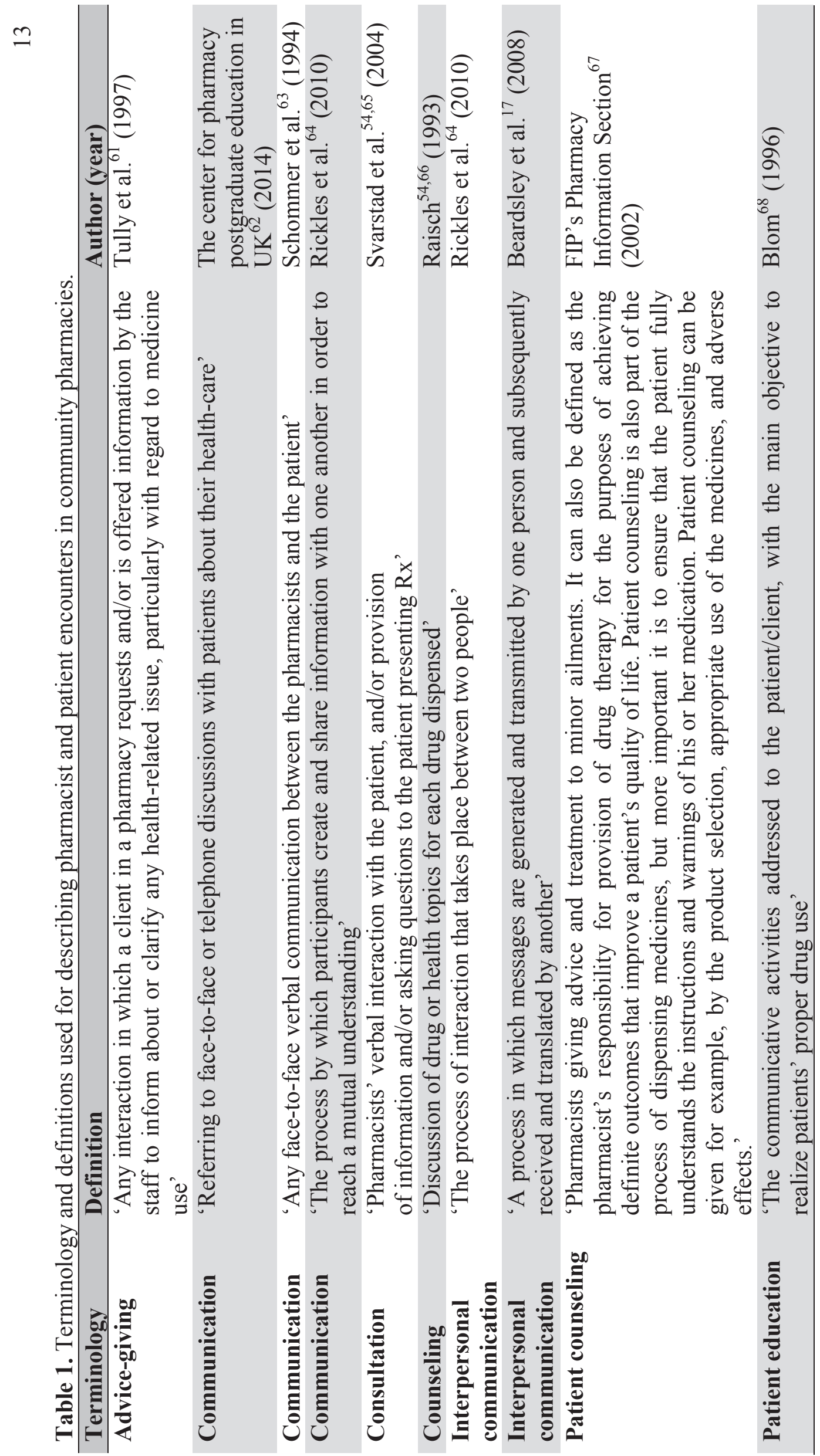


The same models and theories described for other health-care settings are applicable to the pharmacist-patient communication. ${ }^{17,54,69,70} \mathrm{~A}$ model for how the pharmacist-patient communication encounter can be described was suggested by Barnett et al. They suggested a continuum of communication strategies and styles from product centered to advising, supporting, coaching, and being fully patient-centered. ${ }^{71}$ A product-centered interaction includes just a simple exchange of a prescription against a product, an exchange of the standard information, or a medication review without patient contact. Even though no specific pharmacist-patient communication theories exist, several theories such as Role Theory, Facework Theory, and Communication Accommodation Theory have been shown valuable in further understanding the pharmacist-patient interaction. ${ }^{72-74}$

Several 'pharmacist-patient communication' guides exist. They describe how and what a pharmacist should communicate, e.g., the United States Pharmacopeia (1997) Medication Counseling Behavior Guideline, ${ }^{55}$ The Four Habit Model, ${ }^{75}$ and the Health Professions Core Communication Curriculum. ${ }^{76}$ They are further mentioned under the heading 'Essential communication skills for pharmacists.'

\section{'Ideal' pharmacist-patient communication}

The overall aim with communication and the patient-care role of the pharmacist in pharmacies could be said to achieve the best possible health for patients and make them have a positive experience of health-care. ${ }^{34}$ Moreover in the pharmacy, during dispensing and in pharmacy professional services, the pharmacist should use her/his particular health knowledge and communicative skills to optimize the process of care, with the aim to improve health outcomes and the value of health-care..$^{5}$ This is in line with and based on the practice of pharmaceutical care, ${ }^{4}$ and also in accordance with the FIP's Codes of Ethics. $^{34}$

There is no consensus on what constitutes 'ideal,' 'good,' or 'effective' pharmacistpatient communication. Chevalier et al. argue that in order for pharmacists to have an 'effective' communication behavior, it should be patient-centered and include the five domains of the Communication Accommodation Theory, which are approximation, interpretability, discourse management, emotional expression, and interpersonal control. ${ }^{74}$ Murad et al. reason that it should go beyond traditional goals of the communication like information transfer. In order to achieve this, the following factors are important: autonomy, competence or esteem, and fellowship. ${ }^{73}$ Palaian et al. and Ryan et al. use the word 'effective' patient communication as being outcome focused. According to them, 14 
effective pharmacist-patient communication should aim at identifying medicines userelated problems, make sure the patients use a safe and effective medicine for each indication, increase patients' knowledge about medicines and his/her illness, make the patient able to take informed decisions about their medicine use and general health, help the patient to improve their lifestyle, and adherence. ${ }^{77,78}$ To summarize, there are different focuses such as behavior, attitudes, goals, and/or outcomes of what constitutes 'ideal' communication.

\section{Essential communication skills for pharmacists}

By identifying different communication skills, 'ideal' communication is concretized. A skill is defined as the ability to do something that comes from training, experience or practice. ${ }^{79}$ According to Kurtz et al., communication in the broader sense incorporates content skills (what is being said), process skills (how it is being done), and perceptual skills (how the provider feels and reasons during the encounter). ${ }^{80}$ These categories of skills cannot be separated from each other; they are all important for the communicative role of the pharmacist.

A content skill has to do with the transfer of knowledge. Both during dispensing and in more extended professional services, the pharmacist transmits or collects a 'content' to help the patient. For example, the pharmacist discusses the name and indication of the medicine, explains dosage, what to do in case of missing a dose, when to expect an effect, or discusses significant side-effects. Under content skills falls the pharmacists' responsibility to explore information about patients' beliefs about medicines. ${ }^{80}$

Researchers have tried to list key process communication skills for pharmacists. Beardsley concluded that interviewing, listening, assertiveness, and nonverbal communication were common process skills taught in American pharmacy schools. ${ }^{81}$ Hargie et al. identified eleven major skills with descending order of importance: building rapport, explaining, questioning, listening, nonverbal communication, suggesting/advising, opening, closing, assertiveness, disclosing personal information, and persuading. ${ }^{82}$ Others argue that rapport building for a therapeutic relationship, active listening, and emphatic responding are important process skills. ${ }^{69}$ Hyvärinen et al. concluded that essential process skills for pharmacists are asking questions, listening, giving instructions, explaining, and justifying. ${ }^{83}$ In a textbook on pharmaceutical care, the authors stress building the patient- 
provider therapeutic relationship; here central skills are empathy, positive regards, and congruence. ${ }^{4}$

Perceptual skills deal with implicit matters during the interaction, ${ }^{84}$ such as the pharmacist's beliefs about the patient and his/her illness, clinical and professional judgement decisions, awareness of professional confidence, and external distractions. ${ }^{80}$

Professional guidelines and frameworks exist, which are supposed to help pharmacists to put content and process skills together in a logical way. For example, the 'United States Pharmacopeia (1997) Medication Counseling Behavior Guideline' identifies both process skills such as using a lay language, logical flow, empathy, probing, using open-ended questions, nonverbal communication, and content skills such as obtaining information on relevant medicine use, discussing the name and indication of the medicine, explaining dosage and what to do in case of missing a dose, when to expect an effect, and significant side-effects. ${ }^{55}$ Other models like the 'Four Habit Model,' which focuses on the care aspects of an interaction, have been used in the pharmacy setting. ${ }^{75}$ 'The Health Professions Core Communication Curriculum' suggests 61 skills that a health-care professional (including pharmacists) should master, such as rapport building, empathy, and active listening. ${ }^{76}$ 


\section{Impact of the Communicative Role on Patient Outcomes}

There are many studies evaluating pharmacists' professional pharmacy services' impact on patients' health outcomes, but much fewer studies about the standard dispensing encounter. ${ }^{85}$ The evidence of impact on secondary outcomes such as improved patient satisfaction and quality of life, medicine knowledge, promoting and preventing drug therapy-related morbidity, reduction in blood pressure, increased smoking cessation rates, improvement in lipid levels, and adherence is stronger, but not fully convincing, compared to the impact on hard endpoints such as hospitalization and mortality. ${ }^{78,85-91}$

Medicine use-related problems, adherence, reassurance, and patient satisfaction

Pharmacists can by reviewing prescriptions and interacting with patients during dispensing detect and help patients with medicine use-related problems such as wrong dosages, sideeffects, drug duplications, and interactions resulting in improved treatment. ${ }^{92-95} \mathrm{~A}$ telephone intervention with a patient-centered advising style improved adherence, reduced medicine use-related problems, and positively impacted patients' beliefs about medicines. ${ }^{96}$ A review, in institutions and ambulatory care sites, found positive evidence for pharmacist-patient communication increasing patients' knowledge and adherence. ${ }^{97}$ Motivational interviewing techniques also have been shown to improve adherence. ${ }^{98,99}$

Pharmacists can reassure patients and make them feel more secure on their therapies, ${ }^{14,100}$ and counseling makes patients more satisfied with pharmaceutical care services. ${ }^{101}$ Patient satisfaction can increase with a patient-centered communication style. ${ }^{102}$ A Cochrane review studied the effects of pharmacists in community or ambulatory care settings, non-dispensing roles on patient outcomes, and prescribing patterns, for example, identifying, preventing, and resolving drug-related problems, and encouraging proper use of medication. It concluded that in general there is support for pharmacists achieving some results in therapeutic management, aiming at improving clinical outcomes and care processes. $^{103}$

\section{Specific patient groups}

Pharmacists can educate patients about inhalator techniques by using open-ended questions, leading to better inhaler techniques. ${ }^{104,105}$ In more extended services in community pharmacies, it has been shown that pharmacists' educational activities can decrease HbA1c 
for Type 2 diabetes patients, behavioral counseling can help patients quit smoking, ${ }^{91}$ increase antibiotic knowledge, ${ }^{106,107}$ and coaching positively to impact drug attitudes for antidepressant use by depressed patients. ${ }^{108}$ A review presents evidence that interventions in asthmatic patients led to symptom reliefs, improvements are seen in decreasing blood pressure, cholesterol levels, glycosylated hemoglobin, and generally for medicine use, but there was no impact on patients' quality of life. ${ }^{86}$ Another review found positive results for pharmacists in improving LDL levels in dyslipidemia patients. ${ }^{109}$

\section{Conflicting standpoints}

In an editorial in Patient Counseling and Education from 2011, the authors acknowledge a knowledge gap for understanding how pharmacists' communication activities actually impact patients' health outcomes. ${ }^{110}$

A review questioned the impact of single dispensing encounters' effectiveness, if it only included one-way communication of information and no follow-up. The pharmacists who only deliver information to patients without engaging them in the discussion or exploring their experiences appear to be less 'effective' (in impacting health-care outcomes) compared to pharmacists who engage in prolonged relationship building or involve patients in the discussion of improving patients' adherence to medicine advice. However, information can have some positive effects on increasing a patient's knowledge. ${ }^{78}$

Mossialos et al. went through 33 systematic reviews in 2013 and were critical towards expanding the role of the community pharmacists, due to conflicting evidence for pharmacists' impact on minimizing use of inappropriate medicines or in preventing chronic diseases. ${ }^{88}$ This statement is supported by a systematic review from 2013 by Blalock et al. ${ }^{111}$ They argue that there is less evidence for services in community pharmacies compared to other settings for pharmacists. ${ }^{111}$ A Cochrane review from 2014 over systematic reviews concluded that pharmacists' communication activities in medicine management, such as counseling and educating patients, could play an important role in improving adherence, medicine use, and in increasing patients' knowledge about medicines. However, more research is needed to draw firm conclusions. ${ }^{78}$ Nevertheless, Mossialos et al. acknowledge that implementing professional pharmacy services might be acceptable when taking the whole health-care systems' development into account like aging populations, polypharmacy, and economic changes. ${ }^{88}$ 


\section{Quality of the evidence}

A general remark in most of the reviews is that there is a great heterogeneity in studies as regards definitions and details of interventions, mix of interventions in a service (e.g. counseling, medication reviews and pharmacists' prescribing), study design, measurement/instruments used, study length, different study populations, definition and selection of health, and patient outcomes, which makes it difficult to draw firm conclusions, make comparisons or understand why an intervention works, ${ }^{78,85,88,91,103}$ calling for more rigorous and coordinated studies. Especially, there is a lack of studies on economic outcomes. $^{85,91}$

Research evaluating the impact of pharmacist-patient communication activities on health outcomes is mainly conducted as part of a planned intervention, where pharmacists often focus on specific patient groups or conditions and the pharmacists have received additional training, and to a lesser degree part of standard dispensing routines. ${ }^{85}$ Such intervention studies must include verbal communication activities, even though there is not always an explicit description of the communication within the intervention. ${ }^{85,112}$ In addition, none of the reviews ${ }^{78,88,111}$ comment on specific communication skills or behaviors' impact on health outcomes. For example, a review found that research seems to have neglected the impact of communication, i.e., how the patient and pharmacist interact with each other during interventions in diabetes care on health-care outcome. ${ }^{112}$ Further, a review of 101 pharmacists-led patient counseling randomized clinical trials identified a lack of description of the counseling event and few studies used behavioral strategies and patient-centered-care. ${ }^{85}$ 


\section{The Communicative Role in Practice: Extent, Content, and Process of Pharmacist-Patient Communication}

\section{Extent of communication and professional pharmacy services in pharmacies}

An extensive review of 40 studies found the verbal counseling rates of medicine use, i.e., proportion of patients who receive some counseling, to lie between 8-100\% during dispensing. ${ }^{18}$ No distinction was made between different pharmacy staff. The wide range of the rate suggests different study designs, research methods, measures, or cultures like patient populations, pharmacy- and health-care systems, and pharmacy educations. The rate was affected by the research methods used, e.g., patients' reported rates of verbal communication was in the range $8-56 \%$, and reported rates in observation studies were 12 $80 \%{ }^{18}$

The implementation of professional pharmacy services is more noted, e.g., in the United States, Canada or Australia compared to other parts of the world. ${ }^{23}$ An American example presented that time dedicated to 'patient-care services' outside dispensing had increased from 16 to $21 \%$ of total work time from 2009 to $2014 .{ }^{113}$ In 2010, in Europe, the prevalence of pharmaceutical care provision was rather moderate; the "pharmaceutical care scoring ranged from $32 \%$ in Denmark to $52 \%$ in Ireland. ${ }^{21}$ Often most time is still devoted to technical dispensing activities. An example from United Kingdom demonstrated time use for different activities: $25 \%$ on labeling products, $10 \%$ on monitoring prescriptions for clinical appropriateness, $4 \%$ of total time on communicating on prescription medicines, and $3 \%$ of total time on patient-care services. ${ }^{22}$ In total around $40 \%$ of total time was spent on supplying the medicines. ${ }^{22}$ On the other hand, a survey of 25 European countries from 2014 found that almost two thirds had at least one version of a medication review in their country, at least a simple prescription review. ${ }^{114}$

\section{Content of pharmacist-patient communication activities}

The majority of studies exploring pharmacist-patient communication during dispensing has focused on the content of the interaction rather than on process skills. ${ }^{102}$ The above review of counseling rates showed that the pharmacy staff more often provided information on directions for use, dose, name of medicine, and indications than on safety aspects, for example, side-effects, interactions, contraindications, and information on storage. ${ }^{18}$ Newer 
studies showed that adherence discussions are often omitted, with rates between 1.8-6.7\% of the encounters. ${ }^{19,20}$ Also counseling on the effects of the medicine is rarer, between 7.1$18.1 \%$ of the encounters. ${ }^{19,20}$

In Sweden, Olsson et al. not only described the content, but also looked at the proportion of content in total time of the dispensing. ${ }^{115}$ They found that in median, 11 seconds of the interaction was spent on medical issues such as adverse events or user instructions. Instead, more time (median: 72 seconds) was spent on non-medical issues: the validity of the prescription, availability of medicine, or technical aspects of generic substitution. ${ }^{115}$ Encounters with a generic brand included more discussion about administrative issues and/or reimbursement, but not more information on medical issues such as adherence. ${ }^{116}$ For the most part, the dispensing was spent in silence (median: 88 seconds). ${ }^{115}$ Not explored in the study, but here pharmacists might assess the prescriptions for appropriateness. However, a study investigating how pharmacists gather patient information and used their health knowledge found out that Canadian pharmacists missed out on providing patient care during dispensing and rather focused on a technical dispensing. ${ }^{117}$ Eighty percent of the time was spent on technical checking activities like counting pills, labeling, and checking the prescriber's name. They also relied on written prescription information when assessing appropriateness instead of asking relevant questions to patients such as checking for drug allergies, interactions, and refill history. ${ }^{117}$

As opposite to the dispensing situation, a review of pharmacist-led patient counseling in randomized clinical trials found that the most common counseling content of professional pharmacy services contained communication on drug therapy purpose and adherence, but also on negative effects of medicines such as side-effects and interactions. Few of the studies focused on missing doses or storage. ${ }^{85}$

\section{Transmission of content (process skills)}

When it comes to process skills, a study report on pharmacy staff as friendly, seeking eye contact, and being respectful to patients. ${ }^{19}$ However, researchers suggest that pharmacy staff use less patient-centered communication styles, for example, low patient involvement, ineffective listening, low assessment of patients' understanding, missing out on patients' emotional cues, or little exploration of patients' needs. ${ }^{19,118-123}$ In a study from the Netherlands' pharmacy staff, only in 5\% (refills)-10\% (new prescriptions) of the cases tried to involve the patient. ${ }^{19}$ Pilnick suggested the term 'instruction given' to characterize 
the communication style used by pharmacists at a specialized clinic in UK, due to the low level of patient assessment and involvement. ${ }^{52}$ Pharmacists often use closed questions in the interaction. Skoglund et al. and Sleath found only 2-3\% of the questions posed by pharmacists were open-ended. ${ }^{119,124}$ This was confirmed in the UK; researchers found that Medicines Use Review encounters were short, that the pharmacist mainly used closedended questions, and did not involve the patient. ${ }^{122}$

However, in Canada Murad et al. identified that the interaction during dispensing included a desire for autonomy, competence, maintenance, and fellowship for both the pharmacist and the patient. The pharmacist used indirect question techniques and a less forceful communication form to ease a smooth interaction, and they worked to assess, monitor, and educate patients about their medicines. ${ }^{73}$ Further, a review on patient-centered communication found eight studies out of 32 with a patient-centered focus and identified evidence for such counseling style by pharmacists. ${ }^{102}$ Especially, this was the case in more extended professional pharmacy services or at special clinics with highly trained pharmacists. ${ }^{102}$ In a professional service, Montgomery et al. identified two types of counselors: 'the patient medication records-monitor' and 'the listener.' The latter type showed a patient-centered communicative style by first listening and then solving the patient's medicine-use problems. ${ }^{125}$ The review of pharmacist-led patient counseling randomized clinical trials found that teaching back and explaining were the most common process skills used by pharmacists in professional pharmacy services. ${ }^{85}$

The lack of identification of patient-centered communication might be due to the study design of communication studies, which traditionally have been addressing the content by quantitative methods and had a low use of communication theories.

\section{Communication studies from the Nordic countries}

In the Nordic setting, individual studies report of similar counseling rates as above. In a Danish observation study from 2013, 26\% of the encounters had no communication about the medicines at all. ${ }^{126}$ In a mystery shopper study from Iceland, the pharmacists seldom gave patients evidence-based information on the three study medicines. The pharmacists advised the patient to consult their doctor, instead of using their own pharmaceutical expertise. ${ }^{127}$ A Finnish mystery shopper study showed that different patient scenarios gave varying counseling rates; between $22-88 \%$ of the encounters included no information piece. ${ }^{128}$ Another Finnish study using observations found that between $20-82 \%$ of the 
patients received no counseling, depending on the kind of medicine dispensed. ${ }^{129}$ In a study based on patient self-reporting, Finnish patients reported not being counseled in 54\% of their visits. ${ }^{67}$ Norwegian patients report not being informed about the use of medicines in $50 \%$ of the cases. ${ }^{130,131}$ A Norwegian mystery shopper study on smoking cessation advice revealed that in $14 \%$ of the visits, the pharmacies' advice and services were categorized as good. ${ }^{132}$ From Sweden, an observation study from 2014 reports that $22 \%$ of the patients received no counseling and that $50 \%$ of the dispensing encounters contained 10 seconds or less about medical/pharmaceutical issues. ${ }^{115}$ In another Swedish study with mystery shoppers, pharmacists did not ask questions in $37 \%$ of the encounters, gave no information in $26 \%$ of the interactions, or left out counseling (no questioning and no information) in $18 \%$ of the encounters. ${ }^{53}$ However, there exists no study comparing all the five countries under similar study conditions, making sound comparisons difficult. The studies from Iceland (2001) and Finland (2002 and 2005) are rather outdated. (Nevertheless, personal communication with the Association of Finnish pharmacies reported that the results from Finland are on a similar level today.) 


\section{Factors Affecting Pharmacist-Patient Communication in Pharmacies}

Pharmacist-patient communication is not carried out in isolation. Instead various internal and external factors affect it. Several of the factors can be argued to influence both dispensing and professional pharmacy services. Below, factors impacting the dispensing encounter and performance and implementation of professional pharmacy services are presented. Thereafter, pharmacists' beliefs and attitudes, society's expectations of the pharmacist's role as stated in the regulatory framework, and pharmacy undergraduate education's role in promoting good communication practice are outlined more in-depth.

\section{Dispensing}

Factors associated with communication during dispensing can be categorized as environmental-, pharmacist-, interpersonal-, patient- as well administrative factors. ${ }^{17}$ The communication rates are higher for new prescriptions, compared with repeat prescriptions where patients receive little information on medicine use or on adherence problematics. ${ }^{15,18-20,126}$ Studies demonstrate higher communication rates for pharmacists in contrast to technicians. ${ }^{20,102,133}$ Others show that work culture such as managers' attitudes towards communication and communication policies between pharmacies varies and can explain different rates in communication. ${ }^{129,134,135}$ Examples of factors associated with communication during dispensing are listed in Table 2. The studies do not discuss the quality or impact on patients' health outcomes, rather report associations on type of content, amount of time, or simply if communication occurred or not.

\section{Professional pharmacy services}

Many studies have tried to understand barriers and facilitators for pharmacists to implement professional pharmacy services. Factors are both on individual-, interpersonal-, organizational- and external levels. Individual factors often listed are lack of clinical education, professional attitudes, and motivation. ${ }^{136-140}$ On a more interpersonal level, the physician's opinion of the service and building a relationship with the physicians are important, ${ }^{122,136,140-143}$ as well as the patients' demands. ${ }^{136,140,141}$ Factors on a pharmacy organizational level are lack of a support staff and/or better use of technicians/personnel, ${ }^{32,122,138,141,144,145}$ time constraints, ${ }^{122,142,144-146}$ use of patients' medical records, ${ }^{32}$ lack of or burdensome documentation system, ${ }^{140,144}$ consultation area, and 
layout. ${ }^{32,122,141}$ Here organizational culture factors such as prominent leadership, teamwork, marketing of services, and support from managers are central. ${ }^{122,136,141,142,147}$ For example, lack of time can be due to inefficient use of workflow. Also support from health-care authorities $^{136,137}$ and reimbursement systems $^{136,140,141,143,145}$ have been identified as important drivers. In Table 3 examples of factors are listed, which have been shown to be related with increased prevalence of services provision. 


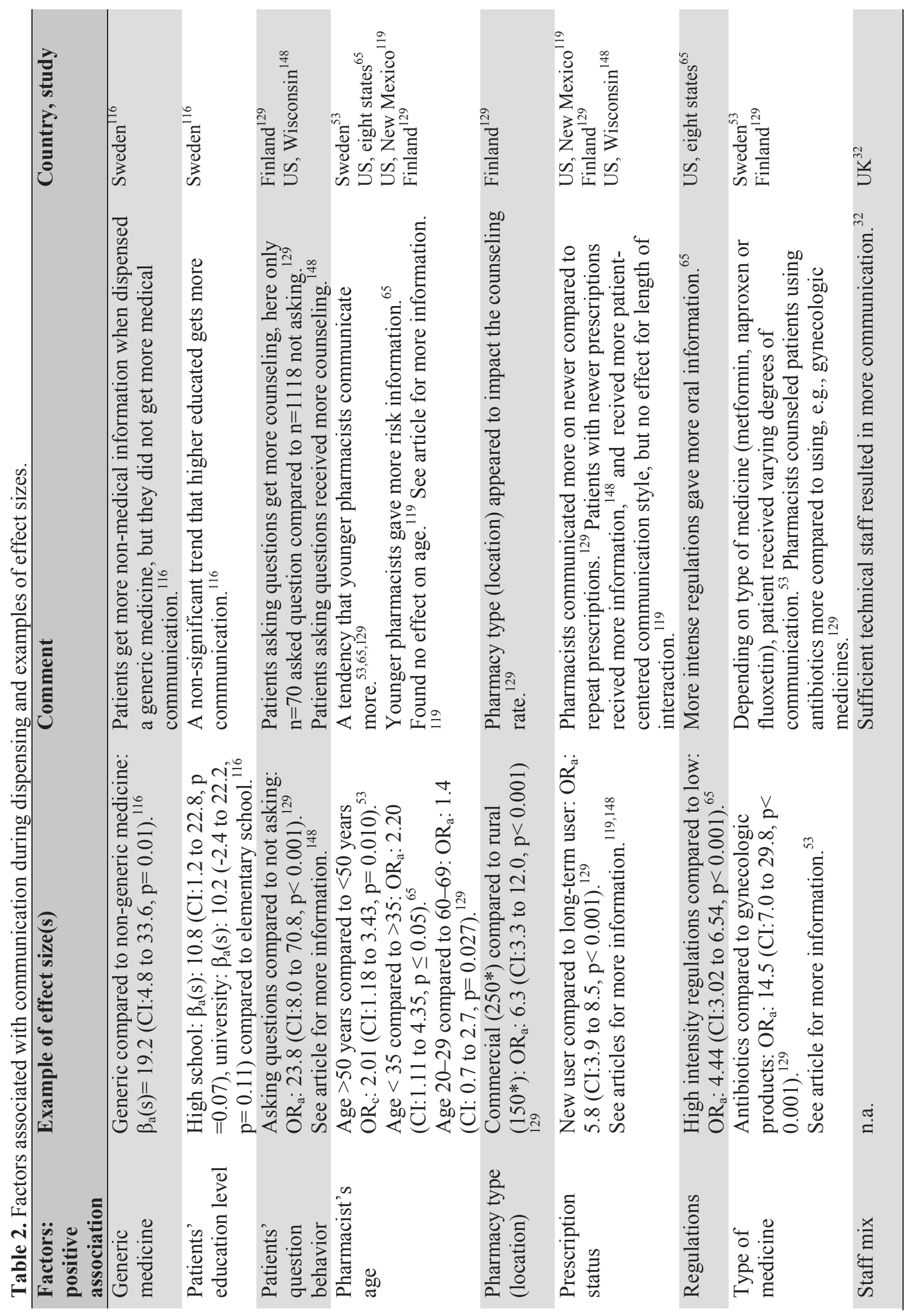




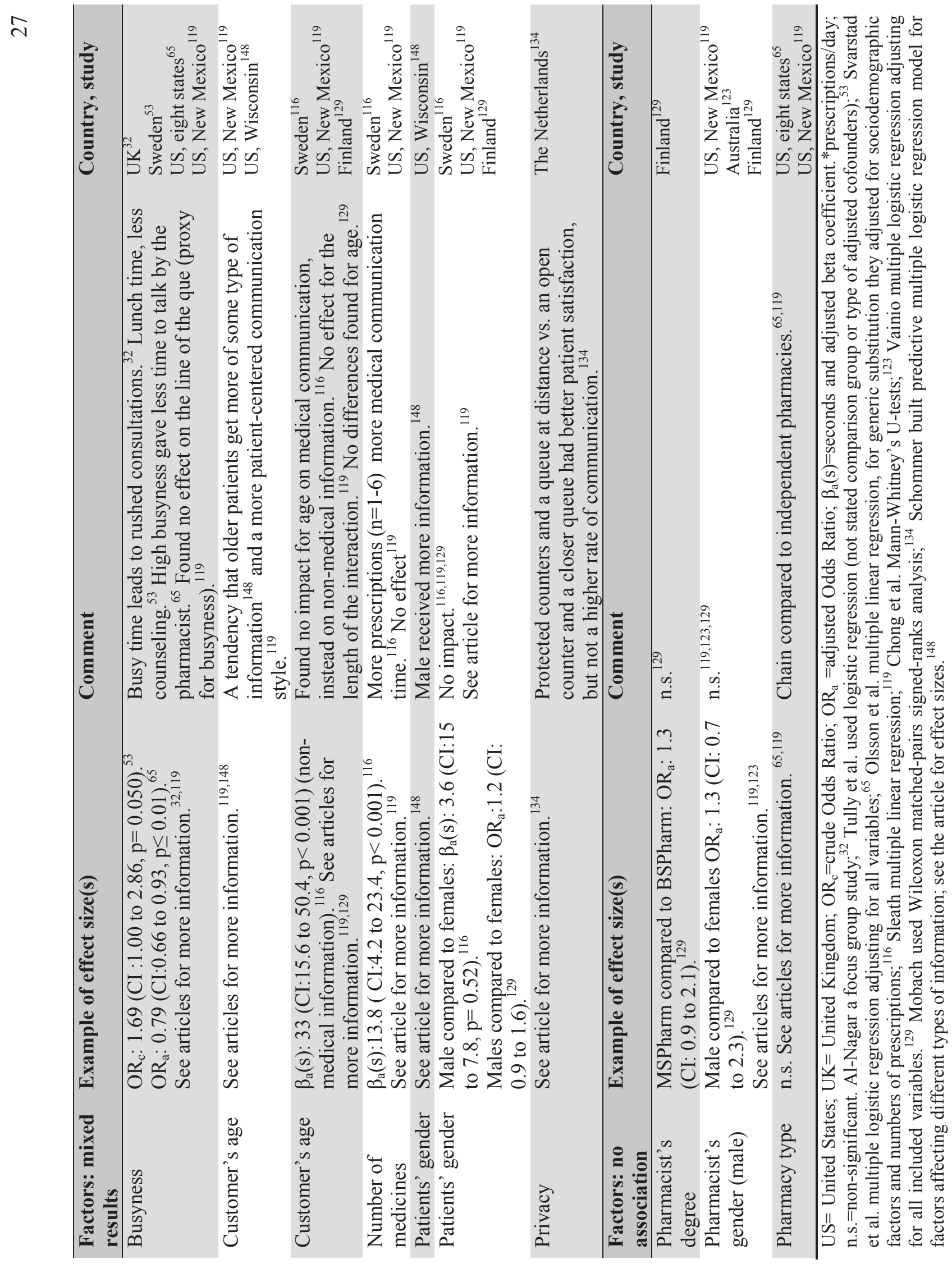




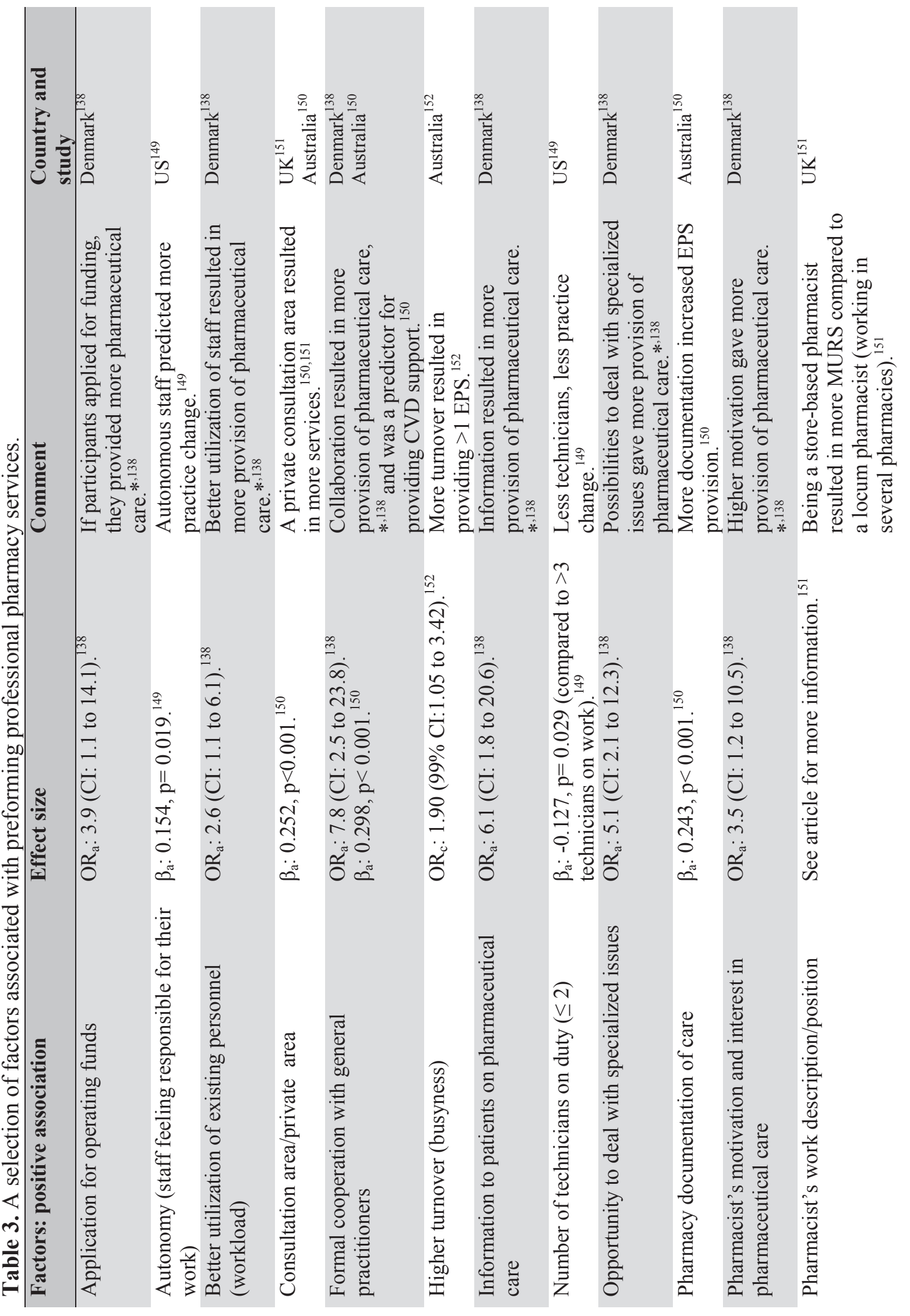


จิ

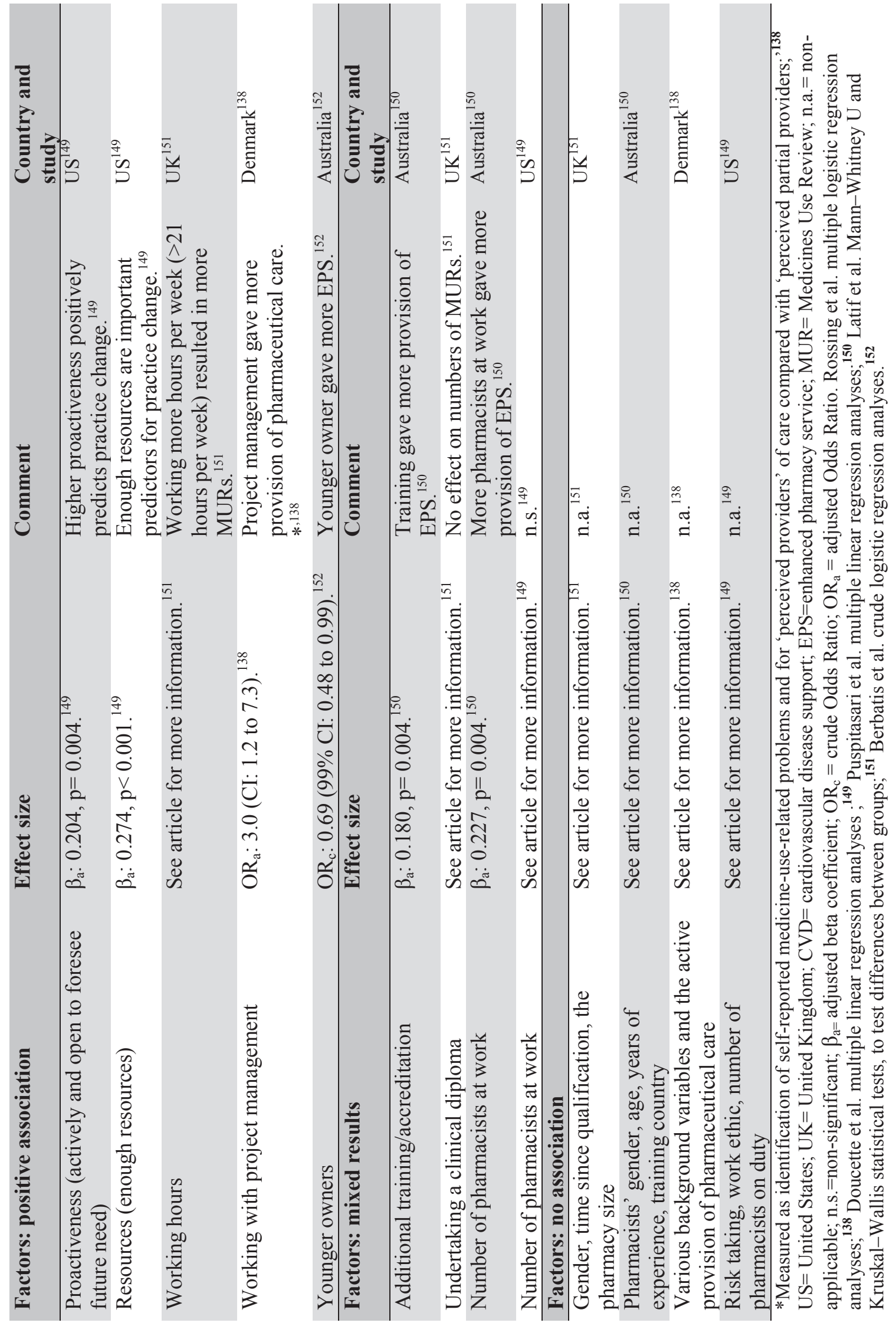




\section{Community Pharmacists' Beliefs towards their Communicative Role}

Understanding pharmacists' attitudes and beliefs about communication and practice changes have been seen as important in role developing, understanding implementation of services, and in changing behaviors. ${ }^{153}$ For example, pharmacists' attitudes of their role was related to increased monitoring of medications' question-behavior, ${ }^{154}$ performance of pharmaceutical care, ${ }^{138}$ and performance of Medicines Use Reviews. ${ }^{32}$ In contrast, a review from 2016 argues that attitudes or personal traits are not to be regarded as a vast problem, since pharmacists mainly are positive towards expanding their role. ${ }^{155}$ Pharmacists often state that professional pharmacy services and patient-centered care gives them a chance for increased use of their pharmacotherapy knowledge. ${ }^{142,143,151,155,156}$

On the other hand, it has been claimed that some pharmacists lack motivation to communicate with patients. ${ }^{17}$ Some studies have identified a lack of readiness ${ }^{157}$ and that pharmacists have a strong attachment to the dispensing role. ${ }^{22,158-160}$ Further, a Canadian study found that pharmacists identified that they are moving to a patient-care role, but also that they were reluctant. Perhaps not all pharmacists were ready to take on more responsibilities and they described an inconsistency in the profession around the role. ${ }^{161}$ Gastelurrurita et al. support the need for a shift in attitudes among pharmacists, regarding implementation of services and a need for more clinical education. ${ }^{136}$ A training package on communication skills for pharmacists showed that while improving participants' communication skills, the largest challenge for changing the communication was the pharmacy counseling culture. ${ }^{162}$ Pharmacy culture has been suggested as a reason for the slow uptake of services and changing practice. ${ }^{140,163}$ A culture can be described as encompassing persistent beliefs, traditions, norms, and expected behavior, which are shared by a larger group, and these values are transferred from one generation to the next. ${ }^{164}$ It has been argued that altruistic values must be grounded in the profession and individual practitioners. ${ }^{27}$ Here, Iceland serves as an example where pharmaceutical care was made mandatory in the legislation. ${ }^{165}$ However, practicing pharmacists had not embraced the philosophy internally, which was believed to be the main reason for not changing their practice. ${ }^{165}$ 


\section{Society's Expectations of a Profession as Stated in the Regulatory Framework}

Parallel to the medical profession, ${ }^{27}$ the pharmacy profession has a social contract with the society. A profession comprises of individual practitioners, professional institutions (like pharmacies, hospitals or universities), and the professional community. ${ }^{27}$ On the other hand, the society also comprises many actors and voices, e.g., the general public, patients, governments, civil servants, and politicians. ${ }^{27}$

The social contract sets implicit and explicit rules for this relationship and gives both partners rights and obligations. ${ }^{27}$ Some of the society's more explicit expectations are reflected in the regulatory framework in this thesis: conceptualized as legislation, economic incentives, and authority control. ${ }^{24-27}$ The expectations set one kind of foundation for norms and standards from the society for professions.

Depending on policymakers' perspective on professions and ideology of politics, different governing models are in question for professionals in a health-care setting. ${ }^{27,166}$ Models can be based on trust or mistrust in the profession or models grounded on choice and market competition. ${ }^{166,167}$ Traulsen et al. argue that perspectives, for example, if the regulators see pharmacies as pure business or acknowledge pharmacists as health-care professions, decide on what kind of policies regulators make. ${ }^{24}$ Therefore, such perspectives have a great impact on pharmacists' scope of practice, ${ }^{24-26}$ and the development of the communicative patient-care role i.e. what is allowed, expected, and encouraged in providing patient care.

The different Nordic legislation on pharmacist-patient communication on medicine use is presented elsewhere (main results of Paper II). An overview of consequences of varying types of legislation for improving pharmaceutical care in pharmacies is outlined in the following paragraphs.

Legal support and sustainable reimbursement mechanisms have been identified as central in improving patient care in pharmacies. ${ }^{136}$ Opinions vary on the right level of details regarding the legislation and who the driving force for a legislative change should be. Some argue the pharmacy profession has a role in showing its value for the society and thereby influencing policymakers in a specific direction. ${ }^{24,168}$ On the other hand, for example, in Sweden some professionals want the politicians to be the driving force in improving patient care in pharmacies. ${ }^{168}$ In the United States, stricter regulations have been shown to give higher rates of communication on medicine use in community pharmacies. ${ }^{65}$ Anell instead claims that stricter 
legislation of making pharmaceutical care mandatory can lead to market collapse, for example, resulting in pharmacy owners decreasing interest. ${ }^{169}$

Economic incentives to quality communication on medicines are important. For example, Gorecki argues that ambitious pharmacy contracts, without good financial backup, are 'unenforceable, does not recognize the conflicting motivations of a pharmacist, and results in no measurable output. ${ }^{170}$ Very often the reimbursement for communication on medicine use is included in the package-fee and not separated, i.e., for the impact that professional cognitive communication has on outcomes. ${ }^{171}$ In some countries pharmacists are paid for extended services. ${ }^{172}$ Roberts et al. argue that support is needed in the establishment phase of services as well as in service delivery. ${ }^{141}$

Lastly, authority control matters; what is controlled is also stressed in pharmacy practice. Jacobs et al. suggest that it is important to inspect both processes and outcomes' impact on patients' health of pharmacist-patient communication, even though it probably is a very laborintense task. ${ }^{173}$

\section{Pharmacy Undergraduate Education of Future Communicators}

Communication skills training and different types of training to develop necessary skills for communication have a great impact on quality of care and patients' health outcomes. ${ }^{80}$ In professional encounters, communication is not merely a matter of common sense or personality traits; this must be taught, ${ }^{80,174}$ in addition to acknowledge the learner's level. Research demonstrates the importance of pharmacists having the right communication skills and the specific need for training them. ${ }^{89,115,120,122}$ Hence, pharmacy educators have strong reasons to develop and strengthen pharmacy students' communication skills by the training in pharmacy schools.

Wallman et al. reviewed communication skills training in pharmacy education during 19952010. ${ }^{175}$ Communication skills were divided into two broad categories: oral and written. Written communication skills were further divided into academic, clinical, and reflective. Oral skills included interpersonal communication and presentation skills. Interpersonal communication skills consist of patient, inter-professional, and general skills. They also found that the most common teaching methods/modules in pharmacy education (published literature) were simulated/standardized patient interactions, interdisciplinary activities, pharmacy practice, and 
experience courses, WebTech activities, courses, and seminars. ${ }^{175}$ However, no comprehensive study in pharmacy education compares different learning methods as regards effectiveness. ${ }^{175,176}$ As Wallman et al. pointed out in their review, published studies mainly reported new educational interventions without a curriculum context, i.e., descriptions of placement in and content of the overall communication curriculum were left out. ${ }^{175}$ In addition, studies seldom included a control group.

Only a few studies, all from the Anglo-Saxon countries, have tried to map the status of communication training in pharmacy schools. ${ }^{81,176-179}$ In 1986 variable levels of commitment from schools and an informal approach towards teaching those skills were identified in the United Kingdom and Ireland. ${ }^{177}$ In the United States in 1990, similar findings emerged with large variations of content, teaching methods, and time devoted to patient communication skills training. ${ }^{178}$ The next study was performed in 2000, and the main conclusion was a need for more formalized assessment methods, ${ }^{81}$ which was still a challenge in the American pharmacy schools in 2006. ${ }^{179}$ In a study from 2013, Canadian and American pharmacy schools were surveyed, and the authors found that communication skills mostly were assessed by written examinations and that lectures dominated communication skills training (total amount of time). ${ }^{176}$ Another study from 2016 found that American pharmacy schools have a much stronger focus on clinical skills and patient care than European schools. ${ }^{180}$

\section{An overall communication curriculum}

For the design of the overall communication curriculum, evidence-based frameworks are recommended, either consensus-skilled or outcome-based. ${ }^{76,181}$ A list of skills or a framework should not be used slavishly. Nevertheless, the students' need an evidence-based toolbox and a framework of communication skills to choose from. ${ }^{80,182}$ A recent statement among aligned health-care professionals, including pharmacists, demands such as a joined approach and argue it is possible and necessary for developing an education with a high standard. ${ }^{76}$ Assessment of communication skills is complex, but necessary as assessments drives learning. It is recommended to combine different types of assessments and assess students several times: from basic theoretical knowledge, to simulations, and to workplace assessments. ${ }^{183}$

The use of behavioral and communication theories in the teaching are important since communication skills teaching are trying to improve the students' counseling behavior and the 
pharmacists' patient-care behavior. ${ }^{17,55}$ For example, the United States Pharmacopeia (1997) Medication Counseling Behavior Guideline could be used in the education of pharmacists. ${ }^{55}$ An absence of theories is probably limiting the effect of the training and pharmacists' impact in practice. $^{17,55}$

Communication skills must be repeated and rehearsed.$^{80}$ Research shows it is essential to start early in the education and thereafter little by little increase the level of training. ${ }^{176,184}$ Blom et al. argue that a well-designed program including only 20 hours spread over six years can be enough to secure a sufficient level of counseling skills among most pharmacy students. ${ }^{185}$ In addition, early placement of the practical training, like an internship in the curriculum, helps pharmacy students to grasp theoretical knowledge better. ${ }^{186}$ An ideal communication curriculum should provide adequate chances for all students to evaluate and then improve their skills. It should also acknowledge existing levels of skills parallel to introducing new skills and increasing complexity of the training. ${ }^{187}$ In medical students, a small group or one-to-one training has been shown to be more effective compared to large group training, and the training should mimic the real-world experience. ${ }^{80,184}$ Investing in patient-communication laboratories can facilitate communication skills learning. ${ }^{188}$

Lectures, including communication theories, help the learner to achieve a context understanding of the use of different communication skills and could be used as an introduction to experiential training. ${ }^{80}$ This increases learners' understanding of evidence of such training, overall concepts, and structures of different communication skills. ${ }^{80}$

A mix of experiential methods is preferable. ${ }^{189,190}$ Experiential learning such as role-play, simulated patients, feedback, video recording, and small group discussions have been shown to be effective since the learner can practice in a safe environment, before they meet real patients. ${ }^{80,184,190}$ From the medical profession, evidence exists of experiential teaching methods' positive impact on students' and physicians' counseling behavior. ${ }^{80,190}$ In contrast, from other health-care professionals such as pharmacists, nurses, and physiotherapists less comprehensive evidence exists for experiential training methods. ${ }^{175,182,191}$ Nevertheless, Berkhof et al. found no reasons for assuming that evidence for training methods would differ among professions or students and practitioners. ${ }^{190}$ Role-play and drama-inspired classes enabled, for example, pharmacy students to understand the perspective of the patient on medicine use. ${ }^{55}$ Simulated patients can be effective in equipping pharmacy students with communication skills, since 34 
students are provided immediate formative feedback on performance and addressed on communication apprehension. ${ }^{80}$ Mesquita et al. concluded an underutilized educational use of simulated patients in today's pharmacy practice and education. ${ }^{57}$ However, studies from other health-care professions have also shown that the quality of evidence to support use of expensive training methods such as standardized/simulated patients' needs should be addressed. ${ }^{182,192}$

\section{Pharmacy students' views and attitudes towards patient communication skills training}

Students' feedback of the communication training they received can help teachers and curriculum planners to improve the training. Pharmacy students' opinions on the value of new educational patient communication interventions are often studied as part of the introduction of new training methods. ${ }^{193,194}$ Some studies have explored how well students believed the whole training prepared them to deal with communications requirements in practice. ${ }^{195,196}$ An American study showed that students whose training program included experiential learning methods felt better prepared to practice counseling with patients than students without such training. ${ }^{195}$ In the United Kingdom, final-year pharmacy students were surveyed on how well they were prepared for practice. This survey included communication skills as an outcome. Significant variation was found between the schools in terms of how well they perceived the training had prepared them to communicate with patients. ${ }^{196}$

Attitudes towards communication skills training may influence the uptake of such skills and future counseling behavior. ${ }^{197,198}$ A relatively common perception is that students in health-care, such as in medicine or pharmacy, perceive communication skills learning as 'soft skills' and therefore implicitly question the relevance of the topic for their professional careers. ${ }^{199,200}$ For example, pharmacy teachers in the US described experiencing negative attitudes towards communication training and learning among their students. ${ }^{81}$ To explore medical students' attitudes towards communication skills learning, Rees et al. created a scale: the Communication Skills Attitude Scale (CSAS). ${ }^{201}$ Using this scale, medical students have been found to have moderate to positive attitudes towards communication skills. ${ }^{202}$ For pharmacy students the literature, based on the CSAS, is limited. In Australia, a study found that communication training improved students' attitudes for several of the scale's items, for example, how important the students thought communication skills learning was. ${ }^{203}$ 


\section{$\operatorname{Aim}(\mathrm{s})$}

The overall aim of this thesis is to explore, in the Nordic setting, how community pharmacists, the regulatory framework, and the pharmacy undergraduate education have responded to the shift in focus towards the increased communicative role of the pharmacists.

The specific aims are:

- to explore Norwegian community pharmacists' motivation and perceived responsibility regarding role development and involvement in patient-centered care.

- to describe society's expectations of community pharmacist-patient communication around medications as expressed by the states in the Nordic legislation, economic incentives, and authority control.

- to map communication skills building in pharmacy curricula in order to find ways to potentially improve the training by 1) exploring current practice and 2) course leaders' opinions regarding teaching of patient communication skills in Nordic pharmacy schools.

- to describe Nordic pharmacy students' opinions of their patient communication skills training, and the association between course leaders' reports of patient communication skills training qualities, and the students' perceptions of their training. Secondary was to determine what factors influence these associations.

- to explore Nordic pharmacy students' attitudes to communication skills learning, as well as the associations with various student characteristics. 


\section{Study setting}

The Nordic countries are similar in many ways; for example, they share similar historical backgrounds, political systems, culture, and welfare systems for all inhabitants, funded by taxes. As regards the pharmacy sector, they have in the last 50 years chosen to organize their pharmacy markets differently. Also, the education systems differ slightly.

\section{Pharmacy Markets}

Pharmacist's ownership has historically been the most common ownership model of pharmacies in Europe. ${ }^{169}$ A recent policy trend is to liberalize such markets. In the Nordic context, several of the pharmacy markets have undergone large changes/transformations in the last 20 years regarding ownership restrictions, competition (establishment and availability), sale of OTCs outside pharmacies, Internet pharmacies, and remuneration schemes.

The Icelandic pharmacy market was first out in 1996, followed by the Norwegian market in 2001. In short, more or less free ownership and establishment was allowed, possibilities to get discounts on medicines at wholesale prices, and free pricing on OTCs. (In 2003 OTCs were available outside Norwegian pharmacies. ${ }^{169}$ ) In 2009, the Swedish pharmacy market experienced a large change in ownership from being a state-owned monopoly; pharmacies were now put out to free ownership and establishment of pharmacies. ${ }^{204}$ A consequence of relieving ownership restrictions and competition has been that the pharmacy density increased in the cities. ${ }^{169,205}$ See Anell for an in-depth analysis of the consequences of the deregulation of the Icelandic and Norwegian markets, as well as Wisell et al. for the Swedish market. ${ }^{169,204}$

Finland and Denmark still have the traditional ownership model: pharmacist only. Nevertheless, after 10 years of discussion, in 2015 the Danish pharmacy law was 'modernized,' e.g., by easing and relieving the establishment restrictions, but without changing the pharmacistonly ownership model. In the law, policymakers placed a condition that pharmacies must provide extended services to new chronic patients (without raising the financial support to the branch). ${ }^{206}$ Also in Finland, there has been a liberalization discussion for over 25 years. Recently, in 2017, 
the Finnish government proposed to increase the numbers of pharmacy licenses, still keeping pharmacist- only ownership, but opening up for employee-partnership. In addition to pharmacies, they want to explore if a few OTCs could be made available outside pharmacies. ${ }^{207}$ An overview of the five different pharmacy systems is shown in Table 1 in Paper II.

Pharmacies in all countries have had projects or provide different professional pharmacy services, e.g., medication (use) reviews, smoking cessation, taking blood pressure or blood sugar, hearing checks, allergy tests, and providing services to nursing homes or general practitioners. ${ }^{40,208-210}$

\section{The Pharmacy Undergraduate Education}

In Finland, Norway, and Sweden there are two higher education programs that lead to authorization as a pharmacist with independent dispensing authority: a three-year Bachelor Degree ('prescriptionists') and a five-year university education leading to a 'Master of Pharmacy.' In Denmark, Finland and in Norway, the five-year education qualifies you to own, respectively, manage a pharmacy. In Sweden there are no such legal differences between the two educations. In Denmark, in addition, to the Master of Pharmacy degree, there is a three-year college training educating 'pharmaconomists, ${ }^{211}$ who are allowed to independently dispense prescriptions, but under a pharmacist's responsibility. Nowadays, Iceland's only education is the Master of Pharmacy, but pharmacists with a Nordic Bachelor Degree can work as prescriptionists there. An overview of the different pharmacy educations are described in under study settings in Paper IV. 


\section{Methods: Procedures and Techniques}

If we knew what it was we were doing, it would not be called research, would it?

Albert Einstein

In order to reach the overall aim of this thesis, five studies were conducted, see Figure 3. The methods were chosen based on the research questions and are presented individually for each paper. In Table 4 an overview of the methods is presented. Paper I explored Norwegian pharmacists' motivation and perceived responsibility regarding role development and involvement in patient-centered care by focus groups. The results from here helped to shape the aims of the other studies. Paper II explored society's expectations of communication in pharmacies as expressed by the Nordic legislation, economic incentives, and authority control by a legal document review and analysis. Papers III-V explored the education of Nordic pharmacy students in communication using three questionnaires to program coordinators, teachers and students. 


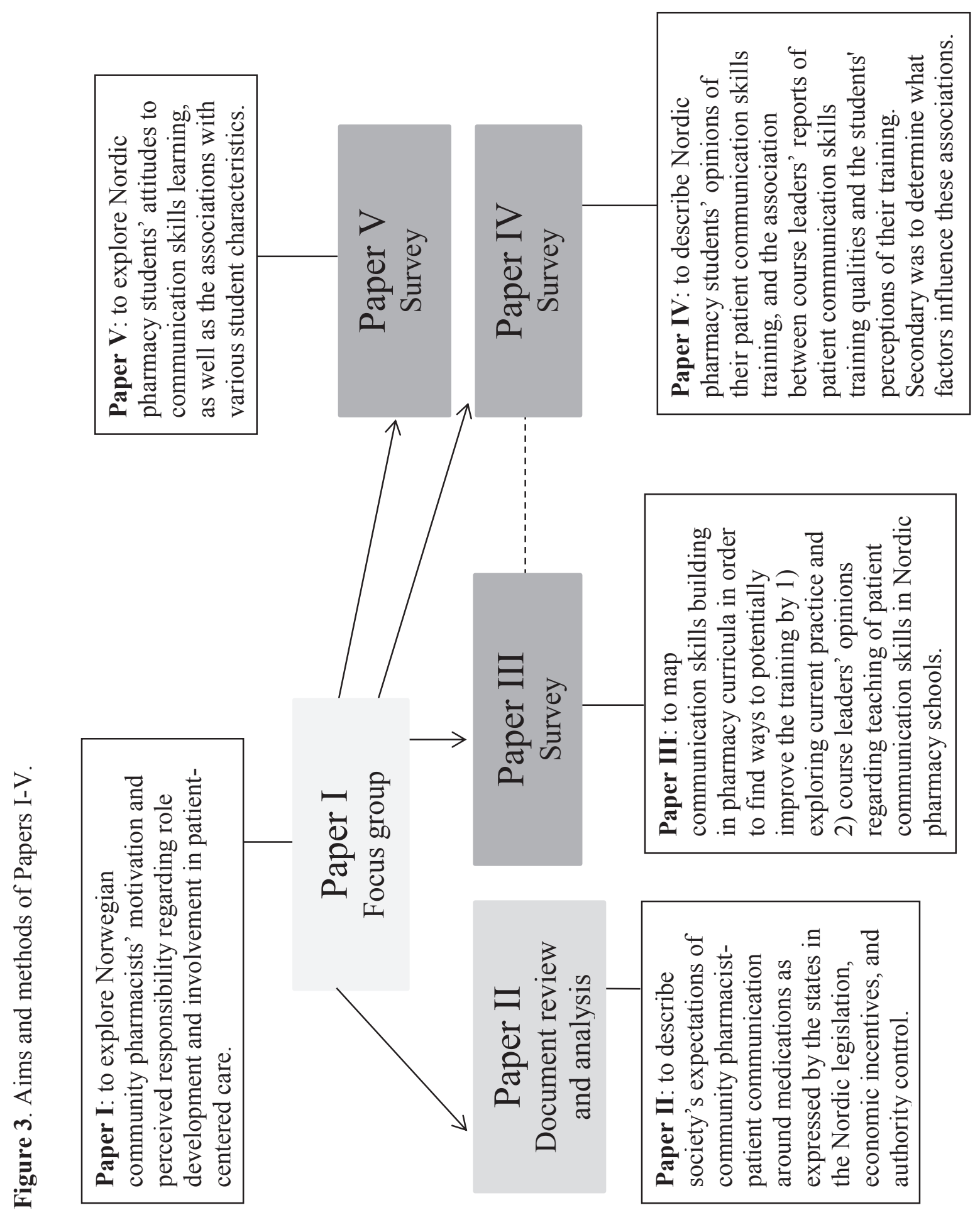




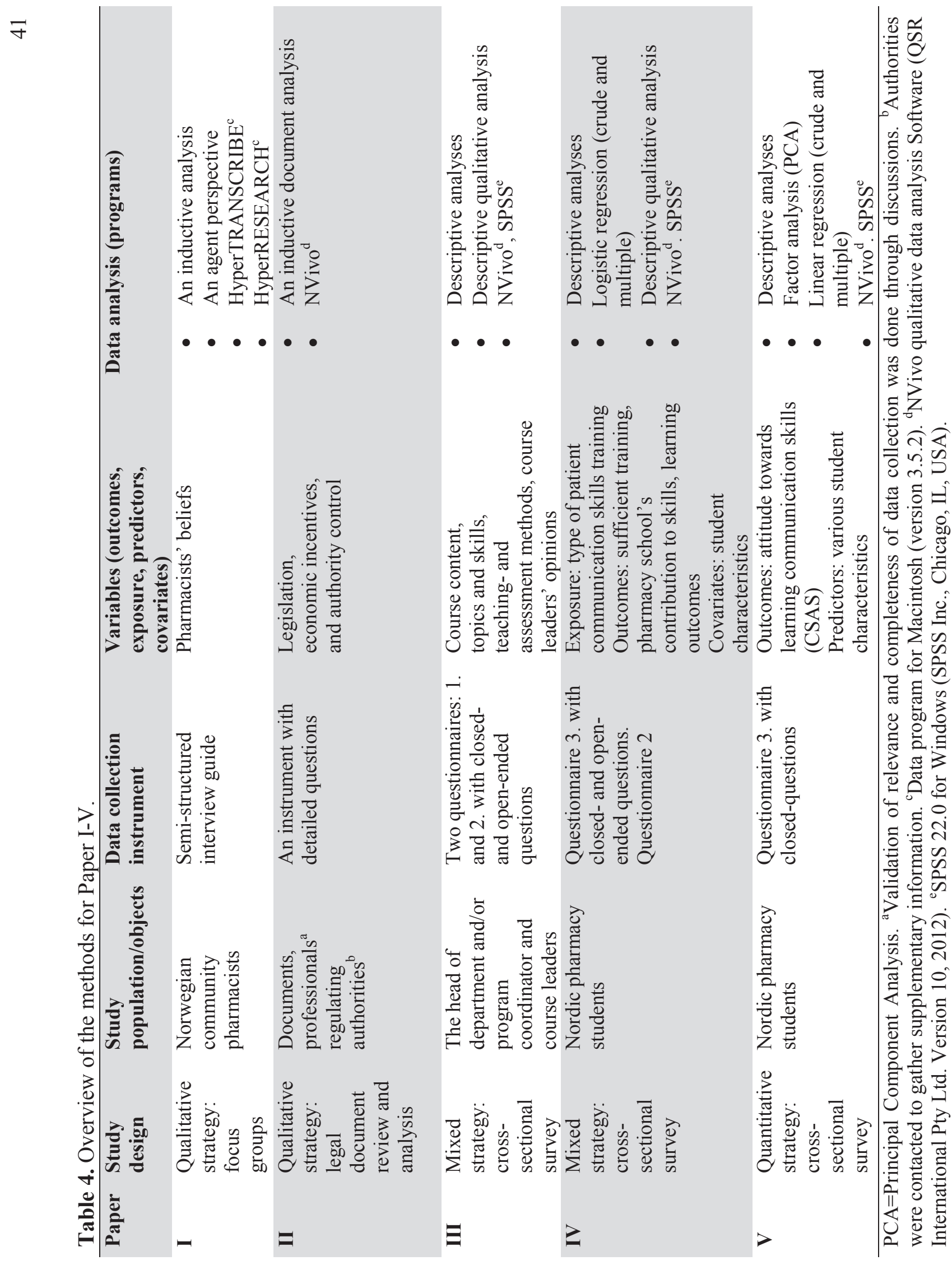




\section{Paper I: Community Pharmacists}

Aim: to explore Norwegian community pharmacists' motivation and perceived responsibility regarding role development and involvement in patient-centered care.

\section{Method}

The data was collected using focus group interviews. ${ }^{212,213}$ The study focus was on pharmacists as a collective and their perceptions and motivation. Hence, focus groups were seen as the most appropriate method, since they added group interactions compared to individual interviews. In the group discussion, the participants can react on each other's opinions and challenge each other. This enables the researcher to 'collect' contrasting opinions, which are of value in trying to understand a group's motivation. ${ }^{212,213}$

\section{Data collection instrument}

A semi-structured interview guide with open-ended questions was developed, containing topics based on the study aims and previous findings. ${ }^{146,160,163,214}$ The main topic areas were: community pharmacists' role in patient-centered care, e.g., responsibilities, possibilities and challenges, and role development with LMS. The guide was piloted.

\section{Study population, sample selection and requirement}

The study population comprised of community pharmacists. A purposive sampling strategy was used to recruit community pharmacists in Oslo, aiming at a heterogeneous sample. ${ }^{215}$ To achieve heterogeneity, diversity in pharmacy profile (from private-owned to the three different chain pharmacies, but excluding hospital pharmacies), geographic dispersion in the Oslo area, education level (Bachelor's and Master of Pharmacy), gender, age, and years of practice were sought for. In total, 43 pharmacies in the Oslo area were contacted based on their location and profile. The recruitment and data collection took place between February and April 2013.

\section{Data collection}

The thesis author moderated all interviews, and the same assistant moderator was present. The focus groups took place at the University of Oslo or at a local pharmacy in Oslo. Each focus group included a short briefing session, which aimed at clarifying how the group dynamic had been, and how the moderator had performed. All group interviews were 
audio-taped with two digital recorders. Participating pharmacists were given a gift card of 200 NOK.

\section{Data analysis}

The audio-tapes were listened to once and after that transcribed verbatim. The initial data analysis was conducted by the thesis author in close collaboration with one of the coauthors (who has background in another discipline: social science). The transcripts and notes were read several times independently. Keywords and phrases were collected during the read through. They were then compared in an initial mind map to form codes and thereafter categories. ${ }^{216}$

All categories were derived at inductively, ${ }^{217,218}$ first individually, and then in several consensus sessions. In the data, one developing key category had to do with the role and involvement of different stakeholders; it was decided to do a supplementary analysis based on the agent and agency framework developed by O'Conner and Wibeck. ${ }^{219,220}$ The framework helped structuring and understanding the data. As quality assurance, the interpretations of the categories were further discussed in the author group.

\section{Paper II: the Regulatory Framework}

Aim: to describe society's expectations of community pharmacist-patient communication around medications as expressed by the states in the Nordic legislation, economic incentives, and authority control.

\section{Method}

A qualitative review of regulatory documents, with a following document analysis was performed. ${ }^{217,221}$ A qualitative strategy was chosen by reviewing documents governing pharmacist-patient communication around medications, since one can argue that on aspects of the society's expectations are found in legislation, economic incentives, and control system. ${ }^{24-27}$

\section{Data collection instrument}

The thesis author developed an instrument (framework) with detailed questions covering the three main categories: legislation, economic incentives, and authority control. This helped structuring the data collection. The instrument was inspired from a similar survey 
from the United States. ${ }^{222}$ In addition, questions were developed to further clarify the legislation and sent to various regulatory authorities. (See Appendix 1, for example, of questions to the Icelandic authorities.)

\section{Data collection}

Data to answer the instrument's questions was first collected by reviewing areas regulating communication using online national legislative databases and various ministry websites,including governmental authorities (the thesis author collected data for Denmark, Finland, Norway and Sweden and in collaboration with the last author for Iceland). The searches (examples of search words: pharmacy, pharmacists, communication, patient, health-care professional) and review process aimed at being comprehensive to capture any pharmacy or closely-related law, regulation, rule or guideline affecting the content and provision of pharmacist-patient communication on medication.

The data collection was then cross-checked with regard to relevance and completeness through discussions with pharmacists within each country. These pharmacists had a special knowledge of pharmacy legislation. Lastly, various regulatory authorities were contacted by e-mail to gather supplementary information, especially concerning clarifications of the authority control. Data were collected between December 2013 and May 2014.

\section{Data analysis}

A qualitative document analysis was conducted. ${ }^{217,221}$ The first author organized the documents, answering questions from the instruments, but open to unexpected issues. The findings and interpretations were discussed in the research team for accuracy.

\section{Paper III: Patient Communication Education: Educators}

Aim: to map communication skills building in pharmacy curricula in order to find ways to potentially improve the training by 1) exploring current practice and 2) course leaders' opinions regarding teaching of patient communication skills in Nordic pharmacy schools.

\section{Method}

A cross-sectional questionnaire-based study was conducted. ${ }^{215}$ It was chosen to use questionnaires as data collection instruments aiming at collecting larger amounts of information that were not officially available, in a standardized way. 


\section{Questionnaire description}

Two questionnaires were developed by the thesis author and discussed in the research team (see Appendix 2. and 3. for full versions). The two questionnaires were developed based on two questionnaires from medical and physiotherapy communication skills education ${ }^{223-}$ 225 and prior studies of pharmacy schools. ${ }^{17,177-179}$

The two questionnaires contained a mix of both closed- and open-ended questions focusing on: course content, topics and skills, teaching- and assessment methods, course leaders' opinions on possibilities and struggles with the training, and future development. The questionnaires were piloted on two teachers involved in communication training. They reviewed them for relevance and time, and small changes were undertaken.

\section{Study population, sample selection and requirement}

All the 11 Nordic pharmacy schools teaching the Master of Pharmacy degree were invited to participate. The study population comprised of the head of the pharmacy school and/or program coordinator and course leaders identified by either the head of department and/or program coordinator or through a snow-balling technique. ${ }^{215}$

In a cover letter, respondents were asked only to include mandatory courses with a clear focus on communication with patients and/or other health-care professions. Questionnaire 1 was sent to the head of department and/or program coordinator, and Questionnaire 2 was directed to course leaders. Data were collected between March and November 2015. The thesis author collected the data.

\section{Data analysis}

For Paper III, descriptive statistical analysis was undertaken by the thesis author. The data was categorized according to the main sections from questionnaire 2: course content, topics and skills, teaching- and assessment methods, and course leaders' opinions. The free-text responses from the questionnaires' open-ended questions were summarized by the thesis author and thereafter discussed in the research team. For the analysis, a descriptive approach to the free-text answers was selected. 


\section{Papers IV and V: Students' Opinions of their Communication Training and Attitudes towards Learning Communication Skills}

Aim (Paper IV): to describe Nordic pharmacy students' opinions of their patient communication skills training, and the association between course leaders' reports of patient communication skills training qualities and the students' perceptions of their training. Secondary was to determine what factors influence these associations.

Aim (Paper V): to explore Nordic pharmacy students' attitudes to communication skills learning, as well as the associations with various student characteristics.

\section{Method}

A cross-sectional questionnaire-based study was chosen. ${ }^{215}$ A quantitative strategy was justified by wanting to gain a quantitative pattern of opinions rather than in-depth perceptions of students' opinions.

\section{Questionnaire description}

The thesis author developed the questionnaire in collaboration with the research team. The data for Papers IV and V were collected by the same questionnaire: Questionnaire 3 contained 39 closed-questions, two open-ended questions, and 12 student characteristic questions. See Appendix 4 for the full version. The face validity of the questionnaire was tested on persons involved in patient communication training at pharmacy and medical schools. Thereafter, the questionnaire was piloted on a sample of 21 recently graduated pharmacists for understandability, time, and layout. Also, two 'think aloud' interviews were used. ${ }^{226}$ Minor modifications were made after the pilot studies. The questionnaire language was English; this choice was made with the aim of minimizing problems caused by translation or cultural adaptation. ${ }^{227}$

\section{Variables (Paper IV)}

\section{Outcomes}

Students' opinions of their training were measured with a five-point Likert-type response scale ( $1=$ strongly disagree to $5=$ strongly agree). The questions were developed based on the findings of previous studies of important components of health-care professionals' patient communication skills curriculum and literature on questionnaire 46 
development. ${ }^{80,175,195,221,228}$ Sufficient training (theoretical, practical) was assessed as well as the universities' contribution to the skills. Ten items were clustered into three domains: 1) Sufficient patient communication skills training, 2) Pharmacy schools' contribution to patient communication skills, and 3) Learning outcome, i.e., perceived improvement of ability to communicate with patients (see Appendix 1 in Paper IV for individual items).

For the first and second outcome domains, two scales were created. The third outcome domain was measured by a single item: Learning communication skills has improved my ability to communicate with patients. An average score was calculated (range 1-5). The outcomes were dichotomized $(3 \leq=$ strongly disagree/disagree/neutral and $3>=$ agree/strongly agree). In addition, preferred teaching methods, general comments and ideas on improvements were asked for by two open-ended questions and are reported in the result section.

\section{Exposure}

Patient communication skills training, based on reports from course leaders from Paper III, was used as an exposure measure. Information included: 1) Teacher-led training (TLT) (including lectures, experiential training): amount in hours; 2) Additional courses containing patient communication skills training, besides the pharmacy practical experience (Yes/No); 3) Numbers of experiential training methods (e.g., role-play, video recording, simulated patients); and 4) Numbers of feedback methods the students had been exposed to. Three pragmatic groups, basic, intermediate, and innovative, were made according to the amount of education they received (e.g., hours: 6-13; 12-16;23-41 and numbers of training experiential training methods: $0 ; 1 ; 2-3)$.

\section{Covariates}

Three main sets of student characteristics were used as covariates, which were based on previous studies or seen as important theoretically: $:^{202,229,230} 1$ ) Sociodemographic factors (age, gender, parents' first language, and parents working in a health-care setting); 2) Experience of additional training or patient contact (participating in extra communication courses, job experience during pharmacy school in a pharmacy and/or health-care setting; and 3) Attitude-related factors (attitudes towards communication skills learning (CSASscale), the role of personality in communication skills, and future preferred work setting. Attitude regarding personality's influence on communication skills was measured via the question 'I believe my communication skills are a result of my personality.' 


\section{Variables (Paper V)}

\section{Outcome}

Attitude towards learning communication skills was the main outcome in Paper V. This was assessed with the Communication Skills Attitudes Scale (CSAS), including 26 items. ${ }^{201}$ Responses were recorded on a five-point Likert-type response scale (1=strongly disagree to $5=$ strongly agree). An explorative factor analysis using principal component analysis (PCA) was conducted. A one-component scale $(\alpha=0.852)$ consisting of 17 items was used as the outcome measuring students' positive attitudes towards learning communication skills in the analysis (nine items were excluded, because they did not fit theoretically; see Appendix 1 in Paper V).

A respondent must have answered 80 percent of the items to be assigned an average attitudinal score (ACSAS); otherwise it was treated as missing. Strong positive attitudes towards learning communication skills are indicated by a higher mean score. A transformation of the ACSAS scores to standardized z-scores was undertaken. The respondent's z-score should be interpreted as the number of standard deviations (SD) from the population sample mean (the reference value for the mean was set to zero). The z-score was used as the outcome variable in the analysis for Paper V.

\section{Predictors}

Student characteristics used as predictors of attitudes were age, gender, parents' first language (ethnicity), parents working in the health-care sector, pharmacy school (university in the Nordic context), participation in extra communication courses, pharmacy practical experience placement (community or hospital pharmacy), patient-care experience during studies, preferred future workplace(s), as well as 'I believe my communication skills are a result of my personality' and 'I believe my communication skills need improvement. $202,229-241$

\section{Study population, sample selection, requirement and data collection}

All 11 Nordic pharmacy schools (universities) were invited to participate in the survey. The inclusion criteria were that students should have fulfilled most (60-100\%) of their pharmacy practical experience and all mandatory communication training and studying required for the Master of Pharmacy degree of five years' duration. The questionnaire was handed out directly to the students as they attended lectures or they were approach by an e- 
mail and sent in an identical online questionnaire. ${ }^{242}$ Data was collected between the spring of 2015 and to the end of January 2016.

\section{Data analysis}

\section{Paper IV}

The first and last author categorized the open-ended questions. Statistical analyses were performed by the thesis author aided by a member from the research team. Descriptive statistics were carried out in characterization of the sample. The three outcomes and the three groups of communication training as exposure measures were fitted in univariate and multivariable logistic regression models, using generalized estimation equations (GEE) for binary outcomes to account for clustering within the pharmacy schools. ${ }^{243}$ Four models were performed where adjustment for the three individual sets of covariates was done. In the fourth model, covariates significantly associated with the outcome or changing the crude odds ratio $(\mathrm{OR})+/-15 \%$ in the previous models were included. Factors were removed from the model if $\mathrm{p}>0.05$ and if removal of a factor did not change the beta coefficients more than $15 \%{ }^{244}$

Crude and adjusted odds ratios (OR) are presented with 95\% confidence intervals (CI). A p value $<0.05$ (two-sided) was considered statistically significant. Individuals were excluded from regression analyses if they were missing data on the outcome or covariates. The robustness of the findings was tested by reclassifying students with neutral opinions, those who agreed/strongly agreed.

\section{Paper V}

Statistical analyses were carried out by the thesis author in collaboration with a member of the research team. Descriptive statistics were calculated for all variables. Thereafter, linear regression models were fitted with ACSAS (z-scores) as the outcome variable and various student characteristics as the predictors. To account for clustering within pharmacy schools, the models used generalized estimating equations (GEE). ${ }^{243}$ In crude analyses, each student characteristic was tested individually and after that adjusted for each other in multiple linear regression models. Finally, a backward stepwise reduced model was built. Here only significant factors $(p \leq 0.20)$ from the crude analysis were included; then, factors were removed from the model if $\mathrm{p}>0.05$ and if removal of a factor did not change the beta coefficients more than $20 \%{ }^{243}$ 
Individuals were excluded from regression analyses if they were missing data on the outcome or covariates. Overall, $2.9 \%$ of the sample was missing data in the final model. Stratified analyses of each country were done to point out possible national differences. Crude and adjusted results are presented with 95\% confidence intervals (CIs). A p value $<0.05$ (two-sided) was considered statistically significant.

\section{Ethical Considerations (Papers I-V)}

None of the five papers required any ethical approval, according to the Nordic regulations. Instead, the study was registered at and assessed by the Norwegian Centre for Research Data (NSD). This was according to an agreement between the Nordic countries stating this must only be registered in one of the Nordic countries (personal communication with NSD). The NSD is a resource center, approving non-health related projects by assessing researchers' data gathering, data analysis, and issues of methodology, privacy and research ethics, i.e., that handling of personal data is in accordance with the Norwegian Personal Data Act and the Personal Health Data Filing System Act.

Ethical considerations were undertaken, the respondents gave their informed consent in writing, and participation was voluntary. All data information on questionnaire respondents, focus groups' recordings, and anonymous transcripts, etc. were stored securely at a password-protected data machine and/or in a locked cabinet. This was in accordance with data protection regulations. Only the research team had access to the data. In focus group research, confidentiality can be difficult since it is conducted in a group setting. This issue was raised in the beginning of each group, and the participants were asked not to reveal anything personal that was discussed during the focus groups. 


\section{Summary of Findings}

\section{Paper I}

The first paper presents results from the focus group study on Norwegian pharmacists' motivation and perceived responsibility regarding role development and involvement in patient-centered care. In the study, 21 Norwegian pharmacists (15 female; 6 male) from 15 different pharmacies in the Oslo area participated in four focus groups lasting approximately two hours each. The key findings are divided into two main categories and nine subcategories. The main categories identified are 'reality vs. vision' and the overall 'agent' category.

\section{'Reality vs. vision'}

A gap was identified: the pharmacists said they were doing one thing in their day-to-day work compared to what they meant were their ideal tasks in the pharmacy. Their day-today activities were pictured as having the central focus on distributing products (subcategory: 'Reality: Medicine distributor') rather than on delivering patient-centered care in, e.g., a LMS. Most respondents stated that they wished for more than 'just' deliver out the product such as reassuring and motivating the patient (subcategory: 'Vision: Responsible and active medicine expert'). They said they wanted to be responsible and active medicine experts and further develop their roles to be more utilized in the society. Here the LMS could be a good solution and the respondents were positive towards such services in pharmacies (subcategory: 'Making vision reality, LMS, and other services as promising tools').

\section{'Agents'}

The pharmacists discussed and pointed out (implicit or explicit) several stakeholders as reasons for not claiming a more active role in patient's medicine use. They were identified as the following subcategories: 'pharmacists as agents,' 'the relationship with the medical profession,' 'the patient perspective,' 'the role of the chains in the pharmacists' workday,' 'abstract agents,' and 'the role of the authorities in the pharmacists' future role development.' 


\section{Paper II}

The second paper outlines the findings about society's expectations of pharmacist-patient communication around medications. The Nordic countries staff-patient communication is regulated by using general laws (i.e., not a detailed legislation regulating the content or process of communication), and in all countries patients have a right to information on how to use their medications. In Finland, only pharmacists (not pharmacy technicians) are allowed to communicate information on medications as compared to the other countries.

The legislation's central focus in the Nordic countries is information on the use of medications both for new prescriptions and refills. During dispensing, the information can be given either orally or in writing. How the communication should be performed varies slightly between countries: from informing to pharmaceutical care (in Iceland). Some elements of patient-centered care are there in all legislations, such as 'individualized' information and that the pharmacists should take into account the patient's culture, age, and experiences. The goals and outcomes with staff-patient communication vary in the five countries, from proper use to reducing the risk of diseases and promoting general health.

Pharmacists' obligation to keep a journal on advice given during dispensing is vaguely regulated in several of the countries; as a health-care professional they should document patient care. However, there is not a consensus about if pharmacists are performing patient care during pharmaceutical dispensing. To assure patients' right to discretion and privacy, the dispensing area should be designed in such a way so that those aspects are provided. Only Iceland has a specific requirement of a private counseling room.

The economic incentives for communication on prescription medication during dispensing are included in the pharmacy mark-up. In none of the countries is professional 'cognitive' communication around medicines linked to any economic incentive specifying the content, amount or outcomes of communication. As of 2015, only Denmark has had an established and financed extended communication service within asthma treatment. The authority control on staff-patient communication emphasizes the pharmacy's management and seems to evaluate structure indicators of communication. 


\section{Paper III}

The third paper presents the results from the questionnaire study on communication skills building in pharmacy curricula. Questionnaire 1 received a $100 \%$ response rate. In Questionnaire 2, 29 relevant courses were identified, and answers were received for 26.

Communication skills were mainly taught towards the end of the students' education (median in year 4). The range of courses was 1-5 (mode 1) per program. The pharmacy practical experience is the core period for patient communication skills training. In four schools patient communication skills training is taught in a separate communication skills course and at two schools within an interdisciplinary course. The teacher-led training varied from six hours to 92 hours. Most of teachers involved in the communication training were pharmacists without any formalized communication education (17 out of 26 courses).

Many course leaders wanted a larger focus on communication skills training, for example, longer courses, more practical training, better ways of transferring communication theory into practice, and time for students to reflect upon communication skills and the professional role. The course leaders reported on barriers in improving the training such as: too large student groups as an obstacle to individualize the education, assuring that everyone gets enough training and feedback, and lack of time and money.

All schools used lectures. Experiential training methods, such as video recording (3 schools), role-play ( 7 schools), and simulated patients (4 schools) were not as well represented as teaching methods. The least used feedback methods were feedback by selfevaluation (1 school) and video recording ( 3 schools). Some course leaders had difficulties to find teaching methods that reflected the real-world experience and to capture students' interest. In a perfect world, many respondents reported they would incorporate more experiential teaching methods in their teaching.

A reflective essay was a common assessment method (6 schools). Objective structured clinical examinations (OSCE) were, at the time of the study, used by one school as a summative assessment method. Assessment (summative and formative, i.e., feedback) was mentioned as a demanding area both in regard to finding good and quality-assured assessment methods, and time, money, and competence for carrying out the assessments. 


\section{Paper IV}

The fourth paper describes results on students' opinions on their communication training. The response rate was $77.2 \%$, with 370 out of 479 students agreeing to participate. In the sample, the median age was 26 and $73.5 \%$ were female. In the study population, $37.0 \%$ of the students agreed on having received enough training on theoretical knowledge, $34.4 \%$ in having enough practical training, $20.3 \%$ in enough feedback on their own skills, and $28.4 \%$ in training to evaluate one's own skills. In the sample, $20.0 \%$ believed that their communication skills were a result of the training at the pharmacy school, and $41.1 \%$ reported that the feedback had significantly improved their communication skills.

Students in the innovative group (training with more experiential training methods and more than 20 hours of training) were significantly more likely to report having received sufficient training (adjusted OR:4.20; 95\% CI:2.03 to 8.69, $\mathrm{p}<0.001$ ), that the pharmacy school had contributed to their skills compared to students in the basic group (adjusted OR:3.65; 95\% CI:1.89 to 7.04, $\mathrm{p}<0.001$ ), and that learning communication skills had improved their ability to communicate with patients (crude OR:3.61; 95\% CI:1.25 to 10.41, $\mathrm{p}=0.05$ ) in contrast to students in the basic group. No differences were seen when reclassifying students with neutral opinions.

There was a dissatisfaction concerning the insufficiency and the level of received patient communication training in many of the students' comments, their knowledge and abilities were learned at other places, the training had been simple 'common sense,' and the training had not prepared them for communicating with patients. The students wanted more feedback on how they communicate with patients.

The students gave several concrete suggestions on how the training could improve: the training could be placed much earlier in the curricula, strengthen the focus on student activating training, i.e., experiential training such as role-playing, practicing with actors and/or real patients, video recording, and training with other health-care professionals. Further, the pharmacy school should have a specific patient communication course or a wider range of voluntary courses. The training must be designed to be relevant and specific for the profession and be transferable into real-world practice. 


\section{Paper V}

The fifth paper presents the findings from the questionnaire study on pharmacy students' attitudes to communication skills learning. The final study population included 367 students. In the whole study population, the mean attitude score on CSAS was 3.67 (SD: $0.49)$.

In the initial multiple analyses, females scored higher than males on attitudes to communication skills learning (adjusted $\beta: 0.35$; 95\% CI:0.13 to 0.57, p=0.002). Further, if students studied at newer pharmacy training programs, they scored higher than those in the oldest pharmacy training programs within each country (adjusted $\beta: 0.75 ; 95 \% \mathrm{CI}: 0.55$ to $0.95, \mathrm{p}<0.001)$. Students who believed their communication skills needed improvement had higher scores compared to students who thought their skills did not need enhancement (adjusted $\beta: 0.48 ; 95 \% \mathrm{CI}: 0.26$ to $0.70, \mathrm{p}<0.001$ ). In addition, students who perceived their communication skills were a result of their personality scored lower in contrast to the reference group in the multiple model (adjusted $\beta$ :-0.32; 95\% CI:-0.54 to $-0.11, \mathrm{p}=0.003$ ). All other included factors were non-significant in the multiple models $(\mathrm{p} \geq 0.05)$.

In the final reduced stepwise regression model four student characteristics remained: female gender (adjusted $\beta: 0.42 ; 95 \%$ CI:0.20 to 0.63, $\mathrm{p}<0.001$ ), newer type of pharmacy education (adjusted $\beta: 0.81 ; 95 \% \mathrm{CI}: 0.63$ to $0.98, \mathrm{p}<0.001$ ), students who thought their skills needed improvement (adjusted $\beta: 0.50 ; 95 \%$ CI:0.30 to $0.71, \mathrm{p}<0.001$ ), and students who thought their communication skills were a result of their personality (adjusted $\beta:-0.24$; 95\% CI:-0.44 to $-0.04, \mathrm{p}=0.017)$.

In the stratified analyses for the individual countries of Norway, Sweden and Denmark, the results showed similar effects on size and overlapping CIs as for the main analyses. However, for the Norwegian students there was a trend that students with parents having a non-Nordic language (crude $\beta:-0.77 ; 95 \% \mathrm{CI}:-1.18$ to $-0.37, \mathrm{p}<0.001$ ) scored lower on attitudes towards communication skills training. In contrast to Denmark, where students with parents having a non-Nordic language instead scored higher on attitudes towards communication skills training (crude $\beta: 0.32 ; 95 \%$ CI: 0.00 to $0.65, \mathrm{p}=0.05$ ). 


\section{Discussion}

You won't find a solution by saying there is no problem.

William Rotsler

This thesis is the first to deal with the communicative role of pharmacists by studying three factors which impact on the role: the community pharmacists, the regulatory framework, and the pharmacy undergraduate education in the Nordic setting. Improving communication and evolving practice change involves a complex interplay among many additional factors on interpersonal, organizational, and external levels. For example there is a need to organize the practice in new, realistic ways by optimizing available time to increase patient care in pharmacies. ${ }^{4,144,145,155,245}$ This discussion focuses on the pharmacists, the regulatory framework, and the pharmacy undergraduate education. It first considers the main findings from the individual papers. Thereafter, a general discussion of all five papers together follows.

\section{Discussion of Main Findings of Individual Papers}

\section{Paper I: The community pharmacists}

In Paper I the pharmacists partly wanted another 'work reality,' with a more patientcentered care philosophy and a stronger focus on patients' medicine use instead of selling additional products and mainly distributing medicines. Nevertheless, they seem to hand over the process of change to other agents such as authorities and pharmacy chains. For over 30 years researchers have explored pharmacists' attitudes to new services and changes of current practice. ${ }^{146,153}$ The identified barriers and facilitators are in line with other studies, ${ }^{32,122,136,137,141,142,146}$ implying that most factors identified in this thesis are common to community pharmacists in many countries. In addition, the pharmacists' desired and appreciated tasks where their knowledge is more utilized, is confirmed in other studies. ${ }^{142,151,155,156}$

Also from other Nordic countries, tendencies to similar attitudes or trends of slow uptake and varying communication practice have been seen. In Sweden, a study demonstrated that pharmacists as a profession is not visible in the printed media and that 
the profession was dissatisfied with the "lack of visibility. ${ }^{246}$ A Finish study found it challenging to change the counseling culture in pharmacies ${ }^{162}$ and also slow implementation rate of a national implementation campaign to increase professionalism in pharmacies. ${ }^{247}$ In Denmark, studies have identified difficulties with implementation of newer services. ${ }^{21,209}$

Paper I brings an agent framework when looking at the barriers and facilitators, raising questions on pharmacists' perceived responsibilities and possibilities in practice changes. Using the perspective of agency was made in order to try to connect the pharmacists' vision of change with their disengagement for the process of change. How do pharmacists position themselves in practice changes? The findings in Paper I imply pharmacists took on a less active position. One explanation could be the 'pharmacy culture,' which has been identified in other studies. Here a technical distributing focus is seen as reasons for slow practice change. $^{22,158-160,163}$

A conclusion from Paper I is that community pharmacists should reflect upon what their main tasks should be and how practice can be evolved in a pharmacy. Should it be patient care, extended services, supply of medicines, selling additional products or something else, and who should set the agenda? The individual should reflect upon how the pharmacist can be more 'utilized' in pharmacies and make the professions' knowledge more visible for the public. On the other hand, maybe the pharmacists instead should practice patient-centered care in non-dispensing roles closer to the patient at the general practitioners or in nursing homes? For example, general practitioners in Canada report on being satisfied with receiving reliable medicine information from pharmacists, gaining fresh perspectives, and they felt more secure in prescribing. ${ }^{248}$

\section{Paper II: The regulatory framework}

Paper II describes how the regulatory framework is enabling and supporting the communicative role of the Nordic community pharmacists. International and Nordic communication studies show that pharmacists omit counseling during dispensing. ${ }^{18,115,126,127,129-131}$ Consequently, the legislation, the economic incentives, and the control system need to be discussed.

An American study identified that several states (9 of 12) have rather detailed laws on the type of information to be asked, e.g., drug-drug interaction, directions for use, and adverse effects. ${ }^{249}$ Several states (11 of 12 ) required pharmacists to keep patient profiles 
with information on allergy or chronic conditions. ${ }^{249}$ The study further highlighted the need for a control system on following up consultation statutes and regulations. Another American study revealed that stricter legislations were associated with increased counseling rates. ${ }^{65}$ Some Canadian pharmacists have a legal mandate and get economic support also for services during the 'traditional dispensing,' such as ordering laboratory tests, changing drug dosages, and making therapeutic substitutions. ${ }^{250}$ Also in the United Kingdom and Australia, pharmacists' legal practice and economic incentives support newer counseling services in pharmacies. ${ }^{172,250,251}$ Compared to other countries, the Nordic legislations (except for Iceland's 'pharmaceutical care') and economic incentives (except for inhalations service in Denmark and Norway) appear to be more limited and focus on the traditional dispensing role, which probably has restricted the development of the pharmacists' communicative role in patient care in Nordic community pharmacies. From the March 1, 2016, all Norwegian asthmatic or COPD patients can get a state-financed inhalation service; therein, they are provided with an extended guidance on how to use inhalation medicines properly.

There is a need to understand more about what kind of regulatory framework and policies would increase the pharmacists' communication practice and hence improve patient outcomes. It should also be acknowledged that having a law or a health-care reform about advanced pharmaceutical practice does not mean it can be implemented into practice if the pharmacists are not ready for it. ${ }^{158,165}$

\section{Papers III-V: Pharmacy undergraduate education}

Paper III identified room for improvement in patient communication skills training in several of the Nordic pharmacy schools. Yet, some of the Nordic students (especially Finland) have better prerequisites for communicating with patients; e.g., they have communication training earlier in the curriculum, more teacher hours dedicated to communication, and training in a specific communication course. In general, the results from Paper III seem to correlate with those identified by previous studies in other countries, e.g., less focus on experiential training methods and struggles with assessments. ${ }^{81,176-179}$

Findings from Paper III are consistent with results from the student survey (Paper IV); the majority of students perceived they have not received sufficient communication training. This paper also showed that there appears to be an association between more varied and more comprehensive communication training and students' positive attitudes. 
Paper V demonstrated that Nordic pharmacy students in general had moderately positive attitudes towards learning communication skills. Attitudes vary, for example, females and students from a newer type of pharmacy training program had more positive attitudes compared to males and students from an older pharmacy education. Among others, gender and type of training/curricula were associated with positive attitudes also in studies from medical and dental students' education. ${ }^{202,229,231-241}$

Papers III-V add new knowledge about to what extent Nordic pharmacy schools have cultivated the communicative role of the pharmacists, and the three studies indicate that there are possibilities to impact students' attitudes and perceptions by structuring the training programs differently. Nevertheless, there is a need to learn more about which factors and components have most impact on pharmacy students' future communication performance.

\section{The Professional Expectation Gap of Pharmacists' Communicative Role (Papers I-V)}

There are different expectations towards the Nordic pharmacists' communicative role from various stakeholders. On the one hand, the professional vison (Paper I) ${ }^{23,24,29,36-41}$ and, on the other hand, patients (Paper I), ${ }^{16,126,252-255}$ the society (Paper II), and the pharmacy education students (Paper III-V) ${ }^{180,256}$ appear to be rather satisfied with the current dispensing role and do not claim more counseling and patient-centered care in pharmacies. There appears to be a professional expectation gap between three issues:

- what the profession wants and should do with regard to communication in patient care

- what community pharmacists are doing in current community pharmacy practice

- what expectations are coming from others regarding the pharmacists' communicative role.

The results from the research made in the thesis show that three main issues seem central regarding the pharmacists' role: Why have community pharmacists not committed themselves more to showing the society how they can solve patients' medicine problems? Why are there not higher expectations of pharmacists from the society? Why have not the pharmacy schools focused more on the communicative role? This will be elaborated on in the next sections. 


\section{Understanding the expectation gap: theories of a profession}

As a way to understand the widespread disagreement on difference of opinion about the communicative role and the social contract between pharmacists and the society, the classic trait- (or criteria)-based framework for ranking a profession can be used. ${ }^{257-261}$ Five criteria for being a profession are applied here to understand the communicative role: ${ }^{246}$

- Authority (has a special knowledge which others cannot question); ${ }^{257}$

- Knowledge and science (has a long university education, and the profession's practice builds on scientific knowledge); ${ }^{260}$

- Sanction by the community (has autonomy and a monopoly; a contract hindering others to conduct their work); ${ }^{257}$

- Ethics and confidentiality (has profession-specific ethical rules for the conduct towards others); ${ }^{257}$

- Professional culture (the profession acts as an united group, takes responsibility, and drives the development of the profession forward; ${ }^{257}$ the members of the community share the same values and language ${ }^{261}$ ).

When looking at the pharmacy profession's communicative role within the five criteria, the following observations can be made: first, the profession only partly has an 'authority,' since other professions have knowledge about medicine use and communicate this and practice patient-care to patients. A Swedish report from 2017 concluded that the role of pharmacies and pharmacists in patients' medicine use and in the health-care system must be more clearly defined. ${ }^{262}$ Several researchers have identified that the public and pharmacists often do not share the same expectations or that patients do not identify pharmacists as health-care professionals. ${ }^{161,252,253,255,263,264}$ Patients have a positive view of the profession in pharmacies, but they have a slightly inconsistent view regarding the communicative patient-care role. ${ }^{252}$ In a Danish, study patients struggled with characterizing the pharmacy staff's health-care role and had difficulties to verbalize how the pharmacy staff's advice had helped them. ${ }^{253}$ Most stated they were reassured and received help with substitution and reimbursement issues. Studies have shown that between $9-38 \%$ of patients tend to decline a counseling offer. ${ }^{16,126}$ Two key behaviors during dispensing of medicines have been identified: 1) patients focusing on the physical drug product and wanting little involvement from the pharmacists and 2) patients who seek personal support from the pharmacists. ${ }^{254,255}$ Reasons reported for not asking questions are 
fear of embarrassment, physicians being the central information source, ${ }^{253}$ lack of incentives, lack of privacy, lack of time, and pharmacists were unapproachable. ${ }^{16}$

In addition, medical information is available for the public on the Internet and the public might not see the use for pharmacists in pharmacies. Therefore, this 'special knowledge' might need to be communicated and used better in practice: the pharmacists' in-depth knowledge about medicine use, which they can individualize as opposed to (one-way) information on the Internet, should be visible. But then they need to be good at communication to find out patients' needs in order to expand beyond only information giving and take a continuous care responsibility. Today this appears not to be the case in medical encounters. ${ }^{16,18,115,126,129,253,254}$

This is tightly coupled with the second criteria 'Knowledge and science,' in the sense that the profession has not been equipped with enough communication (Papers III-IV) and maybe also clinical skills. Many of the Nordic students wanted more communication training (Paper IV), implying they see this as important for their future role (Paper IV). Leutsch argues that in addition to positive attitudes towards a role development, pharmacists need to feel control over new situations, such as by education to receive the necessary skills. ${ }^{155}$ At the same time, one can discuss whether the pharmaceutical education changes practice or if changes must come from within practice itself. ${ }^{165}$ As found in Papers III-V, the Nordic pharmacy undergraduate educations probably need to be more nuanced and take the communicative patient-care role much more into account.

Further, the Nordic pharmacy professions have a strong 'Sanction by the community' with regard to dispensing, but not a monopoly with reference to counseling about medicine use or evaluating appropriate medicine use (Paper II). For example a Swedish study with stakeholders' views on community pharmacy/pharmacists found that many politicians, patient organizations, and also some professionals believed the pharmacies' role mainly should be distribution of medicines (logistics). ${ }^{265}$ Nevertheless, from the society's perspective, as expressed in the legislation, there is an expectation and a demand in all Nordic legislations about communication in pharmacies during dispensing and in extended services in some of the countries (Denmark and Norway) (Paper II). However, even though the society signals that they want communication in Nordic pharmacies, there is a lack of economic incentives and control of the legislation (Paper II). In addition, also other health care-professions have legal responsibilities (Paper II) and control of medicine use. Further, the Nordic pharmacists do not have clear relationships and legal responsibilities towards 
patients' health outcomes, compared to, e.g., Canadian pharmacists. ${ }^{250}$ Pharmacies and pharmacists have a strong business focus, i.e., selling a product and not a service, in contrast to other health-care professionals. In addition, the physical environment in a pharmacy signalizes a commercial setting and not a health-care setting, possibly to the extent of causing confusion with respect to the role.

The fourth criterion is better fulfilled, as the profession has specific ethical rules for their conduct as regarding their communicative role and especially their caring/health profession/patient-care role. The pharmacists should work for a more responsible use of medicines. ${ }^{34}$ Still it can be questioned how those are or can be followed in practice, as not all patients receive counseling. ${ }^{18,115,126,127,129-131}$ Resnik et al. point out the conflict between the pharmacists' ethical responsibility towards patients and the business/commercial emphasis in community pharmacies as an explanation of lack of counseling in pharmacies. ${ }^{266}$ The duality with business and professional altruism was also indirectly embodied in Paper I.

One could question the last criterion, 'Professional culture,' for pharmacists' communicative role. As implied in Papers III-V, the pharmacy educations have not fully given the profession the skills or socialization into a caring communicative role. In addition, a duality was highlighted in Paper I and in other studies; the pharmacists have the positive attitudes and state they want another work reality but identified a need for other actors to act for a practice change to happen. ${ }^{142,151,155,156}$ Similar attitudes about practice changes were found in Sweden, where the pharmacists saw a need for the politicians to set the agenda. On the other hand, the politicians thought the pharmacy profession should drive the development. ${ }^{168}$ An example of a weak voice is from Sweden, where there is no professional organization. ${ }^{246}$ Instead, there are only unions for pharmacists, which might have the consequences for the professional identity and possibilities to unite in developing the communicative role. ${ }^{246}$ Also Swedish students report meeting another reality in pharmacies compared to what they were told during their studies; in reality focus is on fast dispensing and selling additional medicines and not on counseling and improving appropriate medicine use. ${ }^{256}$

For example it is interesting to notice that also in countries with more 'developed' legislation, economic incentives, a longer tradition of educating pharmacists in communication skills, and implementation of more services can be slow. Like in Canada, some pharmacists acknowledge the lack of uniformity around the new patient care and 
communicative role. ${ }^{161}$ The literature presents contrasting impacts from the role of beliefs or personality traits on role development. As already mentioned previously, reasons for not embracing the possibilities might be, as acknowledged in Paper I and in other studies, that pharmacists have an attachment to the supply role. Perhaps there is a need to rethink dispensing to make it less technical? Here theories on organizational changes might be useful. Evidence from the literature on organizational change theories support that the professional role and organizational culture gaps of pharmacies are important components in understanding practice change. ${ }^{137,267}$ This implies that the role of beliefs or a professional culture is important to address for changing pharmacists' behaviors.

\section{Closing the gap: awareness and actions}

As highlighted in the discussion above, in regard to the trait- (or criteria)-based framework, none of the criteria are sufficiently fulfilled. This implies the communicative role is not yet deeply rooted in professional practice, the regulatory framework (society), education or that the change is still on-going. There are possibilities to cultivate and strengthen the role according to the different criteria for the three studied factors.

\section{The pharmacists}

Linked to the discussion above and findings in Paper I, in order to facilitate a culture where pharmacists as individuals and as a profession make practice changes, raise people's awareness of pharmacists as health-care professionals, and make the vision of more patient care and communication come true, probably takes time, as identified in a Finnish project. $^{247}$

As concluded in Paper I, pharmacists could reflect upon real and imaginary barriers and facilitators in practice, which then should be addressed. Often one main barrier put forward by community pharmacists is: time. Two observation studies in pharmacies questioned the 'we don't have time' perception. ${ }^{22,245}$ Gregorio et al. claim there is time for patient care in pharmacies; rather today, the time is not optimally utilized. ${ }^{245}$

Pharmacists' attitudes towards their role in patient care can be improved by training (strengthen criteria: Authority, Knowledge and science, and Professional culture). ${ }^{268}$ Eighty percent of the students saw communication as something non-trainable, but was a part of one's personality (Paper IV). Everyone has experience with communication and that must be acknowledged. However, such skills can be improved by adequate training. ${ }^{80}$ The fact that some Nordic pharmacists have received little formal training in 
communication (Paper III) might have resulted in the lack of tools and, hence, that counseling takes up little space in practice. Here the new standardized services might serve as a way for pharmacists to take control over such situations. ${ }^{155}$ Pharmacy associations can play a key role, as was the case in Denmark and in Norway, with inhalation services. ${ }^{269}$

It must be acknowledged that few intervention studies report having educated pharmacists in communication skills when a new service is implemented; instead, the training provided is instructive. ${ }^{270}$ This might have limited the effects of pharmacists' work in those interventions.

So pharmacists need knowledge and skills (Papers III-V) in addition to having the pertinent beliefs to transform practice (Paper I). ${ }^{155}$ Better trained pharmacists in both communication and theoretical pharmacotherapy skills tend to perform more and better services. ${ }^{150,271,272}$ A study where pharmacists in one group were remunerated for doing clinical interventions, without being educated, showed no increase in interventions, compared to the group receiving education and remuneration. The authors claim that if pharmacists' lack confidence, ability, or knowledge they will not change their practice. ${ }^{272}$ This conclusion is relevant to acknowledge in changing practice towards more counseling in pharmacies.

\section{The regulatory framework}

As revealed in Paper II, there is a general and not detailed communication focus in the Nordic pharmacists-patient communication laws, which leaves it open to many levels of interpretations. Therefore, clearer policies, demands, and research of outcomes associated with communication on medicine use might increase the certainty about the role and aim of communication and cognitive activities for pharmacists (strengthen criteria: Authority, Sanction by the community, and Professional culture).

As shown in Paper II, pharmacists in the Nordic countries are not primarily reimbursed for communicating with patients (except for Asthmatic and COPD patients in Denmark and Norway) and delivering healthcare, this can work as a potential barrier since pharmacy managers might not prioritize this as part of their business plans. Philipsen argues that improving economic incentives is a better way to increase pharmaceutical care in pharmacies, rather than stricter legislation. ${ }^{171}$ The lack of direct payment for professional counseling activities might result in no incentives for communication on medicine use, as pharmacies are only rewarded for selling prescriptions. Here, the authorities might have a possibility to impact communication and patient-care behaviors in pharmacies, and 64 
reimbursement appears to increase pharmacists' motivation to engage in extended services. ${ }^{111}$ For example since 2017 in England, there is a new additional reimbursement model 'Quality payment,' focusing on various domains: patient safety, clinical effectiveness (overuse of asthma treatments), public health, and where the pharmacy must fulfill different requirements to qualify for reimbursement. ${ }^{273}$

In Paper II it was found that authority control, journal keeping and the privacy of communication could be developed further. Using the control system more is a way to make conspicuous the importance of communication with patients without using stricter laws regarding communication on medicines. Demanding pharmacists to keep patient journals would probably increase the legal responsibility, documentation of, and continuity of patient care; if not documented, it is difficult to care for patients. ${ }^{4}$ In addition, the possibilities for privacy in pharmacies should be protected better; only Iceland out of the Nordic countries has a regulation about a private consultation room in pharmacies. The standard encounter's physical environment could be made more private as desired by the patients. ${ }^{274}$ Both this and the previous suggestions would be ways for the public to signify the pharmacists' active communicative role in health care as well as in medication management and improvement.

\section{Socializing and educating for patient interaction}

Good communication training is needed in the context of responsibility for patient outcomes (improving criteria Knowledge and science, Ethics and confidentiality, and Professional culture). Pharmacists regularly fall short regarding process skills and building relationships, ${ }^{19,118-123}$ and patients value more humanistic aspects of pharmacists' communication styles and therefore an understanding of concordance and patient empowerment is nesseccary. ${ }^{55,275}$ Therefore, not only technical and content skills are of importance.

Findings from papers III-V imply that if the education does not commit more to educating communicators and putting communication in the context of responsibility for health-care outcomes, then someone else might take over the pharmacists' domain (Internet pharmacies, nurses, doctors) or the society might get increased medical costs since no one focuses on patients' medicine-related needs. There are trends towards an increased focus on the communicative professional role at the Uppsala University, Sweden; they will as from the autumn 2017 start to strengthen the communicative role by having a course covering professional development running over the first three years of study. ${ }^{276}$ 
Only two schools had communication training with other professions (Paper III). Increasing such training might improve the expectations of pharmacists' communicative role from other professions and strengthen interprofessional collaboration.

It is possible to train students already from the beginning of pharmacy school education to think in clinical terms and in patient-centered care communication. ${ }^{277}$ Schools could use stand-alone communication courses highlighting the importance of the topic and simultaneously integrating it in other courses. One way can be by using clearer learning outcomes, scaffolding techniques, simulated patients, role models from clinical practice in the teaching, early training start, more patient contact outside the pharmacy setting, use of evidence-based frameworks and guidelines, inclusion of more experiential training, electronic communication, and evidence-based assessment of skills. ${ }^{55,80,175,176,183,184,278}$ Further attention should be paid to the factors impacting attitudes towards learning communication skills in designing the communication curricula to better individualize the education (Papers III-V).

\section{Aligning forces: the pharmacist, policies and the education}

To summarize, enhancing provision and quality of professional pharmacist-patient communication in community pharmacies is very complex and a multi-stakeholder challenge and responsibility. Pharmacists are highly trained with a vast pharmaceutical and pharmacotherapy knowledge, which could be better utilized. Pharmacists could take a larger responsibility and be made more accountable in maintaining and improving public health and people's medicine use. Thereby, pharmacists would contribute to improved health outcomes for the patients and rationalization of the medicine budget. 


\section{Methodological Discussion}

Science is facts; just as houses are made of stones, so is science made of facts; but a pile of stones is not a house and a collection of facts is not necessarily science.

Henri Poincare

A main strength of this thesis is that it used several perspectives, methods, and techniques for approaching the study aims. By including all Nordic countries it was made possible to compare and learn from different systems. General limitations for the studies are that, due to the cross-sectional nature of the study designs, no causality can be proven; instead, associations between factors are established and therefore also other interpretations are possible. Secondly, comparisons between countries are challenging and difficult. It can lead to simplifications, as well as context-biased interpretations.

Below, a selection of various criteria ${ }^{218,279-284}$ to evaluate quality in quantitative and qualitative research is elaborated on for the individual Papers I-V. As regards reflexivity, ${ }^{279,280,282}$ the personal background probably impacted the choice of research areas compared to other potential areas. For example several stakeholders' perspectives were not included, such as the patients, policymakers, physicians, pharmacy owners, and pharmacy managers. The researcher was 'objective' in reporting results, but interpretations and implications are probably colored by the personal background and opinions about the 'ideal' communicative role of the pharmacists. This was counterbalanced by having a social scientist on the research team. On the positive side, it can be helpful to explore something the researcher has an in-depth knowledge about.

\section{Paper I: Focus Groups}

The quality of information collected from focus groups depends on the skills of the moderator. The moderator had participated in courses on qualitative methods on focus groups and was guided in the process by more experienced researchers. The transferability and relevance of the results to other settings ${ }^{280}$ are best judged in terms of logical interpretation, the credibility of the analysis, and the context for transferability of the findings. Qualitative findings are not meant to represent pharmacists' beliefs in general, but rather to provide increased understanding and to describe unfamiliar concepts; hence it 
cannot be generalized to a larger group. ${ }^{215}$ The study was conducted in the Oslo area; maybe pharmacists working in smaller cities have other perceptions of their possibilities and patient relationships. For example, it can be argued that they might have a closer relationship with their patients.

Data saturation, that all sides of the phenomena have been studied, ${ }^{218,283}$ was judged after four focus groups, according to the criteria for diversity and the study aim. Saturation was achieved by purposive sampling and early transcribing of data parallel to collecting data.

Vividness production of a rich data account, but at the same time concentrating on its essence, ${ }^{283}$ was obtained by a thick description of the data collection and analysis and using the agent and agency framework. However, by using the agent and agency framework, this may have impacted on the results as to an enhanced focus on the agent perspective. To reach a good level of credibility and authenticity, accurate and 'true' interpretations of the data, ${ }^{218,279,280}$ a search for negative cases, ${ }^{218}$ and utilization of two or more analysts were used. Still, also other interpretations might be possible depending on the analysts' professional backgrounds.

\section{Paper II: Document Analysis}

Regulations were used as a surrogate for societal understanding of the pharmacists' role, which adds a new perspective in this area. An inventory of the regulations provides a view on the frames for the actual counselling services. First, the credibility and authenticity $^{218,279,280}$ depended on if the instruments had identified the right questions and areas and if the right interpretations have been made. It was increased by using a similar study as a template ${ }^{222}$ and it was searched for by respondent validation, contacting the authorities in case of ambiguity, and two or more analysts were used. Data saturation ${ }^{218,283}$ was judged by this. It is difficult to know if the documents mirror society's expectations or if it is the regulatory authorities' expectations that have been measured. Other options could have been to explore the rationales and motives behind the different legislations or performed more in-depth interviews with regulatory authorities. Interviews of key informants from each of the Nordic countries could have enriched the description of the existence of other patient counselling services in community pharmacies., 


\section{Paper III: Questionnaire}

The internal validity, ${ }^{215,281}$ if the study has correctly measured what it intended to do, was sought by using previous established questionnaires and by using two perspectives to study the status of the education (Papers III, IV). Though, this relies on the right measurements being used in the original two questionnaires. The questionnaires were piloted and evaluated for relevance. Still the reliability, the stability of the findings, ${ }^{215,281}$ should be further explored. Data from questionnaires are based on peoples' recollections, introducing difficulties with recalls. In the study on teachers, this should not have been a vast problem; instead, social desirability answers might be problematic, which can impact the internal validity.

The external validity, to what extent the results can be generalized, ${ }^{215,281}$ was assured by inviting all possible responders and the high response rate of almost $100 \%$ in the teacher survey. However, the education is constantly developing.

\section{Papers IV and V: Questionnaire}

The internal validity ${ }^{215,281}$ was obtained by using two outlooks to study the status of the education (Papers III, IV) and reviewing previous studies. The questionnaire was also piloted. For Paper V, the internal validity ${ }^{215,281}$ and reliability ${ }^{215,281}$ were sought by using a previously established scale with a satisfactory internal consistency (Cronbach's alpha), test-re-test reliability, by Principal Component Analyses for construct validity, and which had been tested for validity by an earlier qualitative study. ${ }^{201,285,286}$ However, the reliability of the identified scale in this study, from the Principal Component Analysis, for this specific population should be explored further.

A threat against internal validity can be that respondents might conceptualize communication skills and such training as being different from the intended, since several of them actually have received little formal training. In addition, studies have shown that students can fill out questionnaires such as student evaluations without reading or taking them seriously, which threaten the internal validity and reliability. ${ }^{287}$ Nevertheless, the topic appeared to have engaged the students, judged from the amount of written comments to open-ended questions.

The external validity ${ }^{215,281}$ was assured by inviting all students fulfilling the inclusive criteria and the high response rate $58 \%$ to $85 \%$, but study participants might be the ones most interested in communication skills. A comparison of non-responders was not made. 
In the student survey, difficulties with recalls could have arisen. However, around $65 \%$ of the students filled out the questionnaire in close connection with their final and only communication skills training.

Students might perceive a pressure implying possible consequences of not participating when filling out questionnaires handed out by teachers. In the study this was minimized by not including members of the research team in data collection in their own courses.

The questionnaires were in English. It cannot be guaranteed equal proficiency among students, because there are up to five different countries, cultures, and education systems involved. On the other hand, the average level of English is high in the Nordic countries ${ }^{288}$ and many courses use English literature.

In the Nordic setting, Finnish pharmacy schools have invested resources in and conducted extensive research on counselling in pharmacies and patient communication teaching. ${ }^{55,83,289,290}$ Therefore, inclusion of the Finnish students would have added valuable insights to the analyses. The Finnish students were excluded because of very few respondents. 


\section{Conclusions and Implications}

Knowing is not enough; we must apply. Willing is not enough; we must do. Johann Wolfgang von Goethe

This thesis has studied to what extent the community pharmacists, the regulatory framework, and the pharmacy undergraduate educations have responded to the increasing communicative role of Nordic community pharmacists. A professional expectation gap between ideal communication and practice was identified, which deserves further exploration.

An overall conclusion is that the researched areas need improvement and alignment in order for pharmacist-patient communication to reach full potential in practice. For example, Paper I explored pharmacists' agency in carrying out their patient care role The pharmacists appeared to be constrained by their working conditions and did not feel they had the power to change the situation and considered employers, regulators and patients as having the power. Regarding the whole education program for pharmacists, there are reasons to strengthening the socialization processes into the responsible patient-care role as health-care professionals- as to hopefully make pharmacists take on a larger responsibility (agency) in patient care. As the regulations are broadly defined, there is room for pharmacists to shape their role within the framework- per se agency could be carried out. However, as the pharmacists imply difficulties with taking on agency, there might be reasons to improve the support system for example more directed economic incentives or detailed regulations.

A gap was found between the community pharmacists' vision of patient care and what most pharmacists pointed out that they conduct in their daily work e.g. mainly logistics. In Paper I the pharmacists' appeared to have positive beliefs and embraced the communicative patient-centered role in theory. However, they did not seem to be proactive in practice change. This might be a result of a traditional product-focused pharmacy culture and work description implying that pharmacists have not taken full responsibility in their role development, which might explain some lack of agency in adoption of patientcentered care. Questions about pharmacists' readiness for advanced professional services emerge, as regards necessary knowledge, skills, training, and regulatory support. 
Implications to strengthen practice could be that individual pharmacists take greater responsibility and work in order to obtain abilities to strengthen the communication and clinical skills. Community pharmacists are challenged to reflect upon what their main tasks should be and how pharmacy practice can be evolved.

The Nordic regulatory frameworks have partly responded to the increased communicative role; the legislations are not 'hindering' the communicative role but, on the other hand, the role is not directly supported with economic incentives or effective control. Hence, the authorities seem to take some minimum level of communication for granted and appear to believe no other external or internal forces hinder or encourage pharmacy staff when communicating with patients. The society could expect more from community pharmacists' communicative role and give them more specified agency in providing patient care. There are many levels of challenges attached to policy implications, such as a threat against the professional autonomy if implementing stricter regulations and the balance of adding more administration assignments. However, the Nordic regulators could consider strengthening the regulatory incentives for pharmacists to develop their communicative role in patient care by clarifying pharmacists' responsibilities and role in patient care and outcomes and utilize them better as a continuous care resource. Another potential way is to develop a reimbursement model of professional communication in pharmacies with a focus on cognitive communication and services linked to quality outcomes. Linked to this is a development of quality and value-based outcome measures of professional communication in pharmacies. For this reason, a system of journal keeping when delivering patient care/communicating on medicine use would be favorable. Also by improving the physical environment in pharmacies (privacy) the society could signal to the public the health-care status of pharmacies and pharmacists. This might help in supporting the patient-centered care role of pharmacists. Further strengthening the control system of professional communication in pharmacies could potentially improve the communication focus as what is controlled is often also emphasized in practice by e.g. employers.

In general, Nordic pharmacy schools ought to consider strengthening the patient communication skills training. If pharmacy schools aim to educate professional communicators, they must invest more resources in communication training and acknowledge its linkage to quality patient care. Pharmacists who graduate from a larger and more varied program can probably be expected to be better equipped and ready for communicating with patients as found in this thesis. 
By educating students already from the beginning to think in clinical terms and in patient-centered care communication, greater awareness of their patient-centered role can be achieved. Other potential strategies are to use stand-alone communication courses highlighting the importance of the topic and simultaneously integrating it in other courses. Other ways can be by using clearer learning outcomes, explaining the impact of patient communication on patient outcomes, scaffolding techniques, simulated patients, role models from clinical practice in the teaching, interprofessional training, more patient contact outside the pharmacy setting, use of evidence-based frameworks and guidelines (such as 'the United States Pharmacopeia (1997) Medication Counseling Behavior Guideline'), inclusion of more experiential training, and evidence-based assessment of skills (e.g. OSCE). Another training area of attention, is communication through electronic media such as e-mail communication, through mobile applications, call-centers, as these are increasing when it comes to communication with patients and especially vulnerable patient groups.

\section{Future Research}

There are many aspects of the communicative role that need to be further explored. For example, there is a need to understand the professional socialization process of the communicative role both in the pharmacy education and in practice, thereafter designing an intervention to promote an improved socialization process. The professional expectation gap between ideal communication and practice could be further explored by using organizational theories. It would be interesting to compare pharmacists' perceptions and awareness of a counseling encounter as to what skills they are using with patients' and or simulated patients' opinions of the outcomes. More knowledge is also needed to link a particular communication behavior with specific patient outcomes. Based on this, an intervention could be tailored to improve counseling behavior linked to new mobile techniques of patients' perceived needs.

Further, it is important to monitor what kind of regulations and polices most improve a pharmacist's communication practice and patient outcomes, as well as explore pharmacists' 'social contract' with the society. In addition, interviews with national key informants could enrich the description of the development and importance of patient communication in community pharmacies and serve as a learning lesion for other countries. Further policy 
initiatives/strategies supporting systematic practice and service development could be reviewed.

In order to improve the link between communication education at the university and the communication in practice, several areas need to be researched. There is a need to find ways to measure single educational interventions impact on practice and patient outcomes by a randomized clinical trial, and learning how to organize and implement communication training to gain the best results. In addition, research needs to compare different learning activities as to outcomes and/or effectiveness in relation to resources needed and develop assessment methods for students' communication skills. 


\section{Acknowledgements}

Thank the flame for its light, but do not forget the lamp holder standing in the shade with constancy of patience.

Rabindranath Tagore

My thesis work was carried out at the PharmacoEpidemiology and Drug Safety (PharmaSafe) Research Group, Department of Pharmacy, School of Pharmacy, University of Oslo, Norway during the period 2012-2017. I want to thank everyone who in various ways has contributed in making this thesis come true and formed me as a researcher.

I wish to express my sincere gratitude to:

Everyone, who participated in or contributed to the data collection, thank you all for your invaluable time.

Ingunn Björnsdóttir and Sofia Kälvemark Sporrong, my supervisors, thank you for being such fantastically strong women as well as researchers. Thank you for your invaluable help. You have always been there when I needed advice or someone to talk to (just a Skype, an email or a door away). I have felt that you both believed in me, my decisions, and my capacity as a researcher, and you have always encouraged my enthusiasm and allowed me to follow my curiosity. I appreciate the constructive criticism and for contributing your vast knowledge with me.

Ingunn, it has been such a joy to work with you. Thank you for your thoughtful reflections about my thesis topics, your network, and your wonderful sense of humor: you really make me laugh every time. You have also shared your passion for research with me and the knowledge about the Icelandic pharmacy market. Thanks for your hospitality.

Sofia, you were the first person who introduced me to social pharmacy and qualitative research. I entered your office in 2010 at the Uppsala University with a project idea for my 
Master's thesis and you said go for it! Just as you supported and guided me back then, you have always been by my side during this journey. So thank you for your never-ending enthusiasm for (my) research, time (you always have time for everyone), and enormous hospitality. I am so thankful for the quick, honest, and constructive criticism I have received during the years, which have made me a better researcher. I am especially grateful for the friendship we have developed over the years.

The Faculty of Mathematics and Natural Sciences within the University of Oslo for giving me the opportunity to carry out my $\mathrm{PhD}$. Thanks to the Foundation for the Promotion of Pharmacy (Norway), the Norwegian Pharmaceutical Society, and the Norwegian PhD School of Pharmacy for granting me support to carry out my work.

Else-Lydia Toverud and Helle Håkonsen, co-authors of Paper I. Many thanks for invaluable help at the beginning of my $\mathrm{PhD}$ period at the School of Pharmacy, Oslo.

Andy Wallman, co-author of Papers III and IV. I appreciate all the help I received from you, especially the 'brainstorming' and critical input on my thesis discussion.

Angela Lupattelli, co-author of Paper IV. Angela, we have been sharing an office from the very beginning and shared every small and big things happening in our lives. You have over and over again explained statistic concepts to me with consistent patience. It has been such a pleasure to work with you academically, and you are wonderful friend.

Erika Olsson, co-author of Paper IV. Thank you for all our discussions. It has been a pleasure getting to know you and working with you. I hope our cooperation will continue in the future.

Ragnhild Eek Brandlistuen, co-author of Paper V. I am very grateful for the statistical assistance from you and for being such a good friend and previous colleague. You are always positive and make me smile.

Former and present colleagues of research groups in Social Pharmacy (PharmaSafe and PharmaUse): Walaa Abuelmagd, Ingunn Björnsdóttir, Ragnhild Eek Brandlistuen, 
Åse Ertesvåg, Anna-Simone Josefine Frank, Anne Gerd Granås, Gerd Marie Eskerud Harris, Helle Håkonsen, Angela Lupattelli, Katerina Nezvalova-Henriksen, Hedvig Nordeng, Janne Smedberg, Lene Maria Sundbakk, Else-Lydia Toverud, Bich Thuy Ha Truong, Johanne Naper Trønnes, and Mollie Woods for contributing to a very pleasant work environment. I have enjoyed going to work every day.

Hedvig Nordeng, PharmaSafe's research group leader, for sharing your unimaginable energy and enthusiasm for research. I appreciate your thoughts about building an academic career with me and pushing me to participate in career-building activities inside and outside the university.

Anne Gerd Granås, for drinking a cup of coffee and giving me advice when needed. Thank you for being an inspiring educator. Last, but not least, for challenging the way I think about things.

Afonso Cavaco, thanks for arousing my interest for communication in pharmacies.

Göran Carlsson and Christoffer Holmberg, co-supervisors of my Master's thesis. Thank you for encouraging me to write my first publication, which made me want to take a $\mathrm{PhD}$. I am grateful for you both letting me learn from your different disciplines (medicine and health economics), thereby showing me the benefits of working in an interdisciplinary way.

My Scandinavian social and clinical pharmacy PhD colleagues, Arton Baftiu, HegeTherese Bell, Rasmus Borup, Pia Frisk, Kristine Heitmann, Sofie Rosenlund Lau, Marianne Lea, Erika Olsson, Rikke Mie Rishøj and Kristin Wisell (many of you are no longer PhD students, instead PhDs!). I am thankful for meeting you, as well as working with and discussing research.

\section{My Danish 'social pharmacy colleagues' at the section for Social and Clinical} Pharmacy, University of Copenhagen. Thanks for welcoming me to your department and for interesting discussions around social theories, pharmacists' professional role, and pharmaceutical policy. A special thanks to Susanne Kaae, for critical input on my thesis. 
Owen Hargie and Ruth Parry for kind permissions to let me use your questionnaires about communication education in medical and physiotherapy education, respectively, in Paper III. Charlotte Rees, for letting me use the Communication Skills Attitude Scale in Paper V.

Margot Lundquist, in memory of, proofreader of Paper I, Maxine Ingalls for proofreading Paper II, Jeffery Cosser for proofreading Papers IV-V, and Lynn Stevenson for proofreading Paper III and the thesis. Aitor Yraola for assisting in data entry of the questionnaires in SPSS.

Liv Auberg Czynski and Gunnbjørg Mordt, for introducing me to the pharmacy profession and the Norwegian pharmacy world. Cassandra Andreades, Gunhild Strickert Furuhaug, Reidun Os Husteli and Maria Larsen, thanks for trying out various surveys during the years and for our friendship, good food, and travels we have gone on together. Clas Sporrong, for your unbelievable hospitality, like all the great meals (read Béarnaise sauce).

All my friends for bringing joy into my life!

My parents, for always encouraging me to follow my will, stimulating my curiosity, and making me believe everything is possible with hard work. Thanks, mamma, for giving me your persistence! Thanks to the rest of my close and 'extended' family for your love and care.

Roberth and Theodor, thank you for always reminding me about what matters in life: you guys! I love you both so much. Roberth thanks for being you: always kind, understanding, and supportive. Thanks for being my best friend and the love of my life.

Thank you all!

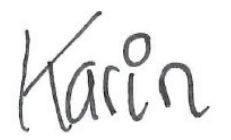




\section{References}

1. Tinning R. Reading action research: Notes on knowledge and human interests. Quest. 1992;44:1-14.

2. Pharmaceutical Services Negotiating Committee (PSNC). MURs: the basics-What is the Medicines Use Review \& Prescription Intervention Service? http://psnc.org.uk/services-commissioning/advanced-services/murs/murs-thebasics/; 2017. Accessed 28, April 2017.

3. Coulter A. The Autonomous Patient: Ending Paternalism in Medical Care. London: Stationery Office (for the Nuffield Trust); 2002.

4. Cipolle RJ, Strand L, Morley P. Pharmaceutical Care Practice: The Patientcentered Approach to Medication Management Services. 3rd ed. USA: The McGraw-Hill Companies; 2012.

5. Moullin JC, Sabater-Hernández D, Fernandez-Llimos F, Benrimoj SI. Defining professional pharmacy services in community pharmacy. Res Social Adm Pharm. 2013;9:989-995.

6. Svensberg K, Sporrong SK, Håkonsen H, Toverud EL. 'Because of the circumstances, we cannot develop our role': Norwegian community pharmacists' perceived responsibility in role development. Int J Pharm Pract. 2014;23:256-265.

7. International Pharmaceutical Federation (FIP) and FIP Education Initiative (FIPEd). Quality Assurance of Pharmacy Education: the FIP Global Framework. The Hague, the Netherlands; 2014.

8. Rønning M et al. The Norwegian Prescription Database 2007-2011. Topic: Drug Use in the Elderly. The Norwegian Institute of Public Health; 2012.

9. Aronson JK. Medication errors: definitions and classification. Br J Clin Pharmacol. 2009;67:599-604.

10. Norwegian Ministry of Health and Care Services. St.meld. nr. 18 (2004-2005). Rett Kurs mot Riktigere Legemiddelbruk: Legemiddelpolitikken [The Right Course towards more Appropriate Use of Medicines: Pharmaceutical policy]. 2005. Norwegian. 
11. Sabaté E. Adherence to Long term Therapies: Evidence for Action. Geneva: World Health Organization; 2003.

12. Gallagher $\mathrm{P}$, et al. Prevalence of potentially inappropriate prescribing in an acutely ill population of older patients admitted to six European hospitals. Eur J Clin Pharmacol. 2011;67:1175.

13. Skoog J, Midlov P, Beckman A, Sundquist J, Halling A. Indication for pharmacological treatment is often lacking: a cross-sectional study on the quality of drug therapy among the elderly. BMC Geriatr. 2015;15:117.

14. Montgomery A, Sporrong SK, Manap N, Tully M, Lindblad ÅK. Receiving a pharmaceutical care service compared to receiving standard pharmacy service in Sweden-How do patients differ with regard to perceptions of medicine use and the pharmacy encounter? Res Social Adm Pharm. 2010;6:185-195.

15. Puspitasari HP, Aslani P, Krass I. Pharmacists' and consumers' viewpoints on counselling on prescription medicines in Australian community pharmacies. Int $J$ Pharm Pract. 2010;18:202-208.

16. Krueger JL, Hermansen-Kobulnicky CJ. Patient perspective of medication information desired and barriers to asking pharmacists questions. J Am Pharm Assoc . 2011;51:510-519.

17. Beardsley R, Kimberling C, Tindall W. Communication Skills in Pharmacy Practice. 5th ed. Baltimore, MD USA: Lippincott Williams \& Wilkins; 2008.

18. Puspitasari HP, Aslani P, Krass I. A review of counseling practices on prescription medicines in community pharmacies. Res Social Adm Pharm. 2009;5:197-210.

19. van Dijk M, et al. Patient-provider communication about medication use at the community pharmacy counter. Int J Pharm Pract. 2016;24:13-21.

20. Boeni F, Arnet I, Hersberger KE. Adherence counseling during patient contacts in swiss community pharmacies. Patient Prefer Adherence. 2015;9:597-605.

21. Hughes $\mathrm{C}$, et al. Provision of pharmaceutical care by community pharmacists: a comparison across Europe. Pharm World Sci. 2010;32:472-487.

22. Davies JE, Barber N, Taylor D. What do community pharmacists do?: results from a work sampling study in London. Int J Pharm Pract. 2014;22:309-318.

23. Mossialos E et al. From "retailers" to health care providers: Transforming the role of community pharmacists in chronic disease management. Health policy. 2015;119:628-639. 
24. Traulsen AM, Almarsdottir AB. Pharmaceutical policy and the pharmacy profession. Pharm World Sci. 2005;27:359-363.

25. Dower C, Moore J, Langelier M. It is time to restructure health professions scopeof-practice regulations to remove barriers to care. Health Aff. 2013;32:1971-1976.

26. Björklund L. Statens Offentliga Utredningar (SOU 1999:66) God Vård på Lika Villkor? -Om Statens Styrning av Hälso- och Sjukvården [Government Official Reports (SOU 1999:66) Good Care on Equal Terms? - the State's Governing of Health Care]. Swedish.

27. Cruess RL, Cruess SR. Expectations and obligations: professionalism and medicine's social contract with society. Perspect Biol Med. 2008;51:579-598.

28. The World Health Organization (WHO). The Role of the Pharmacist in the Health Care System, Preparing the Future Pharmacist: Curricular Development. Report of a third WHO Consultative Group on the Role of the Pharmacist. Vancouver, Canada; 1997.

29. International Pharmaceutical Federation (FIP) and the World Health Organization (WHO). Good Pharmacy Practice. Joint FIP/WHO Guidelines on GPP: Standard for Quality of Pharmacy Services. The Hauge, the Netherlands: International Pharmaceutical Federation (FIP); 2012.

30. Traulsen JM, Bissel P. Theories of professions and the pharmacist. Int J Pharm Pract. 2004;12:107-114.

31. International Pharmaceutical Federation (FIP): FIP Education Initiative (FIPEd). FIPEd Global Education Report. The Hauge, the Netherlands, International pharmaceutical federation (FIP); 2013.

32. Al-Nagar A. An Exploration of Consultation Skills in Community Pharmacists. [Doctoral Thesis] School of Chemical Sciences and Pharmacy, University of East Anglia, United Kingdom; 2014.

33. Cruess SR, Johnston S, Cruess RL. "Profession": a working definition for medical educators. Teach Learn Med. 2004;16:74-76.

34. International Pharmaceutical Federation (FIP). FIP Statement of Professional Standards: Codes of Ethics for Pharmacists.

https://www.fip.org/www/uploads/database_file.php?id=351\&table_id=; 2014. Acessed 28, April 2017. 
35. Blenkinsopp A, Bond C, Raynor D. Medication reviews. Br J Clin Pharmacol. 2012;74:573-580.

36. International Pharmaceutical Federation (FIP), Community Pharmacy Section. Vision 2020. http://www.fip.org/CPSvision/\#/6; 2016. Acessed 28, April 2017.

37. Fruängen A, et al. God Apotekssed $i$ Sverige (GPP) [Good Pharmacy Practice in Sweden]. Uppsala, Sweden: Medical Product Agency Sweden; 2011. Swedish.

38. The Norwegian Pharmacy Association, the Norwegian Association of Pharmacists and the Association of Pharmacy Technicians. Standards for Pharmacy Practice (GPP). 2003; http://www.apotek.no/Default.aspx?ID=8209; 2016. Accessed 28, April 2017.

39. The Association of Danish Pharmacies. Apoteket Tattere på Dig. Strategi for Apotekerne i Danmark [The Pharmacy Closer to you. Strategy for the Pharmacies in Denmark.] http://www.apotekerforeningen.dk/omapotekerne/ /media/Apotekerforeningen/publikationer/Strategibrochure\%202016.a shx; 2016. Accessed 28, April 2017. Danish.

40. The Association of Finnish Pharmacies. Annual Review 2015. http://www.apteekkariliitto.fi/media/3apteekkariliitto.fi/liitto/vuosikatsaukset/vuosikatsaus_2015_en.pdf; 2015. Accessed 28, April 2017.

41. Norwegian Ministry of Health and Care Services. Meld. St. 28 (2014-2015) Riktig Bruk-Bedre Helse [Appropriate Use- Better Health]. 2015. Norwegian.

42. United States' National Library of Medicine; MeSH Descriptor Data 2017. MeSH search word: Communication. 1999;

https://www.nlm.nih.gov/cgi/mesh/2017/MB_cgi?term=Communication. Accessed 28, April, 2017.

43. Ahmed R. Interpersonal Health Communication. Oxford, UK: Wiley-Blackwell; 2012.

44. Higgs J, Croker A, Tasker D. Health Practice Relationships. Rotterdam, the Netherlands: SensePublishers; 2014.

45. Berger CR, Roloff ME, Ewoldsen DR. The Handbook of Communication Science. Thousand Oaks: Sage Publications, Inc; 2009. 
46. Grimes L, Barnett N. Consultation skills for Pharmacy Practice: Taking a PatientCentred Approach. Manchester, United Kingdom: the Centre for Pharmacy Postgraduate Education; 2014.

47. Wright KB, O'Hair D, Sparks L. Health Communication in the 21st Century. 2nd ed. Chichester, United Kingdom: Wiley-Blackwell; 2013.

48. Bylund CL, Peterson EB, Cameron KA. A practitioner's guide to interpersonal communication theory: An overview and exploration of selected theories. Patient Educ Couns. 2012;87:261-267.

49. Shannon CE, Weaver W. The Mathematical Theory of Communication. Urbana, IL USA: University of Illinois Press; 1949.

50. Feldman-Stewart D, Brundage MD, Tishelman C. A conceptual framework for patient-professional communication: an application to the cancer context. Psychooncology. 2005;14:801-809.

51. Street RL. How does communication heal? Pathways linking clinician-patient communication to health outcomes. Patient Educ Couns. 2009;74:295-301.

52. Pilnick A. "Patient counselling" by pharmacists: four approaches to the delivery of counselling sequences and their interactional reception. Soc Sci Med. 2003;56:835849.

53. Tully M, Beckman Gyllenstrand A, Bernsten C. Factors predicting poor counselling about prescription medicines in Swedish community pharmacies. Patient Educ Couns. 2011;83:3-6.

54. Shah B, Chewning B. Conceptualizing and measuring pharmacist-patient communication: a review of published studies. Res Social Adm Pharm. 2006;2:153185.

55. International Pharmaceutical Federation (FIP)-Pharmacy Information Section The International Pharmaceutical Students' Federation (IPSF). Counseling, Concordance, Communication- Innovative Education for Pharmacists. Hauge, the Netherlands: International Pharmaceutical Federation; 2012.

56. van Mil JW, Henman M. Terminology, the importance of defining. Int $J$ Clin Pharm. 2016;38:709-713.

57. Mesquita AR, et al. Developing communication skills in pharmacy: a systematic review of the use of simulated patient methods. Patient Educ Couns. 2010;78:143148. 58. 
58. Chant S, Jenkinson T, Randle J, Russell G. Communication skills: some problems in nursing education and practice. J Clin Nurs. 2002;11:12-21.

59. Pilnick A. 'Patient counseling by pharamcists':Advice, Information, or Instruction? Sociol Q. 1999;40:613-622.

60. Frøyland H. Legemiddelsamtalen-og Klinisk Kommunikasjon ['Medicne Use Review'-and Clinical Communication]. Bergen: Fagbokforlaget Vigmostad \& Bjørke AS; 2011. Norwegian.

61. Tully MP, Hassell K, Noyce PR. Advice-giving in community pharmacies in the UK. J Health Serv Res Policy. 1997;2:38-50. 62.

62. Consultation and Communication Skills Task and Finish Group. Consulting skills for Pharmacy Practic: Practice Standards for England. The Centre for Pharmacy Postgraduate Education; 2014.

63. Schommer JC, Wiederholt JB. Pharmacists perceptions of patients needs for counseling. Am J Hosp Pharm. 1994;51:478-485.

64. Rickles N, Wertheimer A, Smith M. Social and Behavioral Aspects of Pharmaceutical care. 2nd ed. Sudbury, MA: Jones and Barlett Publishers; 2010.

65. Svarstad BL, Bultman DC, Mount JK. Patient counseling provided in community pharmacies: effects of state regulation, pharmacist age, and busyness. J Am Pharm Assoc. 2004;44:22-29.

66. Raisch DW. Patient counseling in community pharmacy and its relationship with prescription payment methods and practice settings. Ann Pharmacother. 1993;27:1173-1179.

67. Kansanaho $\mathrm{H}$, Isonen-Sjolund N, Pietila K, Airaksinen M, Isonen T. Patient counselling profile in a Finnish pharmacy. Patient Educ Couns. 2002;47:77-82.

68. Blom L. Developing Patient Education in Community Pharmacy. [Doctoral Thesis] Faculty of pharmacy, Utrecht University, the Netherlands;1996.

69. Planas LG. Interpersonal Communication for Pharmacetuical Care. In: Rickles N, Wertheimer A, Smith M, eds. Social and Behavioral Aspects of Pharmaceutical care. 2nd ed. Sudbury, MA: Jones and Barlett Publishers; 2010:195-222.

70. Granås AG, Bakken K. Samfunnsfarmasi-Legemiddelbruk og Farmasøytisk Profesjonsutøvelse [Social Pharmacy-Medicine Use and Professionalism]. Bergen, Norway: Fagbokforlaget Vigmostad \& Bjørke AS; 2010. Norwegian. 
71. Barnett N, Varia S, Jubraj B. Adherence: are you asking the right questions and taking the best approach? Pharmaceutical Journal. 2013: 153-156.

72. Guirguis LM, Chewning BA. Role theory: literature review and implications for patient-pharmacist interactions. Res Social Adm Pharm. 2005;1:483-507.

73. Murad MS, Spiers JA, Guirguis LM. Expressing and negotiating face in community pharmacist-patient interactions. Res Social Adm Pharm. 2016; DOI: 10.1016/j.sapharm.2016.10.003.

74. Chevalier BAM, Watson BM, Barras MA, Cottrell WN. Examining hospital pharmacists' goals for medication counseling within the communication accommodation theoretical framework. Res Social Adm Pharm. 2016;12:747-755.

75. Grice GR, et al. Health literacy: use of the Four Habits Model to improve student pharmacists' communication. Patient Educ Couns. 2013;90:23-28.

76. Bachmann C, et al. A European consensus on learning objectives for a core communication curriculum in health care professions. Patient Educ Couns. 2013;93:18-26.

77. Palaian S, Prabhu M, Shankar PR. Patient counseling by pharmacist- a focus on chronic illness. Pak J Pharm Sci. 2006;19:65-72.

78. Ryan R, et al. Interventions to improve safe and effective medicines use by consumers: an overview of systematic reviews. Cochrane Database Syst Rev. 2014;4:CD007768.

79. Merriam-webster Online dictionary. Search word: Skill. 2017; http://www.merriamwebster.com/dictionary/skill; 2017. Accessed 28, April 2017.

80. Kurtz S, Draper J, Silverman J. Teaching and Learning Communication Skills in Medicine. 2nd ed. London: Radcliffe Publishing; 2005.

81. Beardsley RS. Communication skills development in colleges of pharmacy. Am J Pharm Educ. 2001;65:307.

82. Hargie ODW, Morrow NC, Woodman C. Pharmacists' evaluation of key communication skills in practice. Patient Educ Couns. 2000;39:61-70.

83. Hyvärinen M-L, Tanskanen P, Katajavuori N, Isotalus P. A Method for Teaching Communication in Pharmacy in Authentic Work Situations. Commun Educ. 2010;59:124-145.

84. Merriam-webster Online dictionary. Search word: Perception. 2017; http://www.learnersdictionary.com/definition/perception. 
85. Okumura LM, Rotta I, Correr CJ. Assessment of pharmacist-led patient counseling in randomized controlled trials: a systematic review. Int $J$ Clin Pharm. 2014;36:882-891.

86. Roughead EE, Semple SJ, Vitry AI. Pharmaceutical care services: a systematic review of published studies, 1990 to 2003, examining effectiveness in improving patient outcomes. Int J Pharm Pract. 2005;13:53-70.

87. Hatah E, Braund R, Tordoff J, Duffull SB. A systematic review and meta-analysis of pharmacist-led fee-for-services medication review. $\mathrm{Br} J$ Clin Pharmacol. 2014;77:102-115.

88. Mossialos E, Naci H, Courtin E. Expanding the role of community pharmacists: Policymaking in the absence of policy-relevant evidence? Health policy. 2013;111:135-148.

89. Salter C, Holland R, Harvey I, Henwood K. "I haven't even phoned my doctor yet." The advice giving role of the pharmacist during consultations for medication review with patients aged 80 or more: qualitative discourse analysis. $B M J$. 2007;334:1101.

90. Jokanovic N, et al. Pharmacist-led medication review in community settings: An overview of systematic reviews. Res Social Adm Pharm. 2016; DOI: 10.1016/j.sapharm.2016.08.005.

91. The Conference Board of Canada and Canadian Pharmacists Association. A Review of Pharmacy Services in Canada and the Health and Economic Evidence. https://www.pharmacists.ca/cpha-ca/assets/File/cpha-on-theissues/Pharmacy\%20Services\%20Report\%201.pdf;;2016. Accessed 28, April 2017.

92. Westerlund T, Almarsdottir AB, Melander A. Factors influencing the detection rate of drug-related problems in community pharmacy. Pharm World Sci. 1999;21:245250 .

93. Ax F, Branstad JO, Westerlund T. Pharmacy counselling models: a means to improve drug use. J Clin Pharm Ther. 2010;35:439-451.

94. Kuyper AR. Patient counseling detects prescription errors. Hosp Pharm. 1993;28:1180-1181, 1184-1189.

95. Desmaele S, De Wulf I, Dupont AG, Steurbaut S. Pharmacists' role in handling problems with prescriptions for antithrombotic medication in Belgian community pharmacies. Int J Clin Pharm. 2015;37:656-668. 
96. Clifford S, Barber N, Elliott R, Hartley E, Horne R. Patient-centred advice is effective in improving adherence to medicines. Pharm World Sci. 2006;28:165-170.

97. De Young M. Research on the effects of pharmacist-patient communication in institutions and ambulatory care sites, 1969-1994. Am J Health Syst Pharm. 1996;53:1277-1291.

98. Salvo MC, Cannon-Breland ML. Motivational interviewing for medication adherence. J Am Pharm Assoc. 2015;55:e354-361, 362-353.

99. Pringle JL, Boyer A, Conklin MH, McCullough JW, Aldridge A. The Pennsylvania Project: pharmacist intervention improved medication adherence and reduced health care costs. Health Aff. 2014;33:1444-1452.

100. Kooy MJ, Van Geffen EC, Heerdink ER, Van Dijk L, Bouvy ML. Patients' general satisfaction with telephone counseling by pharmacists and effects on satisfaction with information and beliefs about medicines: Results from a cluster randomized trial. Patient Educ Couns. 2015;98:797-804.

101. Bernsten $\mathrm{C}$, et al. Improving the well-being of elderly patients via community pharmacy-based provision of pharmaceutical care: a multicentre study in seven European countries. Drugs Aging. 2001;18:63-77.

102. Murad MS, Chatterley T, Guirguis LM. A meta-narrative review of recorded patient-pharmacist interactions: Exploring biomedical or patient-centered communication? Res Social Adm Pharm. 2014;10:1-20.

103. Nkansah N, Mostovetsky O, Yu C, et al. Effect of outpatient pharmacists' nondispensing roles on patient outcomes and prescribing patterns Cochrane Database Syst Rev 2011;CD000336( 7).

104. Ekedahl A. 'Open-ended questions' and 'show-and-tell'--a way to improve pharmacist counselling and patients' handling of their medicines. J Clin Pharm Ther. 1996;21:95-99.

105. Basheti IA, Armour CL, Bosnic-Anticevich SZ, Reddel HK. Evaluation of a novel educational strategy, including inhaler-based reminder labels, to improve asthma inhaler technique. Patient Educ Couns. 2008;72:26-33.

106. Sarkadi A, Rosenqvist U. Experience-based group education in Type 2 diabetes: a randomised controlled trial. Patient Educ Couns. 2004;53:291-298.

107. Northey A, McGuren T, Stupans I. Patients' antibiotic knowledge: a trial assessing the impact of verbal education. Int J Pharm Pract. 2015;23:158-160. 
108. Brook O, van Hout H, Nieuwenhuyse H, Heerdink E. Impact of coaching by community pharmacists on drug attitude of depressive primary care patients and acceptability to patients; a randomized controlled trial. Eur Neuropsychopharmacol. 2003;13:1-9.

109. Charrois TL, et al. A systematic review of the evidence for pharmacist care of patients with dyslipidemia. Pharmacother. 2012;32:222-233.

110. Blom L, Krass I. Introduction: The role of pharmacy in patient education and counseling. Patient Educ Couns. 2011;83:285-287.

111. Blalock SJ, Roberts AW, Lauffenburger JC, Thompson T, O'Connor SK. The effect of community pharmacy-based interventions on patient health outcomes: a systematic review. Med Care Res Rev. 2013;70:235-266.

112. Babinec PM, Rock MJ, Lorenzetti DL, Johnson JA. Do researchers use pharmacists' communication as an outcome measure? A scoping review of pharmacist involvement in diabetes care. Int J Pharm Pract. 2010;18:183-193.

113. The Midwest Pharmacy Workforce Research Consortium. 2014 National Pharmacists Workforce Survey.;

http://www.aacp.org/resources/research/pharmacyworkforcecenter/Documents/Fina 1ReportOfTheNationalPharmacistWorkforceStudy2014.pdf; 2015. Accessed 28, April 2017.

114. Bulajeva A, Labberton L, Leikola S, et al. Medication review practices in European countries. Res Social Adm Pharm. 2014;10:731-740.

115. Olsson E, Ingman P, Ahmed B, Sporrong SK. Pharmacist-patient communication in Swedish community pharmacies. Res Social Adm Pharm. 2014;10:149-155.

116. Olsson E, Wallach-Kildemoes H, Ahmed B, Ingman P, Kaae S, Sporrong SK. The influence of generic substitution on the content of patient-pharmacist communication in Swedish community pharmacies. Int J Pharm Pract. 2016; DOI: 10.1111/ijpp.12299.

117. Nusair MB, Guirguis LM. How pharmacists check the appropriateness of drug therapy? Observations in community pharmacy. Res Social Adm Pharm. 2017; 13:349-357.

118. Kaae S, Traulsen J, Nørgaard L. Challenges to counseling customers at the pharmacy counter-Why do they exist? Res Social Adm Pharm. 2012;8:253-257. 
119. Sleath B. Pharmacist-patient relationships: authoritarian, participatory, or default? Patient Educ Couns. 1996;28:253-263.

120. Greenhill N, Anderson C, Avery A, Pilnick A. Analysis of pharmacist-patient communication using the Calgary-Cambridge guide. Patient Educ Couns. 2011;83:423-431.

121. Cavaco AM, Romano J. Exploring pharmacists' communication with customers through screening services. Patient education and counseling. 2010;80(3):377-383.

122. Latif A, Pollock K, Boardman H. The contribution of the Medicines Use Review (MUR) consultation to counseling practice in community pharmacies. Patient Educ Couns. 2011;83:336-344.

123. Chong WW, Aslani P, Chen TF. Pharmacist-patient communication on use of antidepressants: a simulated patient study in community pharmacy. Res Social Adm Pharm. 2014;10:419-437.

124. Skoglund P, Isacson D, Kjellgren KI. Analgesic medication--communication at pharmacies. Patient Educ Couns. 2003;51:155-161.

125. Montgomery A, Lindblad AK, Eddby P, Söderlund E, Tully M, Sporrong SK. Counselling behaviour and content in a pharmaceutical care service in Swedish community pharmacies. Pharm World Sci. 2010;32:455-463.

126. Kaae S, Mygind A, Saleem S. A characterization of the current communication patterns in Danish community pharmacies - An observational study. Res Social Adm Pharm. 2013;9:958-964.

127. Lyszkiewicz DA, Gerichhausen S, Björnsdottir I, Einarson TR, Koren G, Einarson A. Evidence based information on drug use during pregnancy: a survey of community pharmacists in three countries. Pharm World Sci. 2001;23:76-81.

128. Puumalainen II, Peura SH, Kansanaho HM, Benrimoj CSI, Airaksinen MS. Progress in patient counselling practices in Finnish community pharmacies. Int $J$ Pharm Pract. 2005;13:149-156.

129. Vainio KK, Airaksinen MS, Hyykky TT, Enlund KH. Effect of therapeutic class on counseling in community pharmacies. Ann Pharmacother. 2002;36:781-786.

130. Håkonsen H, Toverud EL. Cultural influences on medicine use among firstgeneration Pakistani immigrants in Norway. Eur J Clin Pharmacol. 2012;68:171178. 
131. Mamen AV, Håkonsen H, Kjome RL, Gustavsen-Krabbesund B, Toverud EL. Norwegian elderly patients' need for drug information and attitudes towards medication use reviews in community pharmacies. Int $J$ Pharm Pract. 2015;23:423-428.

132. Granas AG, Haugli A, Horn AM. Smoking cessation advice provided in 53 Norwegian pharmacies. Int J Pharm Pract. 2004;12:179-184.

133. Kimberlin CL, Jamison AN, Linden S, Winterstein AG. Patient counseling practices in U.S. pharmacies: effects of having pharmacists hand the medication to the patient and state regulations on pharmacist counseling. $J$ Am Pharm Assoc. 2011;51:527-534.

134. Mobach MP. Counter design influences the privacy of patients in health care. Soc Sci Med. 2009;68:1000-1005.

135. Kaae S, Saleem S, Kristiansen M. How do Danish community pharmacies vary in engaging customers in medicine dialogues at the counter- an observational study. Pharm Pract. 2014;12:422.

136. Gastelurrutia M, et al. Facilitators for practice change in Spanish community pharmacy. Pharm World Sci. 2009;31:32-39.

137. Roberts AS, et al. Understanding practice change in community pharmacy: a qualitative study in Australia. Res Social Adm Pharm. 2005;1:546-564.

138. Rossing C, Hansen E, Traulsen J, Krass I. Actual and perceived provision of pharmaceutical care in Danish community pharmacies: the pharmacists' opinions. Pharm World Sci. 2005;27:175-181.

139. Hopp TR, Sørensen EW, Herborg H, Roberts AS. Implementation of cognitive pharmaceutical services (CPS) in professionally active pharmacies. Int J Pharm Pract. 2005:21-31.

140. Krska J, Veitch GBA. Perceived factors influencing the development of primary care-based pharmaceutical care in Scotland. Int J Pharm Pract. 2001;9:243-252.

141. Roberts AS, Benrimoj SI, Chen TF, Williams KA, Aslani P. Practice change in community pharmacy: quantification of facilitators. Ann Pharmacother. 2008;42:861-868.

142. Montgomery A, Sporrong SK, Henning M, Tully MP, Lindblad ÅK. Implementation of a pharmaceutical care service: prescriptionists', pharmacists' and doctors' views. Pharm World Sci. 2007;29:593-602. 
143. Wells KM, Thornley T, Boyd MJ, Boardman HF. Views and experiences of community pharmacists and superintendent pharmacists regarding the New Medicine Service in England prior to implementation. Res Social Adm Pharm. 2014; 10:58-71.

144. Houle SK, Charrois TL, Faruquee CF, Tsuyuki RT, Rosenthal MM. A randomized controlled study of practice facilitation to improve the provision of medication management services in Alberta community pharmacies. Res Social Adm Pharm. 2017;13:339-348.

145. Law A, Okamoto M, Brock K. Ready, willing, and able to provide MTM services?: A survey of community pharmacists in the USA. Res Social Adm Pharm. 2009;5:376-381.

146. Roberts AS, Benrimoj SI, Chen TF, Williams KA, Aslani P. Implementing cognitive services in community pharmacy: a review of facilitators used in practice change. Int J Pharm Pract. 2006;14:163-170.

147. Chui MA, Mott DA, Maxwell L. A qualitative assessment of a community pharmacy cognitive pharmaceutical services program, using a work system approach. Res Social Adm Pharm. 2012;8:206-216.

148. Schommer J, Wiederholt J. The Association of Prescription Status, Patient Age, Patient Gender, and Patient Question Asking Behavior with the Content of Pharmacist-Patient Communication. Pharm Res. 1997;14:145-151.

149. Doucette WR, Nevins JC, Gaither C, et al. Organizational factors influencing pharmacy practice change. Res Social Adm Pharm. 2012;8:274-284.

150. Puspitasari HP, Aslani P, Krass I. The influence of pharmacy and pharmacist characteristics on the secondary prevention of cardiovascular disease. Int $J$ Clin Pharm. 2015;37:834-843.

151. Latif A, Boardman H. Community pharmacists' attitudes towards medicines use reviews and factors affecting the numbers performed. Pharm World Sci. 2008;30:536-543.

152. Berbatis CG, Sunderland VB, Joyce A, Bulsara M, Mills C. Enhanced pharmacy services, barriers and facilitators in Australia's community pharmacies: Australia's National Pharmacy Database Project. Int J Pharm Pract. 2007;15:185-191.

153. Kaae S. Analyse af Lokale Organisatoriske Forholds Betydning for varig Implementering af den Første Offentligt Betalte Apoteksydelse 'Tjek på inhalation' 
- et Eksplorativt Case Studie af Syv Danske Apoteker [An Analysis of Organizational Factors Importance for Permanent Implementation of the first Public Paid Pharmacy Service 'Inhaler Technique Assessment Service' - an Exploratory Case Study among Seven Danish Pharmacies]. [Doctoral Thesis] Department of Pharmacy, School of Pharmacy, University of Copenhagen, Denmark; 2009. Danish.

154. Witry MJ, Doucette WR. Factors influencing community pharmacists' likelihood to ask medication monitoring questions: A factorial survey. Res Social Adm Pharm. 2015;11:639-650.

155. Luetsch K. Attitudes and attributes of pharmacists in relation to practice change - A scoping review and discussion. Res Social Adm Pharm. 2016; DOI: 10.1016/j.sapharm.2016.06.010.

156. Grindrod K, Marra C, Colley L, Tsuyuki R, Lynd L. Pharmacists' preferences for providing patient-centered services: a discrete choice experiment to guide health policy. Ann Pharmacother. 2010;44:1554-1564.

157. Bryant LJM, Coster G, Gamble GD, McCormick RN. General practitioners' and pharmacists' perceptions of the role of community pharmacists in delivering clinical services. Res Social Adm Pharm. 2009;5:347-362.

158. Mak VS, Clark A, Poulsen JH, Udengaard KU, Gilbert AL. Pharmacists' awareness of Australia's health care reforms and their beliefs and attitudes about their current and future roles. Int J Pharm Pract. 2012;20:33-40.

159. Al Hamarneh YN, Rosenthal M, McElnay JC, Tsuyuki RT. Pharmacists' perceptions of their practice: a comparison between Alberta and Northern Ireland. Int J Pharm Pract. 2012;20:57-64.

160. Rosenthal M, Breault R, Austin Z, Tsuyuki R. Pharmacists' self-perception of their professional role: insights into community pharmacy culture. J Am Pharm Assoc. 2011;51(3):363-367.

161. Schindel TJ, et al. Perceptions of pharmacists' roles in the era of expanding scopes of practice. Res Social Adm Pharm. 2017;13:148-161.

162. Kansanaho H, Pietilä K, Airaksinen M. Can a long-term continuing education course in patient counselling promote a change in the practice of Finnish community pharmacists? Int J Pharm Pract. 2003;11:153-160. 
163. Rosenthal M, Austin Z, Tsuyuki RT. Are pharmacists the ultimate barrier to pharmacy practice change? Can Pharm J. 2010;143:37-42.

164. Myers D. Social Psychology. 7th ed. New York, USA: McGraw-Hill Higher Education; 2002.

165. Almarsdóttir A, Morgall J, Grímsson A. Professional Responsibility for Patient Welfare. Is it possible to legislate Pharmaceutical Care? Res Social Adm Pharm. 2001;18:45-50.

166. Grand JL. Knights and Knaves Return: Public Service Motivation and the Delivery of Public Services. Int Public Manag J. 2010;13:56-71.

167. Davis JH, Schoorman FD, Donaldson L. Toward a Stewardship Theory of Management. Acad Manage Rev. 1997;22:20-47.

168. Wisell K, Sporrong SK. The Raison D'être for the Community Pharmacy and the Community Pharmacist in Sweden: A Qualitative Interview Study. Pharmacy. $2016 ; 4: 3$.

169. Anell A. Deregulating the pharmacy market: the case of Iceland and Norway. Health policy. 2005;75:9-17.

170. Gorecki P. Do you believe in magic? improving the quality of pharmacy services through restricting entry and aspirational contracts, the Irish experience. Eur J Health Econ. 2011;12:521-531.

171. Philipsen NJ. Regulation of Pharmacists: A Comparative Law and Economics Analysis. The European Journal of Comparative Economics. 2013;10:225-241.

172. Bernsten C, Andersson K, Gariepy Y, Simoens S. A comparative analysis of remuneration models for pharmaceutical professional services. Health policy. 2010;95:1-9.

173. Jacobs S, Schafheutle EI, Jee SD, Elvey R, Hassell K, Noyce PR. Existing arrangements for monitoring community pharmacies in England: can they have a role in the revalidation of pharmacists? Res Social Adm Pharm. 2013;9:166-177.

174. Hargie O. The Handbook of Communication Skills. 3rd ed. London, United Kingdom: Routledge; 2006.

175. Wallman A, Vaudan C, Sporrong SK. Communications training in pharmacy education, 1995-2010. Am J Pharm Educ. 2013;77:36. 
176. Schwartzman E, Chung EP, Sakharkar P, Law AV. Instruction and assessment of student communication skills in US and Canadian pharmacy curricula. Curr Pharm Teach Learn. 2013;5:508-517.

177. Hargie ODW, Morrow NC. A survey of interpersonal skills teaching in pharmacy schools in the United-Kingdom and Ireland. Am J Pharm Educ. 1986;50:172-175.

178. Billow JA. The status of undergraduate instruction in communication-skills in United-States colleges of pharmacy. Am J Pharm Educ. 1990;54:23-26.

179. Kimberlin CL. Communicating With Patients: Skills Assessment in US Colleges of Pharmacy. Am J Pharm Educ. 2006;70:8-67.

180. Nunes-da-Cunha I, Arguello B, Martinez FM, Fernandez-Llimos F. A Comparison of Patient-Centered Care in Pharmacy Curricula in the United States and Europe. Am J Pharm Educ. 2016;80:83.

181. Street Jr RL, De Haes HCJM. Designing a curriculum for communication skills training from a theory and evidence-based perspective. Patient Educ Couns. 2013;93:27-33.

182. Grant MS, Jenkins LS. Communication education for pre-licensure nursing students: Literature review 2002-2013. Nurse Educ Today. 2014;34:1375-1381.

183. Kiessling C, Tsimtsiou Z, Essers G, et al. General principles to consider when designing a clinical communication assessment program. Patient Educ Couns. 2017; DOI: 10.1016/j.pec.2017.03.027.

184. Smith S, et al. Teaching patient communication skills to medical students- A review of randomized controlled trials. Eval Health Prof. 2007;30:3-21.

185. Blom L, Wolters M, Ten Hoor-Suykerbuyk M, van Paassen J, van Oyen A. Pharmaceutical education in patient counseling: 20h spread over 6 years? Patient Educ Couns. 2011;83:465-471.

186. Katajavuori N, Lindblom-Ylanne S, Hirvonen J. The significance of practical training in linking theoretical studies with practice. High Educ. 2006;51:439-464.

187. Wouda JC, van de Wiel HBM. Education in patient-physician communication: How to improve effectiveness? Patient Educ Couns. 2013;90:46-53.

188. Taglieri CA, Crosby SJ, Ferullo JW. Implementation of a Communication Skills Laboratory. Curr Pharm Teach Learn. 2014;6:773-781. 
189. Aper L, Reniers J, Koole S, Valcke M, Derese A. Impact of three alternative consultation training formats on self-efficacy and consultation skills of medical students. Med Teach. 2012;34:E500-E507.

190. Berkhof M, van Rijssen HJ, Schellart AJM, Anema JR, van der Beek AJ. Effective training strategies for teaching communication skills to physicians: An overview of systematic reviews. Patient Educ Couns. 2011;84:152-162.

191. Parry R. Are interventions to enhance communication performance in allied health professionals effective, and how should they be delivered? Direct and indirect evidence. Patient Educ Couns. 2008;73:186-195.

192. Lane C, Rollnick S. The use of simulated patients and role-play in communication skills training: a review of the literature to August 2005. Patient Educ Couns. 2007;67:13-20.

193. Rickles NM, Tieu P, Myers L, Galal S, Chung V. The impact of a standardized patient program on student learning of communication skills. Am J Pharm Educ. 2009;73:4.

194. Boesen KP, Herrier RN, Apgar DA, Jackowski RM. Improvisational exercises to improve pharmacy students' professional communication skills. Am J Pharm Educ. 2009;73(2):35.

195. Reisetter B, Grussing PG. Students' perceived satisfaction with and utility of pharmacy communications course work. Am J Pharm Educ. 1997;61271-277

196. Willis SC, Hassell K, Seston EM, Hann M. Using learning outcomes for undergraduate pharmacy education to assess final-year students' perceptions of their preparedness for pharmacy practice. Int J Pharm Pract. 2009;17:351-358.

197. Dornan T, David T. Adult learning and continuing education. Diabet Med. 2000; 17:78-80.

198. Liddell MJ, Davidson SK. Student attitudes and their academic performance: is there any relationship? Med Teach. 2004;26:52-56.

199. Rees C, Sheard C, McPherson A. Medical students' views and experiences of methods of teaching and learning communication skills. Patient Educ Couns. 2004;54:119-121.

200. Bergh A-M, et al. Medical students' perceptions of their development of'soft skills': part II: the development of'soft skills' through'guiding and growing'. S Afr Fam Pract. 2006;48:p. 15, 15a-15d. 
201. Rees C, Sheard C, Davies S. The development of a scale to measure medical students' attitudes towards communication skills learning: the Communication Skills Attitude Scale (CSAS). Med Educ. 2002;36:141-147.

202. Rees C, Sheard C. The relationship between medical students' attitudes towards communication skills learning and their demographic and education-related characteristics. Med Educ. 2002;36:1017-1027.

203. Gilligan C, Outram S, Rasiah R, Cooper J. Exploring the attitudes of pharmacy students to clinical communications training. Focus Health Prof Educ. 2011;13:2536.

204. Wisell K, Winblad U, Sporrong SK. Reregulation of the Swedish pharmacy sectorA qualitative content analysis of the political rationale. Health policy. 2015;119:648-653.

205. Vogler S, Habimana K, Arts D. Does deregulation in community pharmacy impact accessibility of medicines, quality of pharmacy services and costs? Evidence from nine European countries. Health policy. 2014;117:311-327.

206. The Association of Danish Pharmacies. Analyse: Ny Apoteksregulering 1. juli 2015: Apoteker sikrer Sundhedsfaglighed og øger Tilgængelighed i Byerne - men Yderområder og Vagt Presses [Analysis: New Pharmacy Regulation July 1, 2015: Pharmacies still Part of the Health Care System and Increases the Accessibility in Cities, but Rural Areas and Guard Duty are Pressured]. http://www.apotekerforeningen.dk/ /media/Apotekerforeningen/analysertilgaengeli ghed/24062015_NyApotekerlov.ashx; 2015. Accessed 28, April 2017. Danish.

207. Lagercrantz S. Finland ska få "Lagom" mycket Konkurrens [Finland's Pharmacy Market will get "Fair" a lot of Competition] . 2017; http://svenskfarmaci.se/apotek/finland-ska-fa-lagom-mycket-konkurrens/. Accessed 27, April 2017. Swedish.

208. Apoteket AB. Hälsotjänster [Professional Pharmacy Services]. https://www.apoteket.se/halsotjanster/; 2017. Accessed 28, April 2017. Swedish.

209. Herborg H, Sørensen EW, Frøkjær B. Pharmaceutical care in community pharmacies: practice and research in Denmark. Ann Pharmacother. 2007;41:681689. 
210. The Association of Danish Pharmacies. Apotekets Sundhedsydelser [Health Services in Danish Pharmacies].http://www.apotekerforeningen.dk/apoteket-isundhedssektoren/sundhedsydelser.aspx; 2017. Accessed 28, April 2017. Danish.

211. Hansen E, Brown A. Technicians and other pharmacy support workforce cadres working with pharmacists: Denmark case study. Res Social Adm Pharm. 2017;13:286-287.

212. Barbour RS, Kitzinger J. Developing Focus Group Research: Politics, Theory and Practice. London, United Kingdom: Sage Publications, Inc; 1999.

213. David LM. Focus Groups as Qualitative Research. 2nd ed: Thousand Oaks, CA, USA: Sage Publications, Inc.; 1997.

214. Alsadi D. Apotekare, Behövs vi på Apotek? En Analys av Apotekarens Roll på Apotek med hjälp av en Intervjustudie [Pharmacists, are we needed in a Pharmacy? An Analysis of the Pharmacist's Role in the Pharmacy by an Interview study]. [Master Thesis] Department of Pharmacy, Uppsala University, Sweden; 2013. Swedish.

215. Robson C. Real World Research: A Resource for Social Scientists and PractitionerResearchers.Malden, MA, USA: Blackwell Publishers; 2002.

216. Pope C, Mays, N. Qualitative Research in Health Care. 3rd ed. Malden, MA, USA: Blackwell Publishing Ltd; 2006.

217. Patton MQ. Qualitative Research \& Evaluation Methods. 3rd ed. Thousand Oaks, CA, USA: Sage Publications, Inc; 2002.

218. Bazeley P. Qualitative Data Analysis: Practical Strategies. London, United Kingdom: Sage Publications, Inc; 2013.

219. O'Connor PE. Speaking of Crime: 'I don't Know what Made Me do it'. Discourse Soc. 1995;6:429-456.

220. Wibeck V. Genmat i Fokus : Analyser av Fokusgruppsamtal om Genförändrade Livsmedel [Focus on Genetically Modified Food - Analysis of Focus Groups' Discussions on Genetically Modified Food]. [Doctoral Thesis] Department of communication studies, Linköping University, Sweden; 2002. Swedish.

221. Sarantakos S. Social research. 3rd ed. Hampshire,United Kingdom: Palgrave Macmillan; 2005. 
222. Lichtman Spector S, Youdelman M. Analysis of State Pharmacy Laws: Impact of Pharmacy Laws on the Provision of Language Services. National Health Law Program. Available at:

http://www.healthlaw.org/component/jsfsubmit/showAttachment?tmpl=raw\%26id= 00Pd0000006ELhnEAG; 2010. Accessed 28, April 2017.

223. Hargie O, Boohan M, McCoy M, Murphy P. Current trends in Communication Skills Training in UK schools of medicine. Med Teach. 2010;32:385-391.

224. Parry RH, Brown K. Teaching and learning communication skills in physiotherapy: What is done and how should it be done? Physiotherapy. 2009;95:294-301.

225. Hargie O, Dickson D, Boohan M, Hughes K. A survey of communication skills training in UK schools of medicine: present practices and prospective proposals. Med Educ. 1998;32:25-34.

226. Dillman DA. Mail and Internet Surveys: the Tailored Design Method. 2nd ed. New York, USA: Wiley; 2006.

227. Granås AG, Nørgaard LS, Sporrong SK. Lost in translation?: Comparing three Scandinavian translations of the Beliefs about Medicines Questionnaire. Patient Educ Couns. 2014;96:216-221.

228. Johnson B, Christensen LB. Educational Research: Quantitative, Qualitative, and Mixed approaches. 5th ed. Los Angeles, CA, USA: Sage Publications, Inc; 2014.

229. Anvik T, et al. Medical students' cognitive and affective attitudes towards learning and using communication skills - a nationwide cross-sectional study. Med Teach. 2008;30:272-279.

230. Victora CG, Huttly SR, Fuchs SC, Olinto MT. The role of conceptual frameworks in epidemiological analysis: a hierarchical approach. Int J Epidemiol. 1997;26:224227.

231. Shankar RP, et al. Student attitudes towards communication skills training in a medical college in Western Nepal. Educ Health. 2006;19:71-84.

232. Laurence B, Bertera EM, Feimster T, Hollander R, Stroman C. Adaptation of the Communication Skills Attitude Scale (CSAS) to dental students. J Dent Educ. 2012;76:1629-1638.

233. Nor NA, Yusof ZY, Shahidan MN. University of Malaya dental students' attitudes towards communication skills learning: implications for dental education. J Dent Educ. 2011;75:1611-1619. 
234. Cleland J, Foster K, Moffat M. Undergraduate students' attitudes to communication skills learning differ depending on year of study and gender. Med Teach. 2005;27:246-251.

235. Bombeke K, et al. Medical students trained in communication skills show a decline in patient-centred attitudes: an observational study comparing two cohorts during clinical clerkships. Patient Educ Couns. 2011;84:310-318.

236. Power BT, Lennie SC. Pre-registration dietetic students' attitudes to learning communication skills. J Hum Nutr Diet. 2012;25:189-197.

237. Koponen J, Pyorala E, Isotalus P. Comparing three experiential learning methods and their effect on medical students' attitudes to learning communication skills. Med Teach. 2012;34:E198-E207.

238. Molinuevo B, Torrubia R. Validation of the Catalan version of the communication skills attitude scale (CSAS) in a cohort of south European medical and nursing students. Educ Health. 2011;24:499.

239. McKenzie CT. Dental student attitudes towards communication skills instruction and clinical application. J Dent Educ. 2014;78:1388-1396.

240. Marambe KN, Edussuriya DH, Dayaratne KM. Attitudes of Sri Lankan medical students toward learning communication skills. Educ Health. 2012;25:165-171.

241. Fazel I, Aghamolaei T. Attitudes toward learning communication skills among medical students of a university in Iran. Acta Med Iran. 2011;49:625-629.

242. Oslo University. Nettskjema.

http://www.uio.no/english/services/it/admservices/nettskjema/; Accessed 28, April 2017.

243. Kirkwood BR, Sterne JAC. Essential medical statistics. 2nd ed. .Malden, MA, USA: Blackwell; 2003.

244. Hosmer DW, Lemeshow S, Sturdivant RX. Applied Logistic Regression. 3rd ed. Hoboken, NJ, USA: Wiley; 2013.

245. Gregorio J, Cavaco AM, Lapao LV. How to best manage time interaction with patients? Community pharmacist workload and service provision analysis. Res Social Adm Pharm. 2017;13:133-147.

246. Carlsson JR, Renberg T, Sporrong SK. Drug experts of the future, today?Depiction of the pharmacist profession in Swedish professional and lay print media. Res Social Adm Pharm. 2012;8:133-144. 
247. Kansanaho H, Puumalainen I, Varunki M, Ahonen R, Airaksinen M. Implementation of a professional program in Finnish community pharmacies in 2000-2002. Patient Educ Couns. 2005;57:272-279.

248. Pottie K, Farrell B, Haydt S, et al. Integrating pharmacists into family practice teams: physicians' perspectives on collaborative care. Can Fam Physician. 2008;54:1714-1717.e1715.

249. Nichol MB, Michael LW. Critical analysis of the content and enforcement of mandatory consultation and patient profile laws. Ann Pharmacother. 1992;26:11491155.

250. Canadian Pharmacy Association. Pharmacists' Scope of Practice in Canada and Publicly Funded Pharmacy Services by Province. https://www.pharmacists.ca/pharmacy-in-canada/scope-of-practice-canada/; 2016.

251. McKnight AG, Thomason AR. Pharmacists' advancing roles in drug and disease management: a review of states' legislation. J Am Pharm Assoc. 2009;49:554-558.

252. Perepelkin J. Public Opinion of Pharmacists and Pharmacist Prescribing. Can Pharm J. 2011;144:86-93.

253. Kaae S, Traulsen JM, Norgaard LS. Customer interest in and experience with various types of pharmacy counselling - a qualitative study. Health Expect. 2014; 17: 852-862.

254. Renberg T, Törnqvist KW, Sporrong SK, Lindblad ÅK, Tully M. Pharmacy users' expectations of pharmacy encounters: a Q-methodological study. Health Expect. 2011;14:361-373.

255. Cavaco A, Dias JPS, Bates I. Consumers' perceptions of community pharmacy in Portugal: a qualitative exploratory study. Pharm World Sci. 2005;27:54-60.

256. Kullgren Å. Kvalitet och Säkerhet på Apoteksmarknaden-Delbetänkande av Nya Apoteksmarknadsutredningen (SOU 2017_15) [ Quality and Safety in the Swedish Pharmacy Market- Interim Report of the New Swedish Pharmacy Market Investigation (Swedish Government Official Reports (SOU) 2017_15)]. http://www.regeringen.se/contentassets/898886b519fa4630b9b576de75d5cbf9/kval itet-och-sakerhet-pa-apoteksmarknaden-sou-2017_15.pdf; 2017. Acessed 12 April 2017. Swedish.

257. Bisell P, Traulsen J. Sociology and Pharmacy Practice. London, United Kingdom: Pharmaceutical Press; 2005. 
258. Klegon D. The Sociology of Professions: An emerging perspective. Work Occup. $1978 ; 5: 259-283$.

259. Thorner I. Pharmacy: The Functional Significance of an Institutional Pattern. Soc Forces. 1942;20:321-328.

260. Birenbaum A. Reprofessionalization in pharmacy. Soc Sci Med. 1982;16:871-878.

261. Goode WJ. Community Within a Community: The Professions. Am Sociol Rev. 1957;22:194-200.

262. Hoffmann M, Furängen A. NEPI:s Samverkansprojekt [NEPI's Collaborative Project]. http://www.nepi.net/res/dokument/NEPIs-samverkansprojekt-slutrapportexkl-bilagor-2-7.pdf; 2017. Nätverk för läkemedelsepidemiologi (NEPI) [ Swedish Network of Pharmacoepidemiology]. Acessed 28, April 2017.Swedish.

263. Assa-Eley M, Kimberlin CL. Using interpersonal perception to characterize pharmacists' and patients' perceptions of the benefits of pharmaceutical care. Health Commun. 2005; 17:41-56.

264. Worley MM, et al. Pharmacists' and patients' roles in the pharmacist-patient relationship: are pharmacists and patients reading from the same relationship script? Res Social Adm Pharm. 2007;3:47-69.

265. Wisell K, Winblad U, Sporrong SK. Stakeholders' expectations and perceived effects of the pharmacy ownership liberalization reform in Sweden: a qualitative interview study. BMC Health Serv Res. 2016;16:379.

266. Resnik DB, Ranelli PL, Resnik SP. The conflict between ethics and business in community pharmacy: what about patient counseling? J Bus Ethics. 2000;28(2):179-186.

267. Scahill SL, Carswell P, Harrison J. An organizational culture gap analysis in 6 New Zealand community pharmacies. Res Social Adm Pharm. 2011;7:211-223.

268. Guirguis LM, Lee S, Sanghera R. Impact of an interactive workshop on community pharmacists' beliefs toward patient care. Int J Clin Pharm. 2012;34:460-467.

269. Kaae S, Traulsen JM, Sondergaard B, Haugbolle LS. The relevance of political prestudies for implementation studies of cognitive services in community pharmacies. Res Social Adm Pharm. 2009;5:189-194.

270. Patwardhan PD, Amin ME, Chewning BA. Intervention research to enhance community pharmacists' cognitive services: a systematic review. Res Social Adm Pharm. 2014;10:475-493. 
271. Liekens S, Vandael E, Roter D, et al. Impact of training on pharmacists' counseling of patients starting antidepressant therapy. Patient Educ Couns. 2014;94:110-115.

272. Benrimoj SI, Langford JH, Ward PR, et al. Clinical intervention rates in community pharmacy: a randomised trial of the effect of education and a professional allowance. Int J Pharm Pract. 2003;11:71-80.

273. Pharmaceutical Services Negotiating Committee (PSNC). Quality Payments. http://psnc.org.uk/services-commissioning/essential-services/quality-payments/; 2017. Accessed 28, April 2017.

274. Gidman W, Cowley J. A qualitative exploration of opinions on the community pharmacists' role amongst the general public in Scotland. Int J Pharm Pract. 2013;21:288-296.

275. Patricia Antunes L, Gomes JJ, Cavaco AM. How pharmacist-patient communication determines pharmacy loyalty? Modeling relevant factors. Res Social Adm Pharm. 2015;11:560-570.

276. Uppsala University. Master of Science Programme in Pharmacy 2017/2018. http://www.medfarm.uu.se/utbildning/program/programsida/?pKod=FAO2Y; 2017. Accessed 28, April 2017. Swedish.

277. Rivkin A. Thinking Clinically from the Beginning: Early Introduction of the Pharmacists' Patient Care Process. Am J Pharm Educ. 2016;80:164.

278. Wallman A. Pharmacy Internship: Students' Learning in a Professional Practice Setting [Doctoral Thesis]. Department of Pharamcy, Uppsala University, Sweden; 2010.

279. Tong A, Sainsbury P, Craig J. Consolidated criteria for reporting qualitative research (COREQ): a 32-item checklist for interviews and focus groups. Int J Qual Health Care. 2007;19:349-357.

280. Devers KJ. How Will We Know "Good" Qualitative Research When We See It? Beginning the Dialogue in Health Services Research. Health Serv Res. 1999;34:1153.

281. Rothman KJ, Greenland S, Lash TL. Modern Epidemiology. 3rd ed: Philadelphia, PA, USA: Wolters Kluwer Health; 2015.

282. Malterud K. Qualitative research: standards, challenges, and guidelines. Lancet. 2001;358:483-488. 
283. Whittemore R, Chase SK, Mandle CL. Validity in qualitative research. Qual Health Res. 2001;11:522.

284. Mays N, Pope C. Qualitative research in health care: assessing quality in qualitative research. BMJ. 2000;320:50.

285. Rees CE, Sheard CE, McPherson AC. A qualitative study to explore undergraduate medical students' attitudes towards communication skills learning. Med Teach. 2002;24:289-293.

286. Busch AK, Rockenbauch K, Schmutzer G, Brahler E. Do medical students like communication? Validation of the German CSAS (Communication Skills Attitude Scale). GMS Z Med Ausbild. 2015;32(1):Doc11.

287. Philip BS, Richard F. An evaluation of course evaluations. ScienceOpen Res. 2014; DOI: 10.14293/S2199-1006.1.SOR-EDU.AOFRQA.v1.

288. EF Education First. EF English Proficiency Index. 5th ed. EF Education First Ltd. http://mediakey1.ef.com/_/ /media/centralefcom/epi/downloads/fullreports/v5/ef-epi-2015-english.pdf; 2015 Accessed 28, April 2016.

289. Hyvarinen ML, Tanskanen P, Katajavuori N, Isotalus P. Feedback in patient counselling training--pharmacy students' opinions. Patient Educ Couns. 2008;70:363-369.

290. Katajavuori N, et al. Curriculum reform in Finnish pharmacy education. Am J Pharm Educ. 2009;73:151. 


Appendix 1. Example of Questions Sent to Regulatory Authorities (Paper II) 



\section{Iceland}

1. Regarding legislation about health care professionals, section II, article 3, item 10, pharmacists are health care professionals and Lög um réttindi sjúklinga No. 94/1997 Lov om pasientrettigheter II. kafli. Upplýsingar og sampykki. II kapitel. Informasjon og samtykke. How does 5 . Gr 6. gr. 7. gr. apply to the community pharmacists work practice?

2. According to Lög um sjúkraskrár (legislation on patient records): No 55/2009: II. kafli. Færsla sjúkraskráa Health care professionals should keep a journal. A) How does this apply to the pharmacists working in pharmacies? B) Does the pharmacist also have to document, if the patient turn down the offer for counseling/information?

3. According to No. 93/1994, Article 24. third paragraph and regulation 91/2001 necessary information" (on medications) shall be provided and according to regulation 426/1997 information about correct use. A) Is the content thereof further defined or described elsewhere? B) Do you have national counselling guidelines from the authorities further explaining the paragraphs? C) For example questions to be asked? D) According to these regulations what is a minimum level for counseling community pharmacies?

4. Regarding No. 93/1994, Article 24 and regulation 91/2001). How do the counseling requirements outside the pharmacy look like? (when the dispensed patient is not in the pharmacy)?

5. Regarding "necessary information on medications"(regulation 91/2001)/"their use and proper storage (No. 93/1994, Article 24)". Does it has to be oral or can they only be in written?

6. Regarding No. 93/1994, Article 24. third paragraph. A) How do you define pharmaceutical care? B) What is expected of the Icelandic pharmacists regarding pharmaceutical care and its objective reducing the risk of diseases and promoting general health? C) Do you have national guidelines or standardization of pharmaceutical care from the authorities further explaining the paragraph?

7. Regarding No. 93/1994, Article 24 third paragraph. Is the collaboration on medication use and pharmaceutical care further described elsewhere?

\section{Inspections}

6. Regarding 91/2001 and No. 93/1994, Article 24. third paragraph. A) Do you monitor and inspect pharmacist-patient communication/counselling practice and pharmaceutical care in pharmacies? B) If yes, how and what is inspected, when monitoring pharmacist-patient communication/counselling to in pharmacies? C) Which strategy are you using and what quality indicators and methods are you using? D) How many pharmacies are you monitoring each year regarding counseling?

8. A) How is the dispensing area inspected? B) Which strategy are you using and what quality indicators and methods are you using? C) What is regarded as a baseline for assuring that the patients' right for privacy is assured, as well as that the pharmacist can keep their professional secrecy? D) Is there a requirement that no one at the pharmacy should hear or see what is being discussed during dispensing respectively being dispensed?

\section{Economic}

9. Regarding No. 93/1994, Article 24 third paragraph, and regulation 91/2001. A) What kind and amount of counselling on medications are included in the pharmacy-markup? B) And how is payment for preforming pharmaceutical care reassured, the No. 93/1994, Article 24 third paragraph? 



\section{Appendix 2. Questionnaire 1 (Paper III)}

Reprinted with kind permissions from Ruth Parry and Owen Hargie. 



\section{Survey of}

\section{Communication Skills Training in \\ Nordic Pharmacy Education}

-to responsible person for the overall pharmacy education (Head of department and/or program coordinator)

Ph.D. candidate Karin Svensberg, University of Oslo

E-mail: karin.svensberg@farmasi.uio.no

Phone number: 004747270400

Farmas $\varnothing y t i s k$ institutt, Oslo universitet

Post Box 1068, N-0316 Oslo, Norway

Ph.D. Ingunn Björnsdottir, University of Oslo

Ph.D. Sofia Kälvemark Sporrong, University of Copenhagen

Ph.D. Andy Wallman, Umeå University
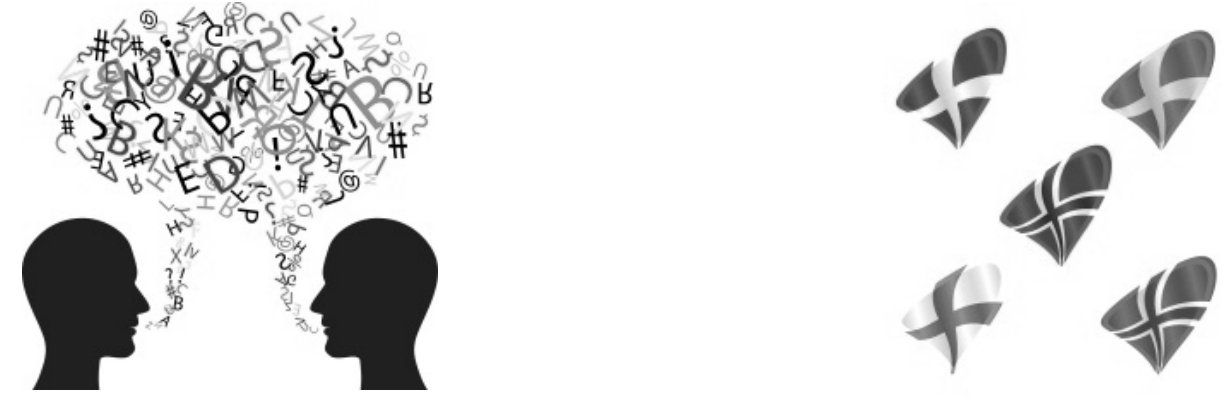


\section{COMMUNICATION SKILLS TRAINING IN NORDIC PHARMACY EDUCATION}

Dear Madam or Sir,

This questionnaire gathers data which will provide information about the current status of communication skills training in Nordic pharmacy schools. The study is part of a Ph.D. project at the School of Pharmacy, University of Oslo. All Nordic pharmacy schools with master students are invited to participate.

There are two questionnaires- one to responsible person for the overall pharmacy education and another to responsible teacher(s) for communication training/courses.

For the purposes of this Questionnaire, we are interested in:

Courses within the "standard" pharmacy curriculum-all five years- (please include the pharmacy internship), with an explicit focus on of any of the following:

1. Communication with patients and/or other health care professions.

2. Theoretical and/or practical training in verbal or non-verbal communication skills and competence including self-reflection.

The above does not include teaching about academic writing or presentation skills.

\section{NOTE:}

a) All information given will be treated in strictest confidence as long as it is not official. Only the research team will have access to the data and the data will be anonymized after study end (01.10.2017). The school will be identified in the publication.

b) Participation in the survey is voluntary. You can anytime leave the questionnaire and thus withdraw from the study.

c) By filling out the questionnaire you agree to participate in a research study.

d) You can answer in your native language.

e) If documents on curriculum or other are easily available to you, please include in your answer either by cut and paste or by referring to them and sending them as appendices/internet links.

\section{It takes approximately 5 minutes to fill out the questionnaire}

\section{Contact Karin Svensberg, if you have any questions:}

karin.svensberg@farmasi.uio.no or +4747270400

Return questionnaire per mail or e-mail to Karin Svensberg.

Kind regards, Karin Svensberg, Ph.D. candidate, School of Pharmacy, University of Oslo Ingunn Björnsdottir, Ph.D. School of Pharmacy, University of Oslo Sofia Kälvemark Sporrong, Ph.D. School of Pharmaceutical Sciences, University of Copenhagen Andy Wallman, Ph.D. Umeå University 


\section{SURVEY QUESTIONNAIRE}

IMPORTANT: After filling out this part- please send contact information about relevant course responsible at your school to

karin.svensberg@farmasi.uio.no, alternatively distribute it further with CC

to me. This will help us to distribute the "communication course specific" questionnaire to the right teacher(s).

Name:

Question 1

Are there any courses within the pharmacy education designed to provide teaching about

Г Yes Go to Q2 communication skills (see the definition on p.2)?

ГNo Go to Q5

Please tick appropriate box

\section{Question 2}

Does your School have a member of staff with responsibility for the co-ordination of communication $\Gamma$ Yes $\Gamma$ No skills training throughout the curriculum?

Please tick appropriate box

\section{Question 3}

Is the student's overall development of communication skills during the curriculum studied and assessed?

Please tick appropriate box 
Question 4

Does your school have a Patient Communication Laboratory?

$\ulcorner$ Yes

Please tick appropriate box

$\Gamma$ No

Question 5

Would you like to add some further information about your school's communication skills education and/or policy? (e.g. if there is something written in the description of the pharmacy programe as a whole.)

\section{Question 6}

If known, please describe any anticipated future (in a two year timeframe) developments in teaching of communication and/or communication skills at your school:

\section{THANK YOU}

\section{FOR TAKING THE TIME TO COMPLETE THIS QUESTIONNAIRE}

Please return the completed questionnaire by email or mail to:

karin.svensberg@farmasi.uio.no

Karin Svensberg

Farmasøytisk institutt, Oslo universitet

Post Box 1068, N-0316 Oslo, Norway 


\section{Appendix 3. Questionnaire 2 (Paper III)}

Reprinted with kind permissions from Ruth Parry and Owen Hargie. 



\section{Survey of \\ Communication Skills Training in \\ Nordic Pharmacy Education}

-course specific questions for responsible teacher(s)

Ph.D. candidate Karin Svensberg, University of Oslo

E-mail: karin.svensberg@farmasi.uio.no

Phone number: 004747270400

Farmas $\varnothing$ ytisk institutt, Oslo universitet

Post Box 1068, N-0316 Oslo, Norway

Ph.D. Ingunn Björnsdottir, University of Oslo

Ph.D. Sofia Kälvemark Sporrong, University of Copenhagen

Ph.D. Andy Wallman, Umeå University
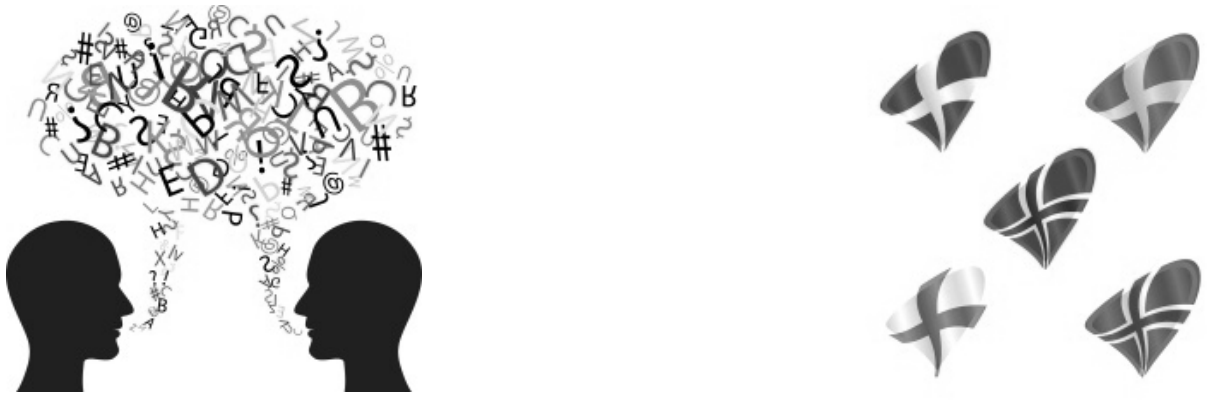


\section{COMMUNICATION SKILLS TRAINING \\ IN NORDIC PHARMACY EDUCATION}

Dear Madam or Sir,

This questionnaire gathers data which will provide information about the current status of communication skills training in Nordic pharmacy schools. Efficient communication and trained pharmacists can increase patient's compliance and improve health outcomes. Traditionally, the pharmacy curriculum has had a strong focus on natural science and little is known about the extent and the form of communication skills training in Nordic pharmacy schools. The present study set out to investigate the extent to which there is a consistent approach to communication skills training in these schools e.g. amount and type of training, placement of training in the curriculum, teaching methods and assessments of skills. The study is part of a Ph.D. project at the School of Pharmacy, University of Oslo. All Nordic pharmacy schools with master students are invited to participate.

For the purposes of this Questionnaire, we are interested in:

Courses within the "standard" pharmacy curriculum-all five years- (please include the pharmacy internship), with an explicit focus on of any of the following:

1. Communication with patients and/or other health care professions.

2. Theoretical and/or practical training in verbal or non-verbal communication skills and competence including self-reflection.

The above does not include teaching about academic writing or presentation skills.

NOTE:

a) All information given will be treated in strictest confidence as long as it is not official. Only the research team will have access to the data and the data will be anonymized after study end (01.10.2017). The school will be identified in the publication.

b) Participation in the survey is voluntary. You can anytime leave the questionnaire and thus withdraw from the study.

c) By filling out the questionnaire you agree to participate in a research study.

d) If documents on curriculum or other are easily available to you, please include in your answer either by cut and paste or by referring to them and sending them as appendices/internet links. However, please indicate relevant sections, if you only have it in Finnish, so it can be translated.

It takes approximately 20-25 minutes to fill out the questionnaire

\section{Contact Karin Svensberg, if you have any questions:}

karin.svensberg@farmasi.uio.no or +4747270400

Return questionnaire per mail or e-mail to Karin Svensberg.

Kind regards,

Karin Svensberg, Ph.D. candidate, School of Pharmacy, University of Oslo

Ingunn Björnsdottir, Ph.D. School of Pharmacy, University of Oslo

Sofia Kälvemark Sporrong, Ph.D. School of Pharmaceutical Sciences, University of Copenhagen

Andy Wallman, Ph.D. Umeå University

The study is reported to the Norwegian Social Science Data Services. 


\section{Section A: Course Specific Questions}

- IMPORTANT: FILL OUT another copy if you are responsible of further courses with an explicit focus on communication and/or communication skills.

- NOTICE! Please attach course descriptions with timetables as appendices/internet links and potential assessment forms of communication skills. Information found therein must not be filled out in the survey.

- Please forward this section, or discuss it with another member of staff in your school if this should be more appropriate.

Please provide the following details about yourself:

\begin{tabular}{|l|l|}
\hline Name: & \\
& \\
\hline
\end{tabular}

Job title:

Job title:

\section{Contact \\ telephone:}

Pharmacy

School:

\section{Course Content}

\section{Question 1}

\begin{tabular}{|l|l|}
\hline $\begin{array}{l}\text { What is the name of the } \\
\text { course? }\end{array}$ & See course description \\
\hline
\end{tabular}




\section{Question 2}

What is the total ECTS (European Credit Transfer and

Accumulation System) or hours of communication training in the ECTS course?

e

$\square \quad \begin{aligned} & \text { See course } \\ & \text { description }\end{aligned}$
Hours

\section{Question 3}

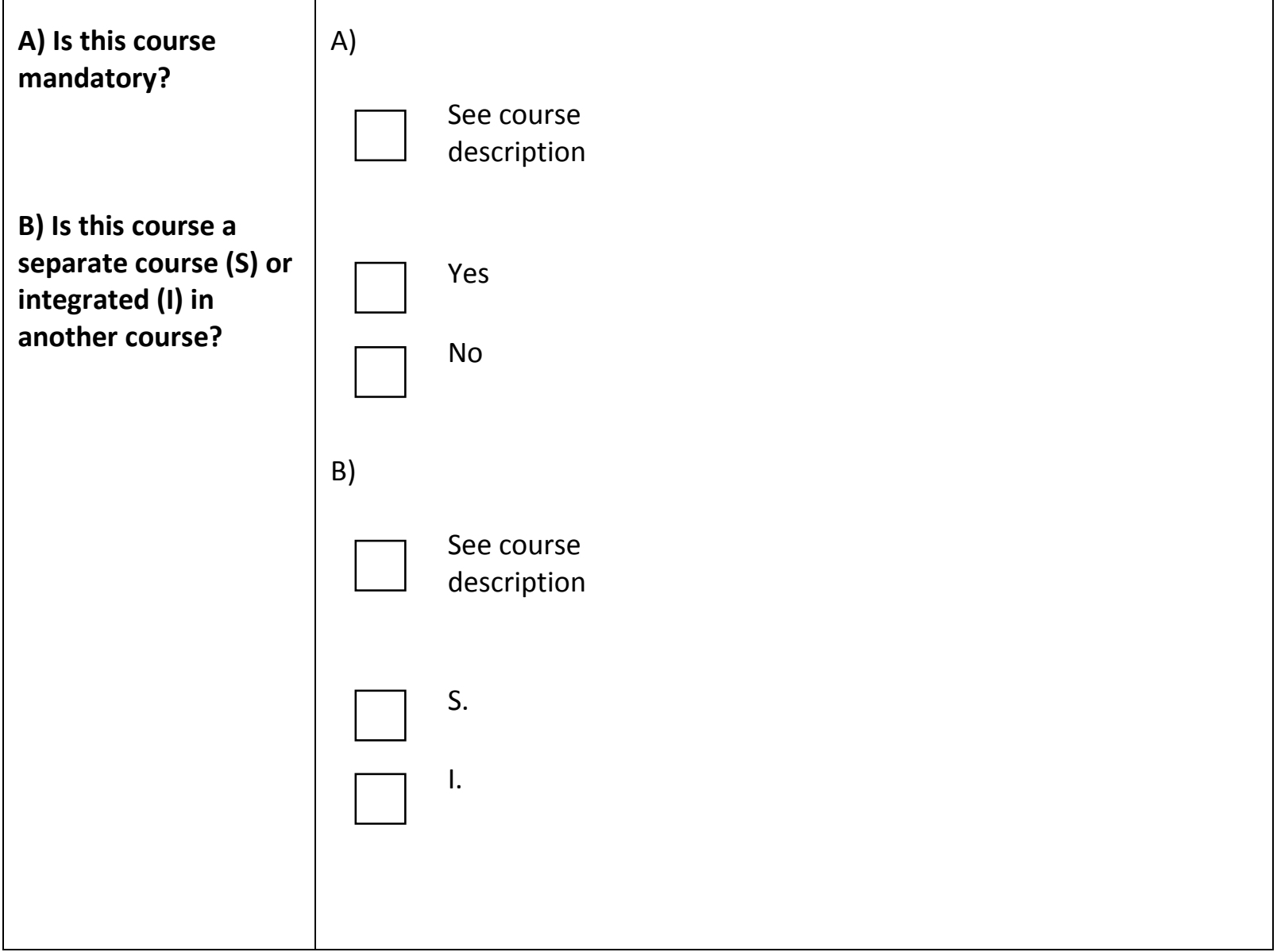

\section{Question 4}

In which year of the pharmacy Year: curriculum is this course delivered? 
What is the educational background of teachers involved in the communication teaching/supervision in the course? Please list additional education in communication science and/or communication skills education/training for e.g. teaching pharmacists.
See course

description

\section{Question 6}

Is the course interdisciplinary, i.e. teaching takes place with students from other educations?

\section{Question 7}

With which students are the course delivered?

Nurses

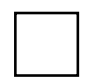

Doctors

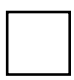

Physiotherapists

Other, please specify below:

\section{Question 8}

How many teachers' "contact hours"/ "teacher led hours" in communication are allocated to this course?
See course description hours 


\section{Teaching methods}

Question 9

What teaching method(s) are used in the course? (multiple answers are possible) Please tick appropriate box(es)

Methods for teaching communication skills:

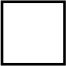

See course description

Video recording of student's patient meetings

Practice with simulated patients e.g. actors

Practice with real patients

Lectures

Practice by role-playing with fellow students

Observing other practioners (pharmacists) communicating with patients

Books/literature reading

Practice in real settings e.g. a pharmacy, hospital

Group discussions of communication cases

Video demonstrations of communication cases

On-line communication learning materials (including lectures, books, self-guides)

Modelling/demonstrating "best communication practice" by teachers (not working

at a pharmacy/hospital)

Modelling/demonstrating by pharmacists working at a pharmacy/hospital

Project work on patient communication

Reflective writing

Others, please specify below: 
Methods for giving students individual feedback on communication skills:

See course description

Video recording

Teacher feedback

Student feedback

Feedback by pharmacy tutor(internship)

No feedback is given

Others, please specify below:

\section{Question 10}

Have the people (e.g. teacher, student, or tutor) who give feedback been trained doing this?
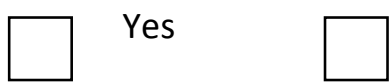

No

If yes: what kind of training?:

Please feel free to further comment on the teaching methods: 


\section{Question 11}

Are the students trained in selfreflection on their own

No communication skills?

If yes, how?

\section{Question 12}

Please list the texts, books, papers etc. that are used in this course:

No literature used

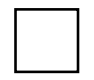

See course description

\section{$\underline{\text { Topics and skills }}$}

\section{Question 13}

Please fill out the central topics and/or skills covered in the course:

$\square \quad$ Advising

Building rapport

Empathy

Explaining

Informing

Importance of caring for patients

Listening

Mirroring patient's behavior

Non-verbal communication

Use of understandable language

Probing 


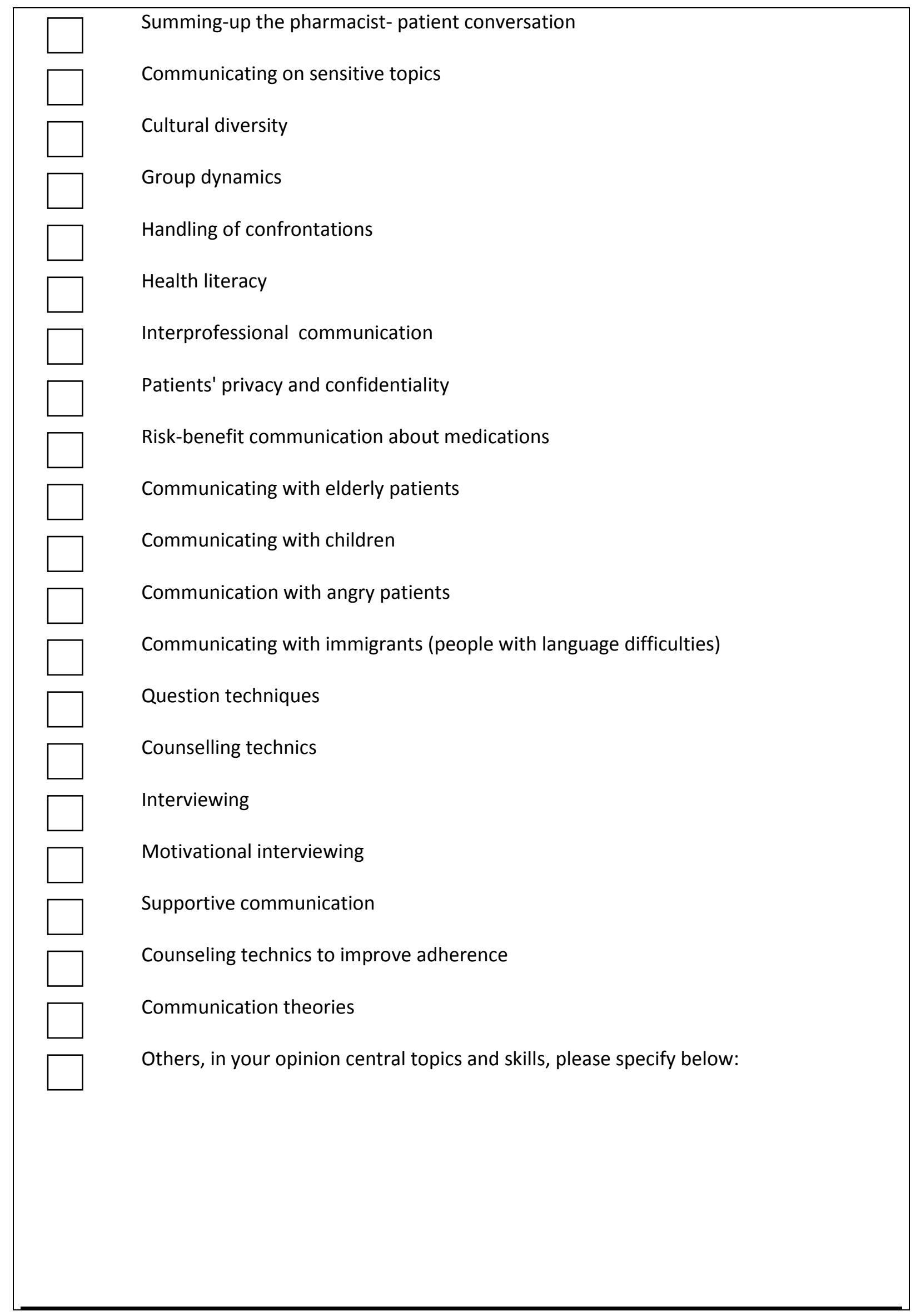


Question 14

How have you selected the central topics and/or skills covered in the course? 


\section{Assessment of communication skills training}

\section{Question 15}

What form(s) of assessments is used for this course to assess students' communication skills with patients? (multiple answers are possible)

None, please go to Q18

See course description

Written Exam

Essay: self reflection

Student self-assessments

A practical exam

\section{Question 16}

Please briefly explain the assessment method (s) used (e.g. how and what is assessed):<smiles>C1CCC1</smiles>

See attached assessment form

\section{Question 17}

Who conducts the formal assessments?(multiple answers are possible) Please tick appropriate box(es)
Examinator WITH formal communication science/communication skills education/training Examinator WITHOUT formal communication science/communication skills education/training Other, please specify using the space below: 


\section{Other}

Question 18

Are there things you would like to see done differently or would do in an ideal world? If so, what would these be?

\section{Question 19}

What do you perceive as the key strengths and opportunities in connection with the communication skills teaching and learning on this course?:

\section{Question 20}

What do you perceive as the key challenges or problems in connection with communication skills teaching and learning?: 
If known, please describe any anticipated future (in a two year timeframe) developments in teaching of communication skills at the course:

Thank you for taking the time to complete this survey. Please feel free to use this box to make any additional comments you may have.

$\Gamma$ I would like to have a copy of the final report

\section{THANK YOU}

\section{FOR TAKING THE TIME TO COMPLETE THIS QUESTIONNAIRE}

Please return the completed questionnaire by email or mail to:

karin.svensberg@farmasi.uio.no

Karin Svensberg

Farmasøytisk institutt, Oslo universitet

Post Box 1068, N-0316 Oslo, Norway

IMPORTANT: FILL OUT another copy if you are responsible of further courses with with an explicit consideration of communication and/or communication skills. 



\section{Appendix 4. Questionnaire 3 (Papers IV-V)}

Reprinted with kind permission from Charlotte Rees. 

$\mathrm{UiO}$ : School of Pharmacy

University of Oslo

\section{Pharmacy students' Communication Skills}

\section{Training}




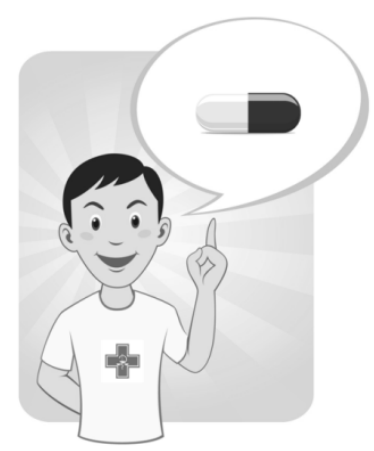

Dear pharmacy student,

The purpose of this study is to gather information about Nordic pharmacy students' attitudes and experiences towards communication training at universities teaching pharmacy. Your participation is important to help us develop the communication education. Nordic master students in pharmacy are invited to participate. The study is part of a Ph.D. project at the School of Pharmacy, University of Oslo.

By filling out this questionnaire you agree to participate in a research study. The information will be kept confidential and only the research group will have access to the data. It will not be possible to identify you in the results of the study. The project will be completed 2018-03-01. Thereafter all data will be anonymized.

Participation in the survey is voluntary. You can leave the questionnaire at any time and thus withdraw from the study. The questionnaire is in English since it is distributed in several countries.

The questionnaire takes about 15-20 minutes to fill out.

Kind regards,

Karin Svensberg, Ph.D. candidate, School of Pharmacy, University of Oslo Ingunn Björnsdottir, Ph.D. School of Pharmacy, University of Oslo

Sofia Kälvemark Sporrong, Ph.D. University of Copenhagen

Inka Puumalainen, Ph.D. University Pharmacy, Helsinki

Andy Wallman, Ph.D. Umeå University

\section{If you have questions please contact}

Karin Svensberg

$+4722845549$

karin.svensberg@farmasi.uio.no

School of Pharmacy, University of Oslo

Post Box 1068, N-0316 Oslo, Norway

\section{$\mathrm{UiO}:$ School of Pharmacy}

University of Oslo

The study is reported to the Norwegian Social Science Data Services. 


\section{Are you a fourth or a fifth year pharmacy student?}

Fourth year pharmacy student

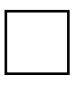

Fifth year pharmacy student

\section{Section 1. Communication skills*learning}

(*Skills=the ability to do something that comes from training, experience, or practice)

Please read the following statements about communication skills learning. Indicate whether you agree or disagree with all of the statements by ticking the most appropriate response.

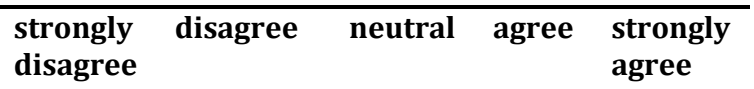

2. In order to be a good pharmacist I must have
good communication skills
3. I can't see the point in learning
communication skills
4. Nobody is going to fail their pharmacy degree
for having poor communication skills
5. Developing my communication skills is just as
important as developing my knowledge of
pharmacy

6. Learning communication skills has helped me or will help me respect patients

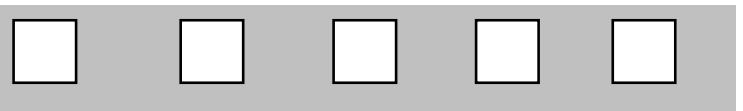

7. I haven't got time to learn communication skills

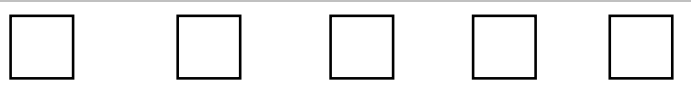

8. Learning communication skills is interesting

9. I can't be bothered to turn up to sessions on communication skills

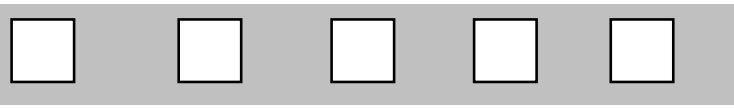

10. Learning communication skills has helped or
will help facilitate my team working skills $\quad \square \quad \square \quad \square \quad \square$

11. Learning communication skills has improved my ability to communicate with patients

$\square \quad \square \quad \square \quad \square$

12. Communication skills teaching states the obvious and then complicates it

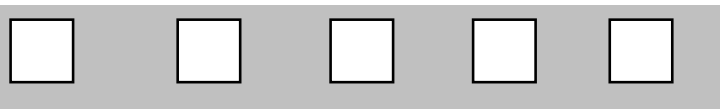

13. Learning communication skills is fun

14. Learning communication skills is too easy

15. Learning communication skills has helped or will help me respect my colleagues

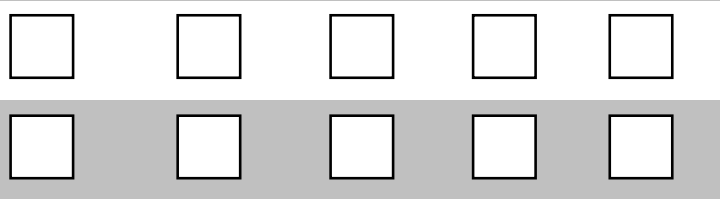

16. I find it difficult to trust information about communication skills given to me by non-
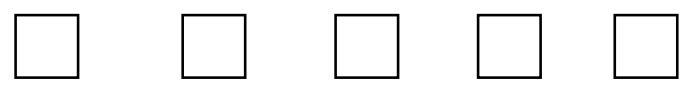
clinical lecturers (teachers/lectures who are not working as pharmacists in a pharmacy/hospital) 17. Learning communication skills has helped or will help me recognize patients' rights regarding

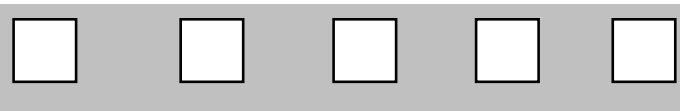
confidentiality and informed consent 
18. Communication skills teaching would have a better image if it sounded more like a science

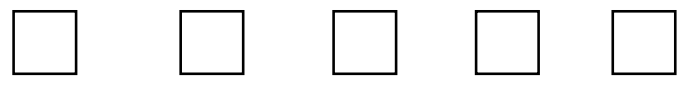
subject

19. When applying to pharmacy school, I thought it was a really good idea to learn communication

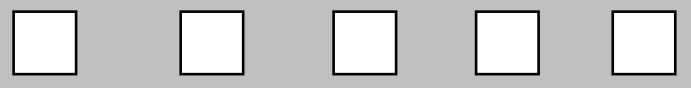
skills

20. I don't need good communication skills to be a pharmacist

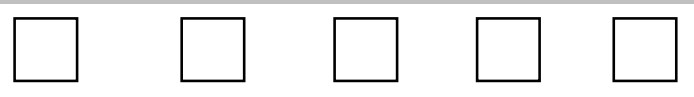

21. I find it hard to admit having some problems with my communication skills

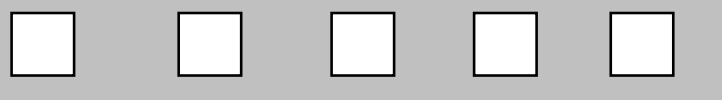

22. I think it's really useful learning communication skills on the pharmacy degree

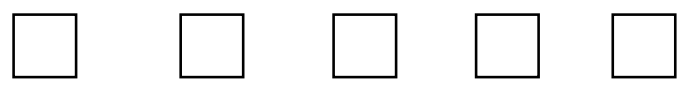
23. My ability to pass exams will get me through pharmacy school rather than my ability to

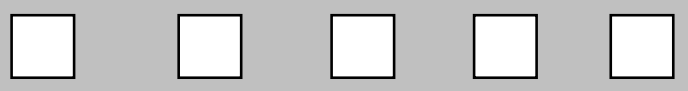
communicate

24. Learning communication skills is applicable to learning pharmacy

25. I find it difficult to take communication skills learning seriously

26. Learning communication skills is important because my ability to communicate is a lifelong
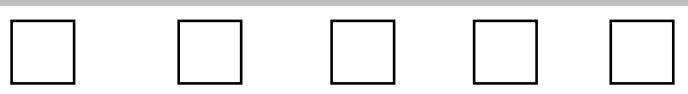
skill

27. Communication skills learning should be left to psychology students, not pharmacy students
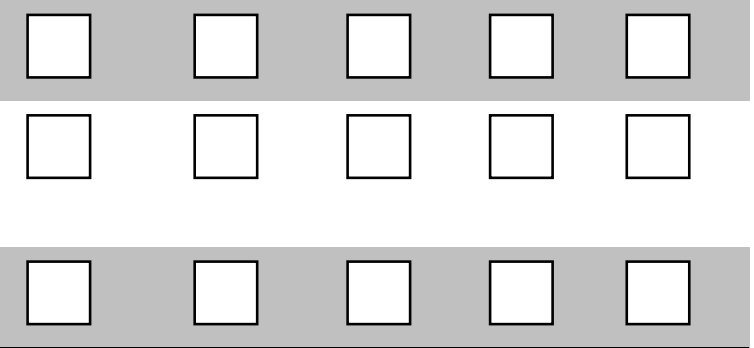


\section{Section 2. Opinions of your communication skills* training}

(*Skills=the ability to do something that comes from training, experience, or practice)

Read the following statements about the communication skills training you had (training to prepare you for communication with patients in a health care setting). When answering, please consider all events that occurred during your pharmacy education including the 6 months of pharmacy internship. Indicate whether you agree or disagree with the statements by ticking the most appropriate response.

$\begin{aligned} & \text { 28. I believe I have received enough theoretical } \\ & \text { knowledge in communication skills }\end{aligned}$
29. I believe I have received enough practical
training in communication skills
30. I believe I have received enough feedback on
my communication skills
31. I believe I have received enough training to
evaluate my own communication performance
32. I believe the university teaches communication
skills that are relevant in a health care setting
33. I believe the teaching methods have
significantly improved my communication skills
34. I believe the practical training has significantly
improved my communication skills
35. I believe the feedback has significantly
improved my communication skills
36. I believe my communication skills are a result
of my personality
37. I believe my communication skills are a result
of the training at the internship
38. I believe my communication skills are a result
of the training at the university
39. I believe my communication skills need
improvement
rimelevant

40. Other comments regarding the communication training you had: (you can answer in English or in a Nordic language) 
41. In your view, what would be the most effective methods to teach communication skills? Please tick maximum 3 boxes.

$\square$ Practice with simulated patients e.g. actors

Practice with real patients

Video recording of my patient meetings

Teacher feedback of my patient meetings

Lectures

On-line communication learning materials

Training with other health care professionals (e.g. doctors, nurses)

Practice by role-playing with fellow students

Observing other practitioners (pharmacists) communicating with patients

Reading books/literature/course material

Reflective writing (e.g. write and reflect about my skills)

Others, please specify:

42. What, if anything, do you think would improve the teaching you had? e.g. what would you like to add or change. (you can answer in English or in a Nordic language) 
Section 4. Background facts

43. What is your year of birth? year

44. What is your gender?
$\square$ Female
$\square$ Male

45. What is your parents' first language(s)?

46. Do any of your parents work in a health care setting (e.g. nurse assistant, nurse, pharmacist, doctor)?
$\square$ No, none
$\square$ Yes, one
$\square$ Yes, both

47. Have you taken any extra communication course(s)?<smiles>[Mg][Mg]C1CCC1</smiles>

48. Where would you like to work when you graduate? (multiple answers are possible)
$\square$
Hospital
$\square$ Community pharmacy
$\square$ Pharmaceutical industry
$\square$ University (academia)
$\square$ Governmental institution/department/authority
$\square$ Others, please specify: 
49. At which university are you studying?

\begin{tabular}{ll}
\hline & University of Copenhagen \\
\hline & University of Southern Denmark \\
\hline & University of Iceland \\
\hline & University of Eastern Finland \\
\hline & University of Helsinki \\
\hline & University of Bergen \\
\hline & University of Troms $\varnothing$ \\
\hline & University of Gothenburg \\
$\square$ & Umeå University \\
\hline
\end{tabular}

50. Please rate your own communication skills on a scale:

$\begin{array}{lllll}\begin{array}{l}\text { very } \\ \text { poor }\end{array} & \text { poor } & \text { average } & \text { good } & \text { excellent } \\ \square & \square & \square & \square & \square\end{array}$

51. Where did you do the main body of the pharmacy internship?

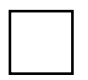

At a community pharmacy

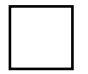

At a hospital pharmacy

I haven't done any internship

52. Have you been working in a pharmacy including patient contact e.g. during summers or on weekends?

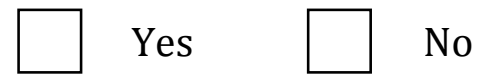

53. Have you been working with taking care of patients such as in a hospital, nursing home, or at a general practitioner (NOT doing any pharmacy related work)?<smiles>[Nb]C1CCC1</smiles>

Thank you for your contribution! Good luck with your studies and as a future pharmacist. 